Universidade de São Paulo

Instituto de Física

\title{
Estudo Estrutural e Termodinâmico de Sistemas Auto-Organizados: Micelas em
} Solução

Pedro Leonidas Oseliero Filho

Dissertação apresentada ao Instituto de Física da Universidade de São Paulo para obtenção do título de Mestre em Ciências.

\section{Comissão Examinadora}

Prof. Dr. Cristiano Luis Pinto de Oliveira (Orientador, IFUSP)

Profa. Dra. Elisabeth Andreoli de Oliveira (IFUSP)

Profa. Dra. Iolanda Midea Cuccovia (IQUSP)

São Paulo 



\section{Ficha Catalográfica}

FICHA CATALOGRÁFICA

Preparada pelo Serviço de Biblioteca e Informação do Instituto de Física da Universidade de São Paulo

Oseliero Filho, Pedro Leonidas

Estudo estrutural e termodinâmico de sistemas auto-organizados: micelas em solução. - São Paulo, 2013.

Dissertação (Mestrado) - Universidade de São Paulo. Instituto de Física Depto. de Física Experimental

Orientador: Prof. Dr. Cristiano Luis Pinto de Oliveira

Área de Concentração: Biofísica experimental

Unitermos: 1. Física da matéria condensada; 2. Biofísica;

3. Mudança de fase.

USP/IF/SBI-092/2013 


\section{Agradecimentos}

Agradeço

a Deus, por tudo na minha vida;

à minha mãe, Cilene, por todo o amor e carinho mesmo antes de eu nascer; ao meu falecido pai, Pedro, por ter me ensinado sobre caráter, honra e o poder da palavra de um homem;

aos meus irmãos, Marcos e Camila, por estarem sempre presentes, mesmo depois que passei a morar sozinho;

à minha linda e amada Babige, com quem tenho aprendido o que é a vida a dois; com ela passei de adolescente para homem, e tenho amadurecido constantemente; sou muito grato pela paciência, compreensão e companheirismo; grande parte desse trabalho só se concretizou porque ela ficou ao meu lado, como sempre...

à família Gerbelli/Voltarelli, por terem me acolhido carinhosamente; em especial, à minha sogra, Roseli, por ser ter sido minha segunda mãe;

ao meu orientador, Prof. Dr. Cristiano, por ter aceitado me orientar e ter sido muito paciente e compreensivo, sempre me cobrando e me impulsionado a dar voos mais altos;

aos colegas do GFCx e do INCTFCx, aos que foram e aos que ainda são alunos, técnicos, professores, por terem colaborado muitíssimo com minha formação;

a todos do USP com que tenho contato;

ao INCTFCx, CNPq e FAPESP pelo auxilio financeiro;

a todos, o meu muitíssimo obrigado. Pedro 
Neste trabalho realizou-se o estudo estrutural e termodinâmico de sistemas micelares em solução formados por surfactantes de diferentes classes, tais como SDS (aniônico), TTAB (catiônico), DM (não-iônico) e SB310 (zwiteriônico). A abordagem experimental proposta neste trabalho consiste do estudo simultâneo de aspectos estruturais e termodinâmicos. Para o estudo estrutural utilizou-se as técnicas de raios $\mathrm{X}$ à baixo ângulo (SAXS) e Condutimetria, e pelo ajuste dos dados experimentais pode-se determinar parâmetros como a anisotropia de forma, número de agregação, grau de ionização, bem como a concentração micelar crítica das micelas em solução. $\mathrm{O}$ comportamento da função de distribuição de pares de distância permitiu concluir que todas as micelas formam estruturas do tipo "core-shell", porém diferem em tamanho dependendo da composição da micela. O buffer usado é possivelmente o responsável por causar a diminuição da concentração micelar crítica e aumento do grau de ionização (para surfactantes iônicos) quando comparados os valores obtidos neste trabalho com aqueles da literatura, que em geral usa água como solvente. Para o estudo termodinâmico utilizou-se a técnica de calorimetria de titulação isotérmica (ITC) e pelo ajuste dos dados experimentais pode-se determinar os valores de entalpia micelar e concentração micelar crítica. A combinação dos resultados obtidos das técnicas de ITC e Condutimetria permitiu calcular o valor energia livre de Gibbs e a entropia de micelização. A partir da determinação dos parâmetros descritos acima, pode-se caracterizar a estrutura e aspectos termodinâmicos de micelas em solução. A metodologia apresentada neste manuscrito consegue fornecer parâmetros independentes e ao mesmo tempo complementares, o que acaba permitindo um estudo correlacionado e confiável. 


\section{Abstract}

In this work was carried out the study of the structural and thermodynamic of micelar systems in solution formed by different classes of surfactants such as SDS (anionic) TTAB (cationic), DM (non-ionic) and SB310 (zwitterionic). The experimental approach proposed in this manuscript consists of the simultaneous study of structural and thermodynamic aspects. For structural studies it was utilized the techniques of Small Angle $X$ ray Scattering (SAXS) and Conductometry, and by fitting the experimental data it was possible to evaluate parameters such as the anisotropy, aggregation number, degree of ionization, and the critical micelle concentration of the micelles in solution. From the analysis of the behavior of the pair distance distribution function we concluded that the micelles form "core-shell" structures, but differ in size depending on the composition of the micelle. The buffer used is possibly responsible for causing the decrease of critical micelle concentration and the increase of the degree of ionization (for ionic surfactants) when values obtained in this study are compared to those ones in the literature, which usually uses water as a solvent. For the thermodynamic study we have used the technique of Isothermal Titration Calorimetry (ITC) and by fitting the experimental data we could determine the enthalpy values and critical micelle concentration. The combination of the results of ITC and Conductometry techniques allowed us to evaluate the value of Gibbs free energy and entropy of micellization. From the determination of the parameters described above we could characterize the structure and thermodynamic aspects of the micelles in solution. The methodology presented in this work can provide independent and complementary parameters, which ends up allowing a correlated and reliable study. 


\section{Índice}

1 INTRODUÇÃO

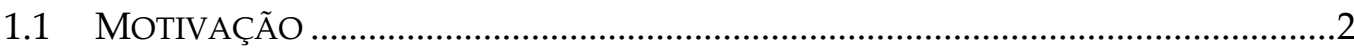

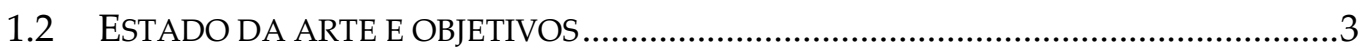

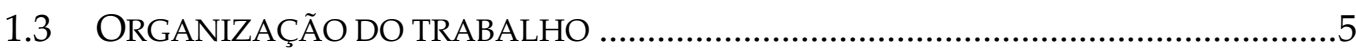

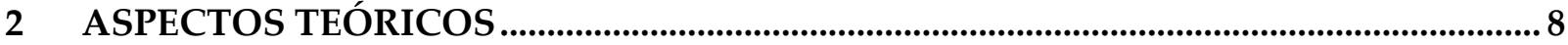

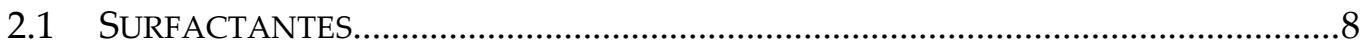

2.1.1 Classificação dos surfactantes .................................................................

2.2 MICELAS........................................................................................................

2.2.1 Concentração micelar crítica: CMC …...................................................12

2.2.2 Forma e tamanho das micelas ................................................................14

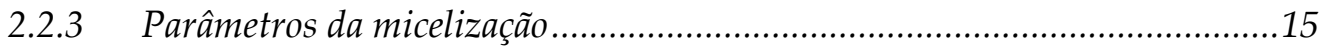

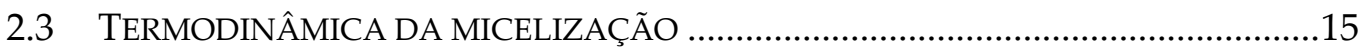

2.3.1 Modelo de separação de fases ..................................................................15

2.3.2 Modelo de ação de massas ............................................................................16

2.4 FUNDAMENTOS TEÓRICOS DAS TÉCNICAS USADAS..........................................18

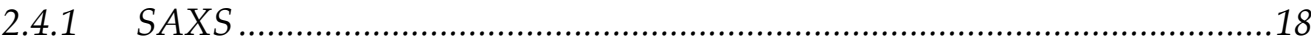

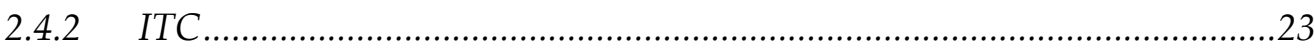

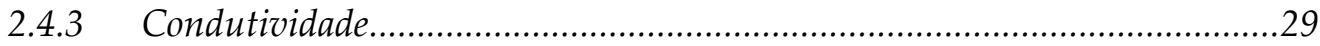

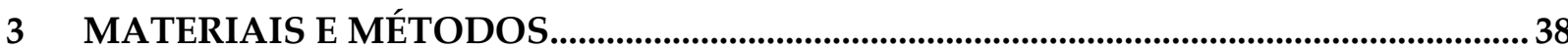

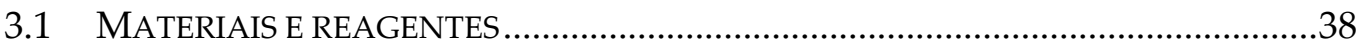

3.2 PROTOCOLOS DE PREPARAÇÃO DAS AMOSTRAS .................................................39

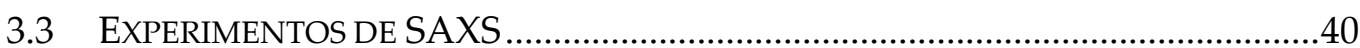

3.3.1 Aparato experimental .........................................................................

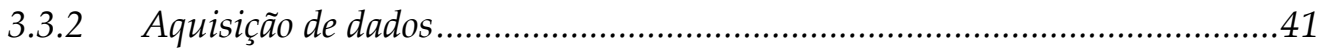

3.3.3 Procedimento de análise dos dados ..............................................................43

3.3.4 Imposição de vínculos moleculares ..........................................................46

3.3.5 Determinação dos parâmetros moleculares..................................................48

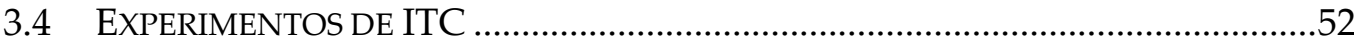

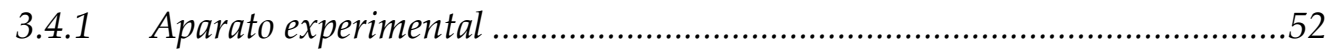




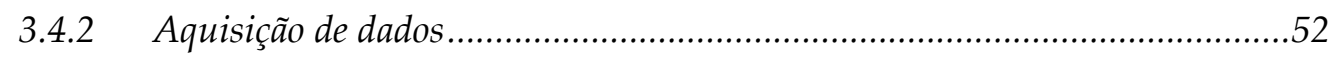

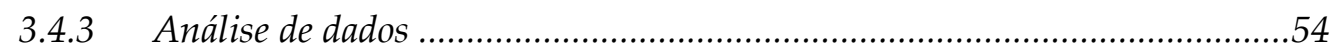

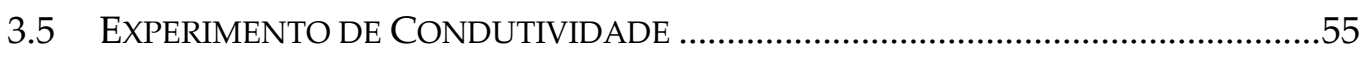

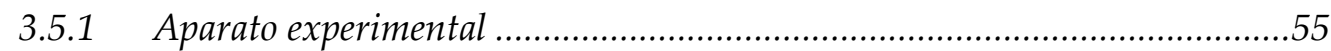

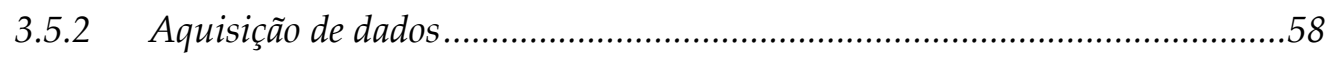

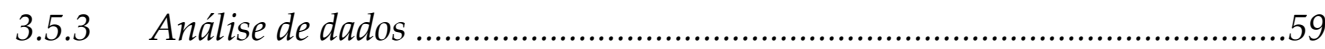

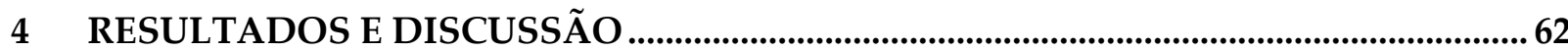

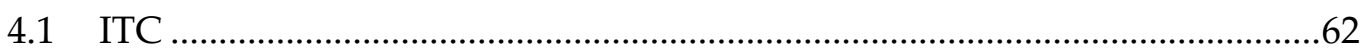

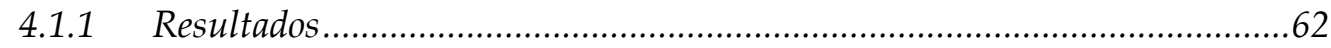

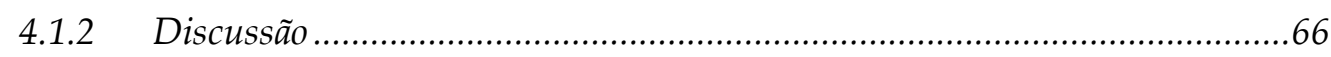

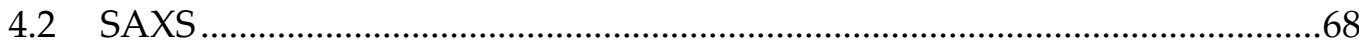

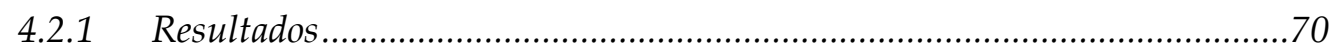

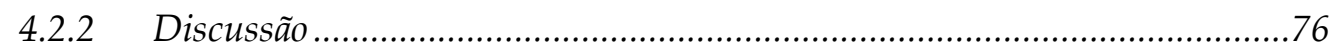

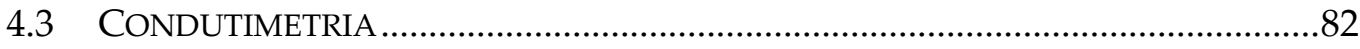

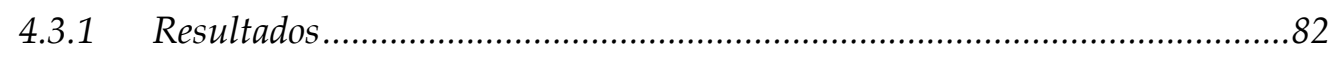

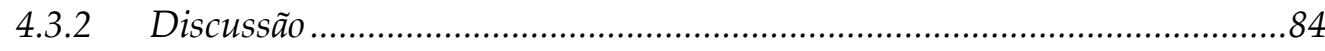

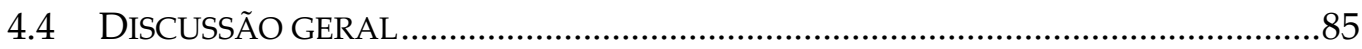

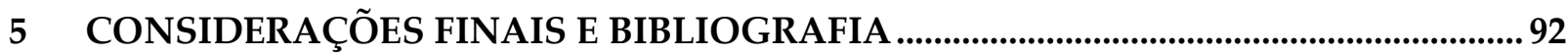

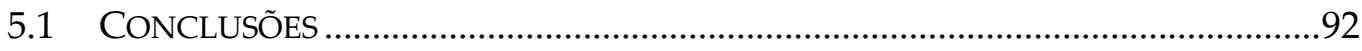

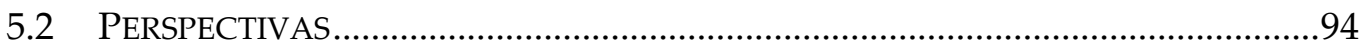

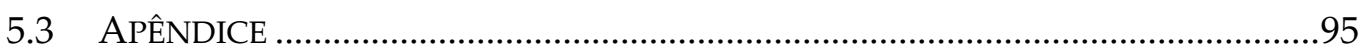

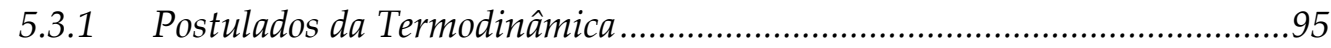

5.3.2 Definição de parâmetros intensivos ...........................................................96

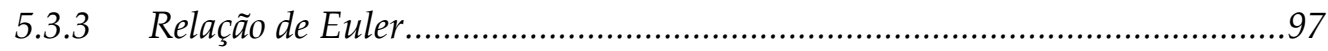

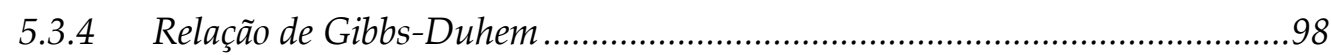

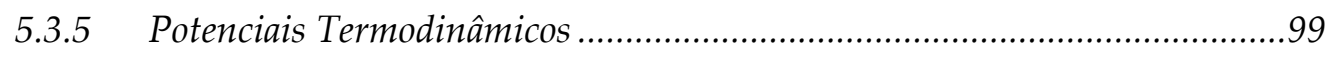

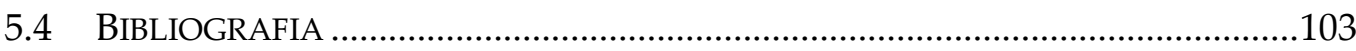




\section{Lista de Símbolos}

ITC

SAXS

SDS

TTAB

DM

SB310

TE

CMC

$N_{a g}$

$\varepsilon$

$\Delta H_{\text {mic }}$

$\Delta G_{\text {mic }}$

$\Delta S_{\text {mic }}$

$c_{\text {free }}$

$c_{m}$

$c$

$p$

$V_{T}$

$\ell_{T}$

$A_{T}$

$\alpha$

$\beta$

$N_{\text {free }}$

$\mu_{\text {mic }}$

$\mu_{\text {free }}$

$N_{S}$

$n_{S}$

$T$

$\Re$

$K_{n}$

$x_{C M C}$

$x_{m}$

$x_{\text {free }}$

$x_{\text {contra-ion }}$

$\vec{q}$

$\vec{k}$

$\vec{k}_{0}$

$\lambda$

$2 \theta$
Isothermal Titration Calorimetry; Calorimetria de Titulação Isotérmica Small Angle X ray Scattering; Espalhamento de Raios X à Baixo Ângulo Dodecil sulfato de sódio

Brometo de tetradeciltrimetilamônio

Decil- $\beta$-D-maltósido

Sulfobetaína caprilil

Buffer Tris-EDTA

Concentração micelar crítica

Número de agregação

Anisotropia de forma

(Variação de) Entalpia de micelização

(Variação de) Energia livre de Gibbs de micelização

(Variação de) Entropia de micelização

Concentração molar de monômeros livres em solução

Concentração molar de monômeros no estado micelar

Concentração molar da solução

Fator de empacotamento

Volume da cauda do surfactante

Comprimento da cauda do surfactante

Área da cabeça polar do surfactante

Grau de ionização micelar

Fração de carga neutralizada na micela

Número de monômeros livres em solução

Potencial químico de formação da micela

Potencial químico de formação dos monômeros

Número de surfactantes

Número de moles de surfactante em solução

Temperatura absoluta

Constante universal dos gases ideais

Constante de equilíbrio no modelo de ação de massas

Fração molar de surfactantes na $C M C$

Fração molar de surfactantes que formam a micela

Fração molar de monômeros livres

Fração molar de contra-íons

Vetor transferência de momento no espaço recíproco

Vetor de onda do feixe incidente

Vetor de onda do feixe espalhado

Comprimento de onda usado no experimento de SAXS

Ângulo entre o feixe incidente e o feixe espalhado 


\begin{tabular}{|c|c|}
\hline$\rho$ & Densidade eletrônica de uma partícula \\
\hline$A$ & Amplitude de espalhamento de uma partícula \\
\hline$I_{1}$ & Intensidade espalhada por uma partícula \\
\hline$\Omega$ & Ângulo sólido \\
\hline$p(r)$ & Função de distribuição de pares de distâncias \\
\hline$r_{m a ́ x}$ & Tamanho máximo das partículas \\
\hline$\aleph$ & Número de partículas espalhadoras \\
\hline$P(q)$ & Fator de forma \\
\hline$S(q)$ & Fator de estrutura \\
\hline$\Delta H_{\text {demic }}$ & (Variação de) Entalpia de demicelização \\
\hline$\Delta H_{o b s}$ & (Variação de) Entalpia de micelização observada no experimento de ITC \\
\hline$c_{0}$ & Concentração molar inicial \\
\hline$\Delta c$ & Largura de transição \\
\hline$\kappa$ & Condutividade elétrica específica da solução \\
\hline$U$ & Tensão elétrica \\
\hline$i$ & Corrente elétrica \\
\hline $\mathrm{K}$ & Condutância elétrica \\
\hline$d$ & Distância entre as placas \\
\hline$a$ & Área \\
\hline$g$ & Constante de célula \\
\hline$\Psi$ & Condutividade elétrica molar da solução \\
\hline$\psi$ & Condutividade elétrica molar dos íons \\
\hline$z$ & Carga elétrica do íon \\
\hline$\mu$ & Mobilidade iônica \\
\hline$F$ & Constante de Faraday \\
\hline$\psi_{\text {ion }}$ & Condutividade elétrica molar dos monômeros, livres ou não \\
\hline$\psi_{\text {contra-ion }}$ & Condutividade elétrica molar dos contra-íons, livres ou não \\
\hline$\psi_{m}$ & Condutividade elétrica da micela \\
\hline$c_{\text {contra-ions }}$ & Concentração molar de contra-íons livres \\
\hline$c_{\text {mic }}$ & Concentração molar de micelas \\
\hline$V$ & Volume \\
\hline$m$ & Massa \\
\hline$M$ & Peso molecular \\
\hline$\rho^{\prime}$ & Densidade de comprimento de espalhamento \\
\hline$k_{B}$ & Constante de Boltzman \\
\hline$\chi_{T}$ & Compressibilidade isotérmica na temperatura $\mathrm{T}$ \\
\hline$\Delta \rho$ & Contraste de densidade eletrônica entre a partícula e o meio \\
\hline$\Delta \rho^{\prime}$ & Contraste de comprimento de densidade de espalhamento entre a partícula e o meio \\
\hline$\Delta \rho_{H}$ & Contraste eletrônico da cabeça do surfactante \\
\hline$\Delta \rho_{T}$ & Contraste eletrônico da cauda do surfactante \\
\hline$\Delta \rho_{H}^{\prime}$ & Contraste de comprimento de espalhamento da cabeça do surfactante \\
\hline back & Parâmetro de ajuste background \\
\hline$V_{\text {shell }}$ & Volume do shell formado pelas cabeças dos surfactantes que constituem a micela \\
\hline$V_{\text {core }}$ & Volume do core formado pelas caudas dos surfactantes que constituem a micela \\
\hline
\end{tabular}


$A_{\text {shell }}$

$A_{\text {core }}$

$A_{\text {tot }}$

$V_{\text {tot }}$

$A_{\text {esfera }}$

$P_{\text {core-shell }}$

$P_{\text {cs-essera }}$

$P_{c s-\text { elipsoide }}$

$R_{\text {core }}$

$R_{t o t}$

$V_{H}$

$N_{e}$

$N_{e_{-} T}$

$N_{e_{-} H}$

$\rho_{T}$

$\rho_{H}$

$f$

$r_{T}$

$\kappa_{\text {Tref }}$

$\kappa_{T}$

$\gamma$

$\rho_{V}$

$\rho_{k}$

$\rho_{k}^{\prime}$

$f_{i, k}$

$N_{i, k}$

$c_{\text {solvente }}$

$\rho_{\text {solvente }}$

$c_{i}$

$\rho_{i}$

$c_{\mathrm{H}_{2} \mathrm{O}}$

$\rho_{\mathrm{H}_{2} \mathrm{O}}$

$\rho_{\mathrm{H}_{2} \mathrm{O}}^{\prime}$

$\rho_{\text {buffer }}$

$c_{f}$

$V_{n}$

$n$

$v$

$V_{f}$

Amplitude de espalhamento do shell

Amplitude de espalhamento do core

Amplitude de espalhamento total

Volume total

Amplitude de espalhamento de uma esfera

Fator de forma de um core-shell

Fator de forma de um core-shell esférico

Fator de forma de um core-shell elipsoidal

Raio do core

Raio total

Volume da cabeça do surfactante

Número de elétrons

Número de elétrons da cauda do surfactante

Número de elétrons da cabeça do surfactante

Densidade eletrônica da cauda do surfactante

Densidade eletrônica da cabeça do surfactante

Fator de espalhamento

Raio clássico do elétron de Thomson

Condutividade específica na temperatura de referência

Condutividade específica na temperatura $\mathrm{T}$

Coeficiente de compensação no experimento de Condutimetria

Densidade volumétrica de uma solução

Densidade eletrônica da espécie $\mathrm{k}$

Comprimento de densidade eletrônica da espécie $\mathrm{k}$

Fator de espalhamento do i-ésimo átomo da espécie $\mathrm{k}$

Número de elétrons do i-ésimo átomo da espécie $\mathrm{k}$

Concentração molar do solvente

Densidade eletrônica do solvente

Concentração molar do i-ésimo componente

Densidade eletrônica do i-ésimo componente

Concentração molar da água

Densidade eletrônica da água

Densidade de comprimento de espalhamento da água

Densidade eletrônica do buffer

Concentração final

Volume de surfactante injetado até à n-ésima injeção

Número da injeção

Volume de cada injeção no experimento de ITC

Volume final 
$V_{0} \quad$ Volume inicial

$\bar{v}$

Volume médio injetado pela micropipeta no experimento de condutividade

$m_{0}$ Massa inicial de buffer no experimento de condutividade

$\bar{m}$

Massa média correspondente a uma injeção no experimento de condutividade 


\section{Lista de Figuras}

Figura 2.1: a) Fórmula estrutural química da molécula anfifílica aniônica SDS (dodecil sulfato de sódio); b) Representação esquemática da molécula SDS.

Figura 2.2: Esquema representando o efeito hidrofóbico. Em a) a molécula de surfactante está rodeada de água, incluindo a parte não polar. Essa situação, desfavorável termodinamicamente, é substituída por aquela mostrada em b), mais favorável. Adaptado de (Nelson e Cox, 2011).

Figura 2.3: a) Solução com baixa concentração de surfactante, sendo que a maior parte das moléculas encontra-se nas interfaces. b) Solução com alta concentração de surfactante, nas quais formam-se agregados. Nesse caso estão representadas apenas micelas. Adaptado de (Angarten, 2007).

Figura 2.4: a) Concentração das moléculas anfifílicas livres (cfree) e micelas (cm) em função da concentração de moléculas anfifílicas de uma solução (c). A partir da CMC as micelas passam a ser formadas e sua concentração cresce em detrimento da concentração de moléculas livres, que permanece constante. Adaptada de (Otzen, 2011). b) Acima da CMC coexistem tanto micelas quanto moléculas livres.

Figura 2.5: Comportamento de algumas propriedades físicas em função da concentração de surfactante. Adaptado de (Elworthy, Florence e Macfarlane, 1968).

Figura 2.6: Fatores de empacotamento para algumas estruturas mais comuns. Adaptado de (Israelachvili, 1991)

Figura 2.7: a) Feixe de raios X espalhado por uma partícula, fixa no espaço, formando um ângulo em relação ao feixe incidente. b) A partir de considerações geométricas escreve-se o módulo do vetor de transferência de momento no espaço recíproco $(q)$ em função do ângulo de espalhamento e do módulo do vetor de onda.

Figura 2.8: Cada estrutura mostrada à direita (esfera, cilindro, prisma...) possui um único perfil de intensidade assim como um único perfil de $p(r)$. Conhecendo-se esses perfis, pode-se em uma análise inicial dar palpites sobre a forma das partículas em um sistema qualquer assim como o tamanho máximo envolvido $\left(r_{\text {máx }}\right)$, informação esta relacionada com a curva $p(r)$. Adaptado de (Oliveira, 2005)......

Figura 2.9: Para sistemas diluídos (primeira imagem da esquerda para a direita) nos quais as partículas estão muito distantes umas das outras (como em um gás), apenas o fator de forma (linha azul) é predominante. Para sistemas mais concentrados (como em um líquido) as partículas estão mais próximas umas das outras e passam a interagir, sendo que o fator de estrutura (linha preta) passa a ser importante. Para sistemas muito concentrados (como em um sólido) nos quais as partículas interagem fortemente, ambos o fator de estrutura e fator de forma devem ser levados em conta a fim de que a intensidade espalhada possa ser descrita completamente. Adaptado de (Craievich, 2009). 
Figura 2.10: Esquema de um equipamento de ITC. Adaptado de (Pierce, Raman e Nall, 1999)...... 24

Figura 2.11: No processo exotérmico ocorre a diminuição do fluxo de calor a fim de se manter a temperatura da célula de amostra constante. Em um fluxograma de calor isso é representado por um vale. Para o processo endotérmico é necessário fornecer calor, de modo que o fluxo aumenta. Isso corresponde a um pico no fluxograma. A linha de base, horizontal, corresponde a todo o momento no qual o processo não é exotérmico nem endotérmico. Adaptada de http://www.microcal.com/technology/itc.asp (acessado em janeiro/2013).

Figura 2.12: a) Fluxograma, mostrando aumentos e diminuições de fluxo de calor ao longo do experimento. b) Entalpograma. A linha azul representa o ajuste dos dados experimentais.

Figura 2.13: a) Entalpograma da titulação de SB3-12 em água, na temperatura de 25ํo . b) Método gráfico da primeira derivada para a determinação do CMC a partir do entalpograma. Adaptado de (Antonio, 2011).

Figura 2.14: a) A região 1 corresponde a região pré-micelar; a região 2 corresponde a região micelar; a região 3 corresponde a região pós-micelar. b) Método gráfico para a determinação da entalpia de micelização, no qual o ponto de inflexão corresponde ao CMC, determinado previamente pelo método gráfico da primeira derivada. Adaptado de (Antonio, 2011).

Figura 2.15: Exemplo de ajuste obtido usando-se a Eq. 2-29. Adaptada de (Antonio, 2011)...... 29

Figura 2.16: Esquema para a determinação da condutividade elétrica de uma solução iônica. 30

Figura 2.17: a) Perfil típico de dados de condutividade. A mudança do comportamento linear dos dados reflete a passagem do surfactante em estado monomérico para o estado micelar. b) Surfactantes iônicos, quando em solução, dissociam-se dando origem ao íon e contra-íon. Os contra-íons se inserem no meio micelar (coroa circular colorida), a chamada camada de Stern, ajudando na estabilização do agregado formado. Adaptado de (Felippe, 2006).

Figura 2.18: Exemplo de dados experimentais mostrando o perfil típico dos dados de condutividade. Método gráfico usual empregado para a análise dos dados experimentais, o qual permite obter a CMC e o grau de dissociação iônica......

Figura 2.19: Representação do problema do método gráfico para análise dos dados de condutividade. Quando a região de transição não é bem definida, existe grande dificuldade para se traçar as duas retas, levando a um erro grande no valor da CMC.

Figura 3.1: Arranjo experimental utilizado para a técnica de SAXS. O feixe de elétrons, ao ter sua trajetória desviada por um octopolo magnético, emite radiação (nesse caso, do comprimento de onda de raios X) que ao passar por um monocromador e sistema de colimação, incide na amostra. Extraído de (Barbosa, 2008). 
Figura 3.2: Exemplo de difratograma obtido no LNLS. A imagem foi adquirida usando-se programa FIT2D (disponível em http://www.esrf.eu/computing/scientific/FIT2D/). 41

Figura 3.3: Ao final do tratamento dos dados obtém-se o espalhamento apenas dos elementos que compõem sistema. Extraída de (Oliveira, 2005).

Figura 3.4: A partir da curva de intensidade é possível obter a função distribuição pares de distâncias via a Transformada Inversa de Fourier. Acima está mostrado uma partícula do tipo core-shell, na qual cada uma das partes possui um contraste eletrônico diferente em relação ao solvente. Extraído de (Oliveira, 2011).

Figura 3.5: a) Esquema de uma micela. b) Modelo esférico tipo core-shell usado para descrever uma micela.

Figura 3.6: a) Equipamento VP-ITC. b) Detalhe da seringa automatizada, na região central.

Figura 3.7: Gráfico do fluxo de calor em função da concentração de SDS. Os pontos circulares e quadrados se referem experimentos com diferentes condições que mostram boa reprodutibilidade dos dados obtidos de ITC.

Figura 3.8: a) Condutivímetro (à esquerda) e agitador magnético com aquecimento (à direita). b) Detalhe da ponta do condutivímetro, composta por duas placas metálicas dispostas paralelamente uma à outra. Na figura estão destacados os parâmetros área (a) e distância entre placas (d) usados para o cálculo da constante de célula (Eq. 2-32).

Figura 3.9: Reprodutibilidade dos dados de condutividade. Os dois conjuntos de pontos usados como exemplo apresentam comportamentos muito próximos.

Figura 3.10: a) Pontos experimentais e primeira derivada numérica dos pontos. b) Função sigmoidal de Boltzman (curva azul) e a função integral dela (curva vermelha).

Figura 4.1: a) Fluxograma para a amostra de SDS $100 \mathrm{mM}$ titulada em buffer. b) Entalpograma. c) Primeira derivada do entalpograma em relação à concentração. A seta indica o CMC, que nesse caso foi 5,44 mM. d) Perfil obtido na literatura (Chatterjee et al., 2001).

Figura 4.2: a) Fluxograma para a amostra de TTAB 100 mM titulada em buffer. b) Entalpograma. c) Primeira derivada do entalpograma em relação à concentração. A seta indica o CMC, que nesse caso foi 1,08 mM. d) Perfil obtido na literatura (Wang et al., 1997).

Figura 4.3: a) Fluxograma para a amostra de DM 100 mM titulada em buffer. b) Entalpograma.c) Primeira derivada do entalpograma em relação à concentração. A seta indica o CMC, que nesse caso foi 1,92 mM. d) Perfil obtido na literatura (Tsamaloukas, Beck e Heerklotz, 2009).

Figura 4.4: a) Fluxograma para a amostra de SB310 450 mM titulada em buffer. b) Entalpograma. c) Primeira derivada do entalpograma em relação à concentração. As setas indicam as possíveis posições do CMC. d) Perfil obtido na literatura (Antonio, 2011). 
Figura 4.5: Para o entalpograma de cada surfactante foram escolhidas concentrações indicadas por meio de barras verticais, em relação às quais foram realizados experimentos de SAXS.

Figura 4.6: a) Curvas de intensidade para cada concentração escolhidas para o surfactante SDS. $b$ ) Curvas $p(r)$ 71

Figura 4.7: a) Curvas de intensidade para cada concentração escolhidas para o surfactante TTAB. $b$ ) Curvas $p(r)$

Figura 4.8: a) Curvas de intensidade para cada concentração escolhidas para o surfactante DM. b) Curvas $p(r)$

Figura 4.9: a) Curvas de intensidade para cada concentração escolhidas para o surfactante SB310. b) Curvas $p(r)$

Figura 4.10: Ajuste dos dados experimentais para o surfactante SDS (a) e TTAB (b)........................74

Figura 4.11: Ajuste dos dados experimentais para o surfactante DM (a) e SB310 (b)........................ 75

Figura 4.12: Comparação da forma da curva $p(r)$ para cada surfactante............................................. 77

Figura 4.13: Valores de rmáx para cada surfactante obtidos da curva $p(r)$. Para melhor visualização estão mostrados no canto superior direito os valores de rmáx no intervalo de concentração de 0 à $20 \mathrm{mM}$.......78

Figura 4.14: Valores de número de agregação obtidos nos ajustes para cada surfactante em função da concentração. Para melhor visualização estão mostrados no canto superior direito os valores de $N_{a g}$ compreendidos no intervalo de concentrações de 0 à $20 \mathrm{mM}$.

Figura 4.15: Valores de concentração de monômeros ("free") obtidos dos ajustes. Para cada conjunto de dados está indicado o valor de CMC encontrado nos experimentos de ITC. Para melhor visualização estão mostrados, no detalhe, os valores de cfree compreendidos no intervalo de concentrações de 0 à $18 \mathrm{mM}$... 80

Figura 4.16: Valores dos dados de anisotropia obtidos dos ajustes para cada surfactante. 81

Figura 4.17: Ajuste dos dados experimentais (linha vermelha) e a função derivada (linha azul) multiplicada por um fator 20 para melhor visualização.

Figura 4.18: Ajuste dos dados experimentais (linha vermelha) e a função derivada (linha azul) multiplicada por um fator 10 para melhor visualização. 


\section{Lista de Tabelas}

Tabela 2.1: Surfactantes utilizados neste estudo...... 10

Tabela 3.1: Todos os surfactantes usados neste estudo e seus fornecedores. ....................................38

Tabela 3.2: Informações moleculares dos surfactantes utilizados neste trabalho. . .49

Tabela 3.3: Exemplos de átomos constituintes de surfactantes e buffers bem como informações sobre eles. . ....

Tabela 3.4: Contrastes de densidades eletrônicas e de comprimento de espalhamento da cabeça e das caudas para todos os surfactantes usados neste trabalho.

Tabela 3.5: Para a calibração da ponta de prova do condutivímetro foi usado cloreto de potássio na temperatura desejada.

Tabela 4.1: Parâmetros obtidos no ajuste dos dados experimentais e CMC obtido graficamente. .....65

Tabela 4.2: Parâmetros usados para a correção de $\Delta$ Hobs.

Tabela 4.3: Comparação entre valores de CMC e $\triangle H$ mic obtidos neste trabalho usando buffer com os da literatura usando água.

Tabela 4.4: Injeções escolhidas do experimento de ITC e a correspondente concentração de surfactante.

Tabela 4.5: Valores do parâmetros de ajuste das curvas experimentais. ........................................ 75

Tabela 4.6: Volumes da cauda e da cabeça e valores de rmáx para cada surfactante. ......................... 78

Tabela 4.7: Valores médios dos parâmetros de ajuste.................................................................. 82

Tabela 4.8: Valores dos parâmetros de ajuste das curvas de condutividade para SDS e TTAB........84

Tabela 4.9: Valores de CMC e grau de ionização para os surfactantes SDS e TTAB.....................8 84

Tabela 4.10: Comparação dos valores de CMC obtidos pelas três técnicas. ....................................87

Tabela 4.11: Variação da energia livre de Gibbs....................................................................... 88

Tabela 4.12: Parâmetros termodinâmicos para o sistema estudado e comparação com dados da literatura.

Tabela 4.13: Resumo de todos os parâmetros obtidos neste trabalho. 89 


\section{Capítulo 01}

\section{Introdução}




\section{Introdução}

Neste capítulo será feita uma introdução ao trabalho, com informações sobre o que motivou a realização dele, bem como os objetivos e informações sobre a estrutura deste manuscrito.

\subsection{Motivação}

O fenômeno da auto-organização é essencial para a vida, uma vez que os cientistas propõem que a origem da mesma se deve ao aumento espontâneo da complexidade e especificidade molecular (Kotz, Kosmella e Beitz, 2001).

O uso pelo homem de substâncias com propriedades de auto-organização data da época dos babilônios (2200 a.C.), porém o interesse econômico em relação a elas bem como o seu estudo científico só iniciou-se no final do século XVIII, com a Revolução Industrial (Otzen, 2011). Descobriu-se que essas substâncias são formadas por um grupo de moléculas, nomeadas hoje anfifílicas, que exibem características de substâncias polares e apolares, possuindo afinidade simultânea por ambas. Como essas moléculas atuam na superfície e interface entre substâncias, reduzindo a tensão superficial, elas passaram também a serem chamadas de surfactantes ou tensoativos (Moroi, 1992).

A necessidade do conhecimento e caracterização das propriedades dessas moléculas é fundamental devido à sua grande aplicabilidade na indústria e meio científico. Os surfactantes estão muito presentes na sociedade contemporânea, sendo usados na composição de produtos de higiene pessoal, produtos de limpeza doméstica e industrial, agroquímicos, extração de petróleo, tratamento de superfícies de metal, indústria alimentícia, e outros. Esta vasta área de atuação se deve às propriedades de detergência, emulsificação, lubrificação, capacidade espumante, capacidade molhante e solubilização, que dependem de fatores intrínsecos ao surfactante (estrutura e composição química) e extrínsecos a ele, estes últimos dependendo das características do meio (temperatura, 
força iônica, pH, etc) (Attwood e Florence, 1983; Evans e Wennerström, 1999). Sendo assim, o estudo dos surfactantes em solução é vital para a compreensão e verificação de como eles atuarão nos ambientes que foram designados/projetados para funcionar, sendo necessárias técnicas como Espalhamento de Raios $X$ à Baixo Ângulo (SAXS), Condutimetria e Calorimetria de Titulação Isotérmica (ITC) que viabilizem tal estudo em solução (Galgano e El Seoud, 2010; 2011; Oliveira, 2011).

\subsection{Estado da arte e objetivos}

Existem na literatura vários trabalhos voltados para o estudo de propriedades termodinâmicas e estruturais de surfactantes em solução. A abordagem na maioria dos trabalhos apresentados na literatura são ou de caráter estrutural ou de caráter termodinâmico, sendo poucos aqueles que relacionam ambos os estudos.

Várias técnicas foram utilizadas para o estudo de sistemas de surfactantes em solução, como Condutimetria (Zana et al., 1981; Graciani et al., 2005; Galgano e El Seoud, 2010; 2011), Tensiometria (Anderson et al., 2003; Graciani et al., 2005), Calorimetria (Galgano e El Seoud, 2010; 2011), Espalhamento de Luz (Zana et al., 1981; Anderson et al., 2003; Galgano e El Seoud, 2010; 2011), Espalhamento de Raios X à Baixo Ângulo (Reisshus.F e Luzzati, 1966; Chen, 1986; Holt et al., 2003; Lipfert et al., 2007) e Espalhamento de Nêutrons (Zana, Picot e Duplessix, 1983; Chen, 1986; Anderson et al., 2003), entre outras.

Nestes trabalhos o principal surfactante estudado é o dodecil sulfato de sódio (SDS) em solução aquosa (Moroi, 1992), onde se tem bem estabelecidos parâmetros como concentração micelar crítica $(C M C)$, número de agregação $\left(N_{a g}\right)$, anisotropia $(\varepsilon)$, entalpia de micelização $\left(\Delta H_{\text {mic }}\right)$, energia livre de Gibbs de micelização $\left(\Delta G_{\text {mic }}\right.$ ) e entropia de micelização $\left(\Delta S_{\text {mic }}\right)$ (Attwood e Florence, 1983; Moroi, 1992; Evans e Wennerström, 1999; Holmberg, Jönsson e Kronberg, 2003). Abordagens semelhantes foram feitas para outros surfactantes como o brometo de tetradeciltrimetilamônio - TTAB - (Aguiar et al., 
2002; Perger e Bester-Rogac, 2007), decil- $\beta$-D-maltósido - DM - (Dupuy, Auvray e Petipas, 1997; Hoffmann e Platz, 2001; Capalbi, Gente e La Mesa, 2004) e sulfobetaína caprilil - SB310 - (Tran e Yu, 2005; Antonio, 2011).

Em alguns trabalhos da literatura varia-se a temperatura a fim de se determinar a entalpia de micelização pelo método de van't Hoff (Galgano e El Seoud, 2010), enquanto outros ainda usam sistemas compostos por mais de um surfactante, avaliando a mudança da $C M C$ e comparando com resultados teóricos (Li, Rosen e Sulthana, 2001; Anderson et al., 2003; Graciani et al., 2005).

A partir do cenário descrito acima, o objetivo deste trabalho é estudar a autoorganização de surfactantes de diferentes classes, tais como SDS, TTAB, DM e SB310. A abordagem experimental deste estudo permite avaliar simultaneamente características estruturais e termodinâmicas no processo de formação dos agregados, permitindo ao final a obtenção de dados correlacionáveis e consistentes.

Optou-se, neste trabalho, pela utilização de um buffer (Tris-EDTA ou simplesmente TE) para a preparação das amostras. Esse buffer é muito usado na preparação de amostras de DNA, RNA e proteínas, pois a faixa de $\mathrm{pH}$ é bastante próxima do meio fisiológico.

Para a caracterização termodinâmica utilizou-se a técnica de ITC, que permitiu a investigação de parâmetros como $C M C$ e $\Delta H_{m i c}$. A partir do entalpograma pode-se calcular as concentrações de surfactante para as quais observou-se grandes mudanças energéticas. Para essas concentrações foi realizado o estudo estrutural utilizando a técnica de SAXS e Condutimetria, esta última usada apenas para os surfactantes iônicos TTAB e SDS. Os dados obtidos de SAXS foram ajustados com o modelo cs-elipsoide (elipsoide core-shell de revolução), que leva em conta o fato de que as micelas não são perfeitamente esféricas, mas possuem certa anisotropia (Andersen et al., 2009), e, além disso, que são constituídas por um núcleo (core) e uma casca (shell). Como os dados de SAXS foram obtidos em escala absoluta, foi possível impor vínculos moleculares na modelagem, o que permitiu ajustar satisfatoriamente os dados usando apenas três 
parâmetros: $\varepsilon, N_{a g}$ e $C M C$. Os dados de Condutimetria permitiram realizar o estudo dos parâmetros grau de ionização $(\alpha)$ e $C M C$, completando a caracterização estrutural.

Constatou-se que todos os parâmetros estudados, quando comparados com informações disponíveis na literatura, foram provavelmente alterados pela mudança do solvente. Os valores de $C M C$ obtidos pelas três técnicas apresentaram um ótimo acordo entre si. A partir do valor de $\alpha$, obteve-se a energia livre de Gibbs. Relacionando-se o valor deste último parâmetro com o valor de entalpia oriundo de experimento de ITC, foi possível se calcular a entropia, completando assim a caracterização termodinâmica do conjunto de surfactantes.

\subsection{Organização do trabalho}

No Capítulo 02 serão apresentados os aspectos teóricos fundamentais sobre surfactantes e sua classificação quanto ao grupo polar, fórmula química e sinônimos mais comuns. Em seguida são discutidas as micelas, os parâmetros mais usuais para sua caracterização, os fatores que influenciam na forma e tamanho desses agregados e os modelos termodinâmicos comuns empregados para a descrição da formação dos agregados. Neste capítulo também será apresentada a fundamentação teórica das técnicas de SAXS, ITC e Condutimetria.

No Capítulo 03 serão apresentados o protocolo de preparação das amostras e informações de cunho metodológico tais como obtenção, tratamento e análise de dados sobre cada técnica discutida no capítulo anterior.

No Capítulo 04 serão apresentados os resultados e a discussão dos mesmos, sendo que esta última foi dividida em dois momentos: no primeiro, uma discussão individual dos dados para cada técnica, procurando-se extrair o máximo de informações possíveis; no segundo momento é feita uma discussão geral, ressaltando-se os pontos mais importantes das discussões anteriores e relacionado os resultados das três técnicas, o que permitiu encontrar outras informações importantes para a caracterização do sistema. 
No Capítulo 05 é feita uma discussão dos principais resultados obtidos neste trabalho e a contribuição destes resultados para a compreensão do estudo termodinâmico e estrutural de micelas em solução bem como são comentadas brevemente perspectivas para trabalhos futuros. 


\section{Capítulo 02}

\section{Aspectos Teóricos}




\section{Aspectos Teóricos}

Nesse capitulo serão apresentados os fundamentos teóricos que serão usados nos demais capítulos. São descritos os constituintes dos sistemas estudados (surfactantes), aspectos da formação micelar bem como as técnicas utilizadas neste estudo.

\subsection{Surfactantes}

O termo surfactante (do inglês surfactant, que vem da contração de surface active agent) é aplicado a compostos que, como a denominação sugere, possuem atividade na superfície e interface entre duas fases como, por exemplo, líquido-líquido, líquidogasoso, etc. Também são chamados de tensoativos, detergentes ${ }^{1}$, ou mais geralmente de moléculas anfifílicas ou anfipáticas (Moroi, 1992).

Esse tipo de molécula possui duas regiões muito distintas. Parte dela tem afinidade com a água (em geral, qualquer solvente polar), sendo chamada região hidrofílica, liofílica ou lipofóbica. A outra região não possui afinidade com a água (em geral, com qualquer solvente não polar) sendo chamada parte hidrofóbica, liofóbica ou lipofílica (Moroi, 1992; Holmberg, Jönsson e Kronberg, 2003).

Como convencionado na literatura, a parte polar de um surfactante, que contém o grupo iônico, é chamado de "cabeça", enquanto a parte não polar, que corresponde a uma ou mais cadeias hidrocarbonadas (também chamadas de parafínicas ou alquílicas), é chamada de "cauda". Na Figura 2.1 é mostrada a representação esquemática de um surfactante.

${ }^{1}$ Detergentes comerciais possuem outras substâncias além da molécula de surfactante, tais como pigmentos de coloração, aromatizantes, glicerina, etc. (Handbook of detergents: Part D - Formulation, 2006). 


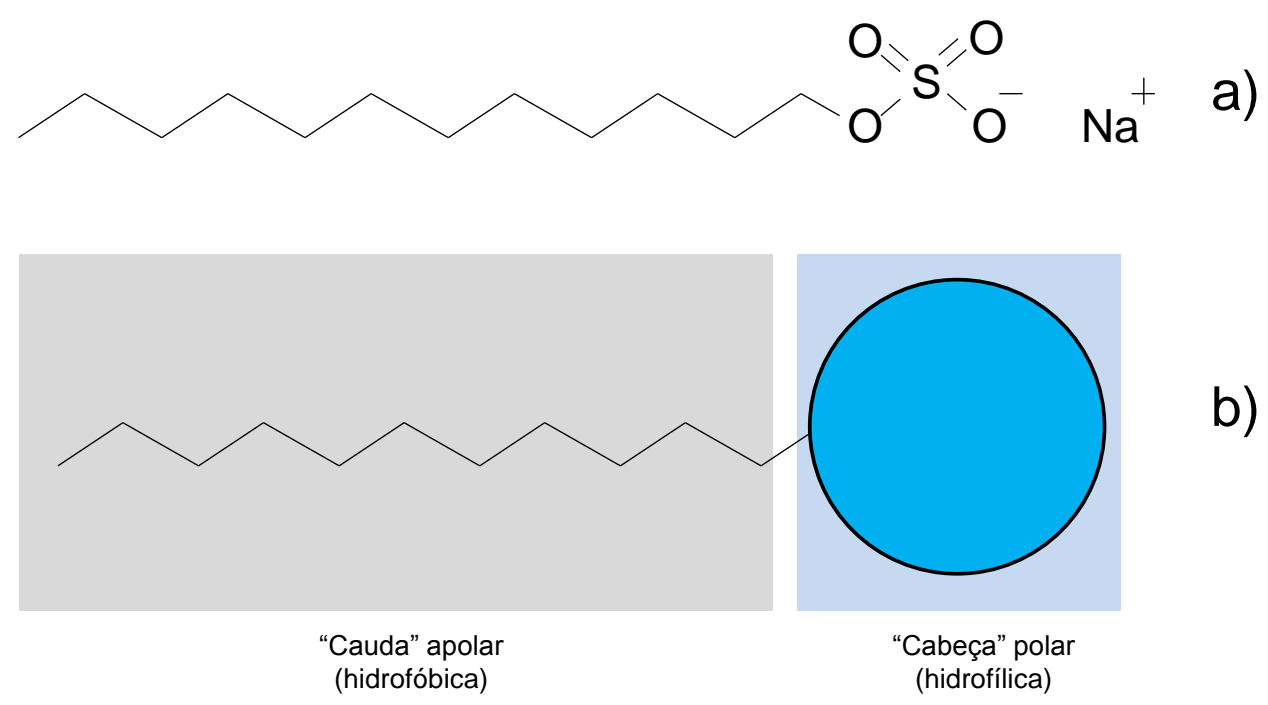

Figura 2.1: a) Fórmula estrutural química da molécula anfifílica aniônica SDS (dodecil sulfato de sódio); b) Representação esquemática da molécula SDS.

\subsubsection{Classificação dos surfactantes}

De acordo com a natureza do grupo polar na cabeça, o surfactante poderá ser classificado em iônico (que possui carga elétrica) ou não-iônico (que não possui carga elétrica) (Holmberg, Jönsson e Kronberg, 2003).

Os surfactantes iônicos podem ainda ser catiônicos, se na cabeça existe um íon positivo, ou aniônicos, se na cabeça existe um íon negativo. Os não-iônicos podem ser neutros ou zwiteriônicos, sendo que a diferença entre eles está no fato de que na cabeça do zwiteriônico existe uma separação de cargas elétricas, formando um dipolo elétrico, enquanto o neutro não apresenta dipolo. $\mathrm{O}$ termo anfotérico também é usado na literatura como sinônimo. Entretanto, anfotérico é o surfactante que passa de catiônico para zwiteriônico e deste para aniônico quando é alterado o pH do meio de ácido para básico. Logo, se apresentarão como zwiteriônicos apenas em uma faixa de $\mathrm{pH}$ (Holmberg, Jönsson e Kronberg, 2003). O surfactante SB310, usado neste trabalho, é estritamente zwiteriônico em toda faixa de $\mathrm{pH}$.

Neste trabalho utilizaremos um representante de cada classe de surfactante. As moléculas escolhidas são apresentadas na Tabela 2.1. 
Tabela 2.1: Surfactantes utilizados neste estudo.

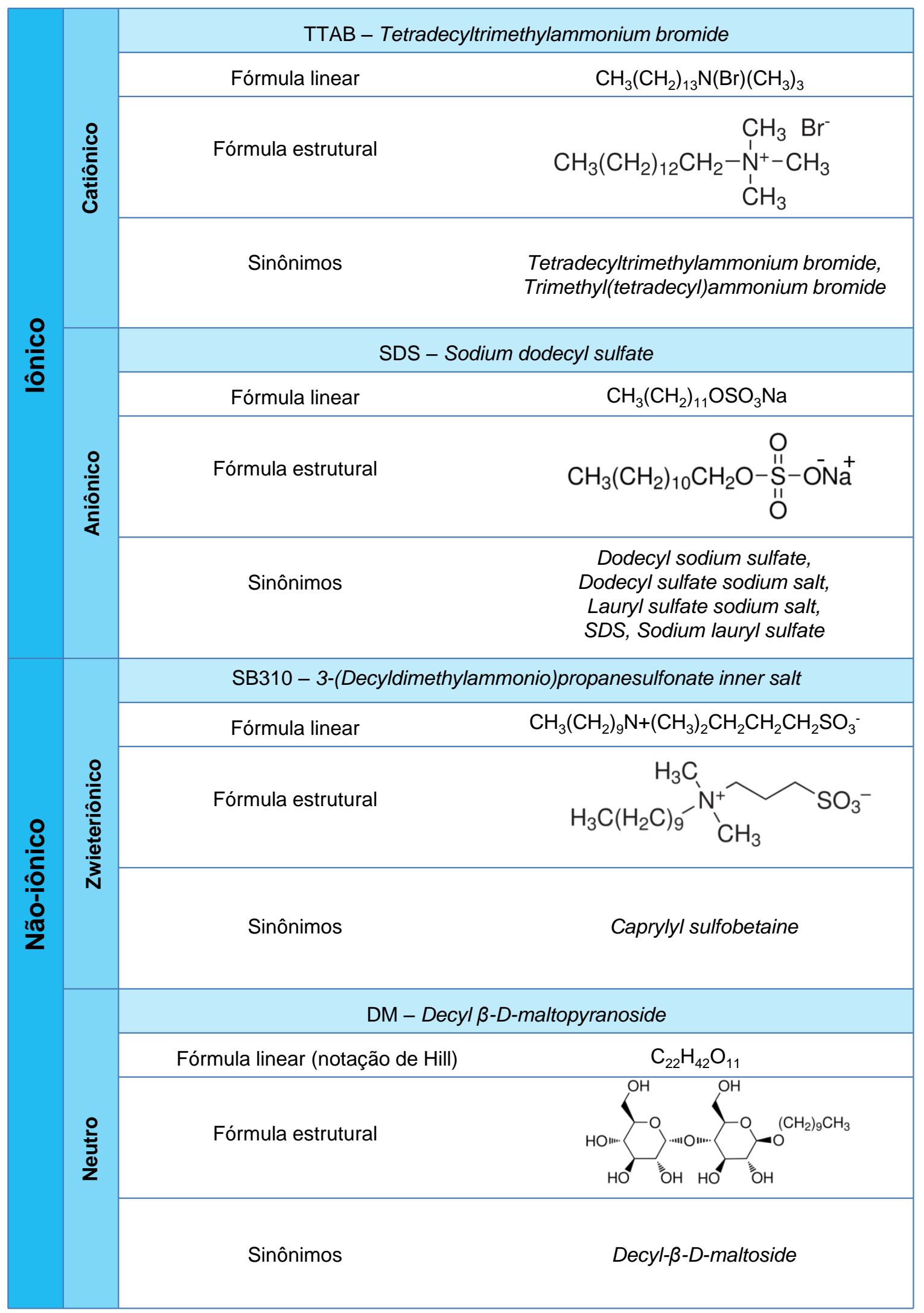




\subsection{Micelas}

Os surfactantes possuem duas regiões distintas na mesma molécula e, quando em solução, a parte hidrofílica tenta maximizar o contato com o solvente polar, enquanto o contrário ocorre para a parte não polar (Figura 2.2). Esse efeito recebe o nome de efeito hidrofóbico (Tanford, 1980).

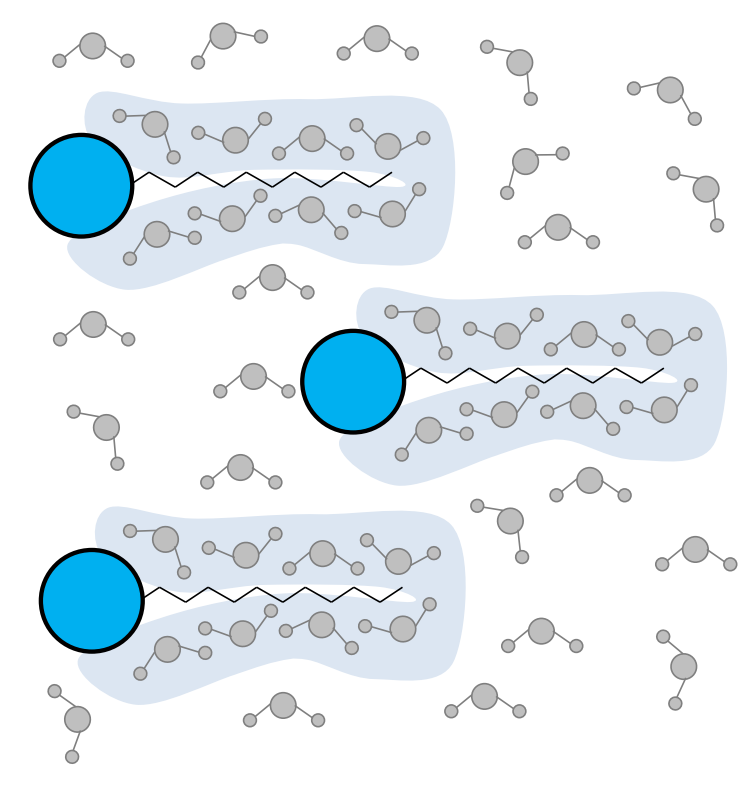

a)

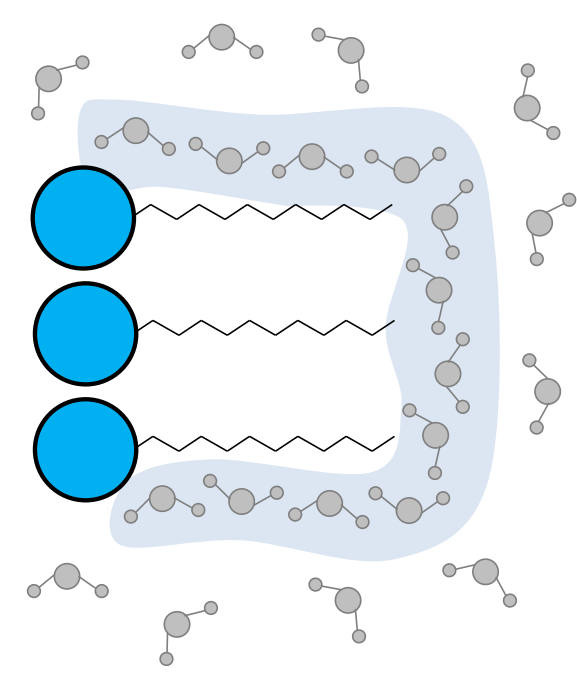

b)

Figura 2.2: Esquema representando o efeito hidrofóbico. Em a) a molécula de surfactante está rodeada de água, incluindo a parte não polar. Essa situação, desfavorável termodinamicamente, é substituída por aquela mostrada em b), mais favorável. Adaptado de (Nelson e Cox, 2011).

Em concentrações relativamente baixas de surfactante, as moléculas em solução encontram-se em sua maioria em alguma interface (Figura 2.3a), por exemplo, interface água-ar e água-sólido. Em concentrações relativamente altas (Figura 2.3b) as moléculas de surfactante tendem a se auto-organizarem em agregados, minimizando o contato com as moléculas de água. Esses agregados podem ser micelas, bicamadas e vesículas (Tanford, 1980; Attwood e Florence, 1983). Este trabalho visa uma faixa de concentração que permite o estudo apenas de micelas. 


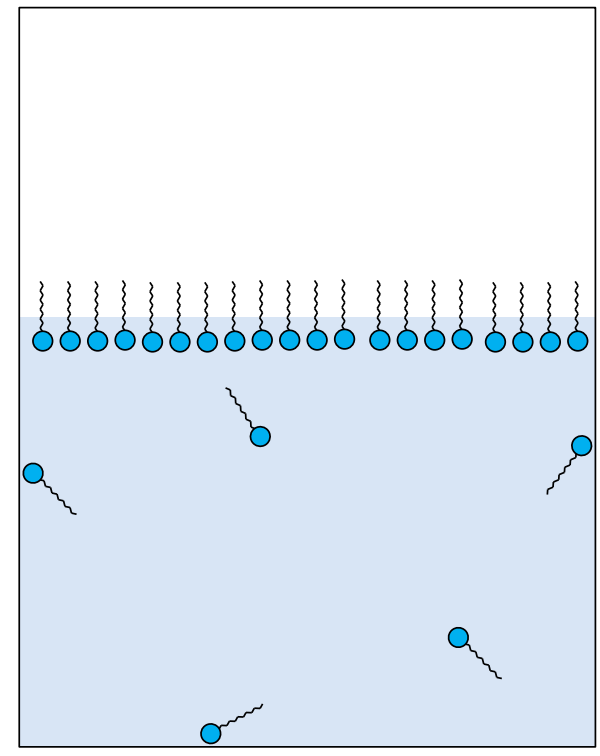

a)

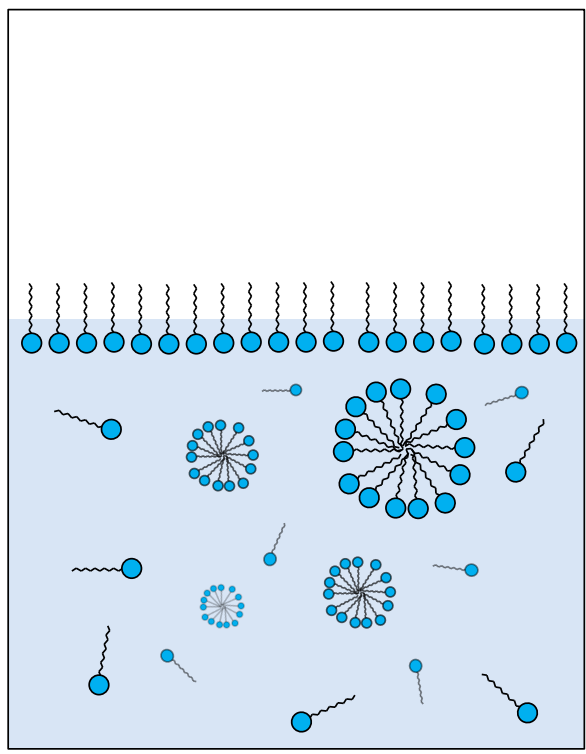

b)

Figura 2.3: a) Solução com baixa concentração de surfactante, sendo que a maior parte das moléculas encontra-se nas interfaces. b) Solução com alta concentração de surfactante, nas quais formam-se agregados. Nesse caso estão representadas apenas micelas. Adaptado de (Angarten, 2007).

\subsubsection{Concentração micelar crítica: CMC}

A formação das micelas somente acontece a partir da concentração micelar crítica ( $C M C$ ) (Figura 2.4). Essa concentração particular depende de diversos fatores, tanto intrínsecos ao tipo de molécula do surfactante, por exemplo, o tamanho da cauda hidrocarbonada, quantidade de caudas, grupo iônico/não-iônico na cabeça, quanto extrínsecos, relacionados ao ambiente, como temperatura, adição de eletrólitos e adição de co-surfactantes. (Attwood e Florence, 1983). 


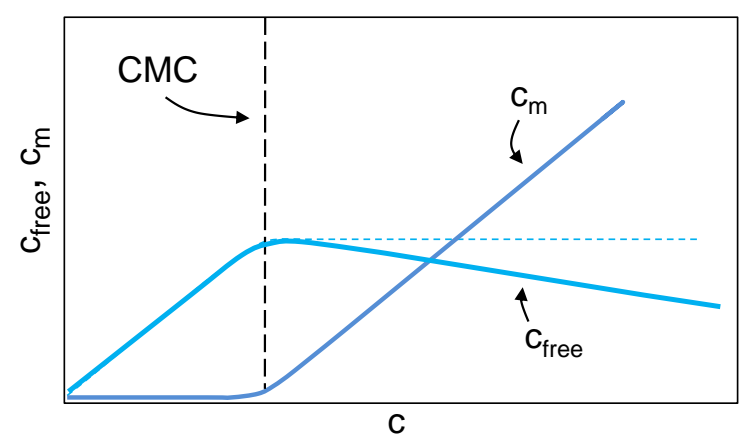

a)

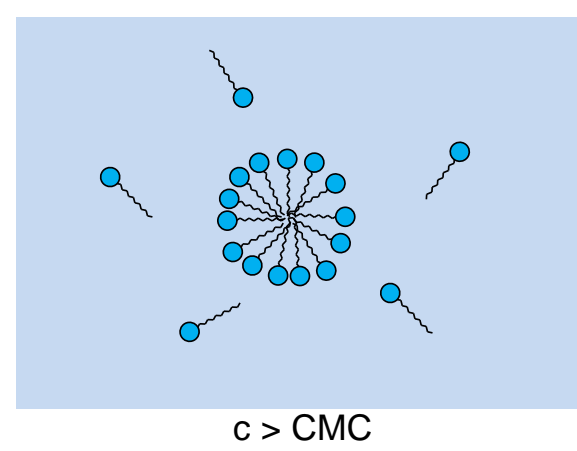

b)

Figura 2.4: a) Concentração das moléculas anfifílicas livres $\left(C_{f r e e}\right)$ e micelas $\left(C_{m}\right)$ em função da concentração de moléculas anfifílicas de uma solução (C). A partir da $C M C$ as micelas passam a ser formadas e sua concentração cresce em detrimento da concentração de moléculas livres, que permanece constante. Adaptada de (Otzen, 2011). b) Acima da CMC coexistem tanto micelas quanto moléculas livres.

Na $C M C$ várias propriedades físicas são modificadas, tais como detergência, pressão, condutividade, e outras (Elworthy, Florence e Macfarlane, 1968), como mostra a Figura 2.5 a seguir. Usando técnicas apropriadas que quantifiquem a variação dessas propriedades, é possível se determinar a $C M C$ para diferentes sistemas.

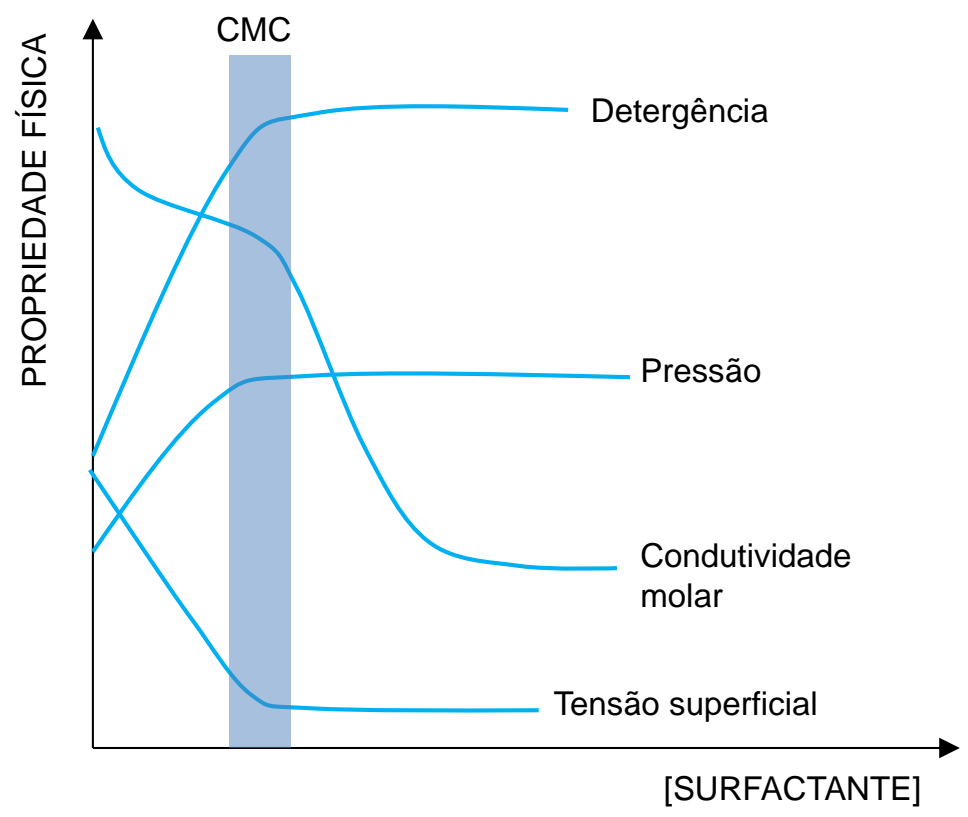

Figura 2.5: Comportamento de algumas propriedades físicas em função da concentração de surfactante. Adaptado de (Elworthy, Florence e Macfarlane, 1968). 
A CMC determinada por qualquer método físico não se restringe a um único ponto, mas a sua ocorrência abrange uma faixa de concentração.

\subsubsection{Forma e tamanho das micelas}

As micelas possuem forma e tamanho variados que dependerão, não unicamente, porém grandemente, da geometria da molécula de surfactante que a constitui. Por isso é bastante útil apresentar o chamado fator de empacotamento $p$ (Israelachvili, 1991), definido como

$$
p=\frac{V_{T}}{A_{H} \ell_{T}},
$$

onde $V_{T}$ é o volume da parte hidrofóbica, $A_{H}$ é a área da cabeça polar e $\ell_{T}$ é o comprimento da cauda hidrocarbonada. Na Figura 2.6 estão mostrados fatores de empacotamento de algumas estruturas.

\begin{tabular}{|c|c|c|}
\hline $\begin{array}{l}\text { Parâmetro de } \\
\text { empacotamento }\end{array}$ & $\begin{array}{c}\text { Geometria da molécula } \\
\text { anfifílica }\end{array}$ & Estruturas \\
\hline$p<\frac{1}{3}$ & Cone & 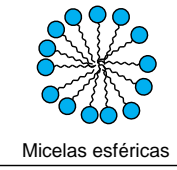 \\
\hline$\frac{1}{3}<p<\frac{1}{2}$ & Cone truncado & $\begin{array}{c}0 \\
0.8353 \\
\text { Micelas cilindricas }\end{array}$ \\
\hline$\frac{1}{2}<p<1$ & $\begin{array}{l}33 \\
\text { Cone truncado }\end{array}$ & 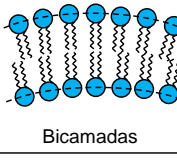 \\
\hline$p>1$ & Cone truncado invertido & Micelas reversas \\
\hline
\end{tabular}

Figura 2.6: Fatores de empacotamento para algumas estruturas mais comuns. Adaptado de (Israelachvili, 1991). 


\subsubsection{Parâmetros da micelização}

$\mathrm{Na}$ formação micelar, chamada de micelização, ocorre a formação de agregados com certo número médio de moléculas, chamado número de agregação $\left(N_{a g}\right)$. Este parâmetro fornece informação média, visto que a micela é um sistema dinâmico, ocorrendo associação e dissociação dos monômeros (Oh e Shah, 1993). Além disso, dada essa característica dinâmica, podem-se definir constantes de equilíbrio e relacioná-las também com a micelização.

Para surfactantes iônicos, a formação micelar também dependerá do equilíbrio eletrostático dos monômeros constituintes da micela. Quando em solução aquosa ocorre a dissociação iônica do surfactante. Um íon da cabeça polar (chamado contra-íon) passa para a solução, enquanto a cabeça polar e a cauda formam um único íon de carga oposta à do contra-íon. Na micela, por sua vez, ocorreria repulsão elétrica entre os monômeros se não fossem os contra-íons que se colocam entre eles, ajudando na estabilização elétrica do agregado. Contudo não são todos os contra íons que se associam à micela. Para esses associados define-se $\alpha$ como sendo o grau de ionização micelar ou, o que é equivalente, $\beta=1-\alpha$ como sendo a fração de carga neutralizada na micela (Seção 2.4.3).

\subsection{Termodinâmica da micelização}

Uma breve introdução da Termodinâmica na qual foi baseada algumas deduções deste manuscrito está dada como apêndice na Seção 0 .

\subsubsection{Modelo de separação de fases}

No modelo de separação de fases considera-se que as micelas formam uma nova fase, analogamente à separação de fases que existe entre água e gelo, por exemplo. Assim, acima da CMC, pode-se escrever que 


$$
\left(N_{a g}+N_{\text {free }}\right) S \rightarrow N_{\text {free }} S+S_{N_{a g}}
$$

onde $N_{a g}$ é o número de agregação, parâmetro definido anteriormente, $N_{\text {free }}$ é o número de moléculas de surfactantes livres, $S$ representa a molécula do surfactante e $S_{N_{a g}}$ a micela com número de agregação $N_{a g}$, nesse caso a nova fase formada.

Para esse modelo define-se a variação da energia livre de Gibbs de micelização, $\Delta G_{m i c}$, como sendo (Evans e Wennerström, 1999)

$$
\Delta G_{\text {mic }}=\mu_{\text {mic }}-\mu_{\text {free }}=\mathfrak{R} T \ln \left(x_{C M C}\right),
$$

onde $\mu_{\text {mic }}$ e $\mu_{\text {free }}$ são os potenciais químicos de formação da micela e do monômero, respectivamente, em solução, e $x_{C M C}$ a fração molar de surfactantes na $C M C$, dada por

$$
x_{C M C}=\frac{n_{S}}{n_{S}+n_{H_{2} O}},
$$

onde $n_{S}$ é o número de moles de surfactante livres em solução e $n_{\mathrm{H}_{2} \mathrm{O}}$ é o número de moles de água. Para surfactantes iônicos a expressão anterior é reescrita como (Evans e Wennerström, 1999)

$$
\Delta G_{m i c}=\Re T(2-\alpha) \ln \left(x_{C M C}\right),
$$

a fim de se levar em conta a presença dos contra-íons. O parâmetro $\alpha$ é o grau de ionização micelar, $\mathfrak{R}$ é a constante universal dos gases ideiais e $T$ a temperatura absoluta.

\subsubsection{Modelo de ação de massas}

No modelo de ação de massas as micelas e os monômeros livres são considerados em equilíbrio químico, podendo esse processo ser representado em várias etapas, 


$$
\begin{aligned}
& S_{1}+S \stackrel{K_{1}}{\longleftrightarrow} S_{2} \\
& S_{2}+S \stackrel{K_{2}}{\longleftrightarrow} S_{3} \\
& S_{3}+S \stackrel{K_{3}}{\longleftrightarrow} S_{4} \\
& \vdots \\
& S_{N_{a g}-1}+S \stackrel{K_{n}}{\longleftrightarrow} S_{N_{a g}}
\end{aligned}
$$

ou em apenas uma etapa,

$$
N_{a g} S \stackrel{K_{n}}{\longleftrightarrow} S_{N_{a g}}
$$

O parâmetro $K_{n}$ é a constante de equilíbrio, definida como

$$
K_{n}=\frac{\left[S_{N_{a g}}\right]}{[S]^{N_{a g}}} .
$$

Nesse modelo define-se a variação da energia livre de Gibbs de micelização para surfactantes não-iônicos como (Evans e Wennerström, 1999)

$$
\Delta G_{m i c}=\Re T\left[\left(1-\frac{1}{N_{a g}}\right) \ln \left(x_{C M C}\right)+f\left(N_{a g}\right)\right]
$$

onde $f\left(N_{a g}\right)$ é dado por (Attwood e Florence, 1983)

$$
f\left(N_{a g}\right)=\frac{1}{N_{a g}}\left\{\ln \left[N_{a g}^{2}\left(\frac{2 N_{a g}-1}{N_{a g}-1}\right)\right]+\ln \left[\frac{N_{a g}}{2}\left(\frac{2 N_{a g}-1}{N_{a g}{ }^{2}-1}\right)\right]^{N_{a g}-1}\right\} .
$$

Para surfactantes iônicos a variação da energia livre de Gibbs de micelização é

$$
\Delta G_{m i c}=\frac{-\mathfrak{R} T}{N_{a g}} \ln \left[\frac{x_{m}}{\left(x_{\text {free }}\right)^{N_{a g}}+\left(x_{\text {contra-ion }}\right)^{N_{a g}-\alpha N_{a g}}}\right] .
$$

onde $x_{m}$ é a fração molar de surfactantes que formam as micelas (surfactantes não livres), $x_{\text {free }}$ é a fração de surfactantes livres e $x_{\text {contra-ion }}$ a fração molar de contra-íons. 
No limite de $N_{a g}$ grande, $f\left(N_{a g}\right) \rightarrow 0$ e a Eq. 2-9 coincide com a Eq. 2-3. Da mesma forma, para $N_{a g}$ grande, a Eq. 2-11 coincide com a Eq. 2-5. Com $N_{a g} \sim 100$, que é a ordem de grandeza do número de surfactantes que constitui uma micela típica, já é possível garantir a equivalência das equações nos dois modelos.

A diferença entre o modelo de ação de massas e o modelo de separação de fases está na forma de se calcular as frações molares. No primeiro modelo o número total de moles presentes na $C M C$ leva em conta o número de moles de água e surfactante. No segundo modelo, diferentemente, o número total de moles leva em conta o número de moles de água, de íons de surfactante, de contra-íons livres e micelas (Evans e Wennerström, 1999).

\subsection{Fundamentos teóricos das técnicas usadas}

\subsubsection{SAXS}

Raios $\mathrm{X}$ tem sido usados desde os primórdios do século $\mathrm{XX}$ para a investigação da estrutura da matéria, sendo a técnica de Cristalografia de raios $X$ a mais tradicional. Posteriormente, por volta de 1930, surgiu a técnica de espalhamento de raios X a baixo ângulo, trazendo a vantagem de se estudar materiais biológicos diretamente em solução. A resolução típica de SAXS $(1-3 \mathrm{~nm})$ é menor do que a de cristalografia, de modo que não é possível ver detalhes da constituição atômica da amostra. No entanto, possui um vasto campo de aplicações, fornecendo não apenas informações sobre formas e tamanhos mas também grau de ordenamento e interações entre partículas. Os primeiros experimentos de SAXS aplicados para a investigação de micelas em solução são da década de 1950 (Luzzati, Mustacchi e Skoulios, 1957). Desde lá, tanto a obtenção dos dados quanto a análise dos mesmos passaram por aprimoramentos, de modo que hoje se dispõem de um acervo bastante rico de informações no que diz respeito a micelas. Tendo em vista a busca constante de maior conhecimento sobre processos biológicos bem como a caracterização de novas substâncias, a técnica de SAXS é uma poderosa aliada. 
(Todo o texto abaixo foi baseado em (Oliveira, 2011))

A sigla SAXS vem de Small Angle X-ray Scattering que significa Espalhamento de Raios X à Baixo Ângulo. Quando um feixe colimado de raios X incide na amostra, parte desse feixe interage com os elétrons de cada molécula, podendo gerar vários processos possíveis (espalhamento Rayleigh, efeito Compton, produção de pares e outros). Para energias de $\sim 7$ a $12 \mathrm{keV}$ o espalhamento é bem descrito pela primeira aproximação de Born, que considera que o feixe espalhado é resultado do espalhamento primário dos objetos espalhadores (elétrons, átomos, partículas), isto é, não existem espalhamentos múltiplos. Na Figura 2.7a está esquematizado uma situação de espalhamento. Seja $\vec{k}_{0}$ o vetor de onda do feixe incidente e $\vec{k}$ o vetor de onda do feixe espalhado. Define-se

$$
\vec{q}=\vec{k}-\vec{k}_{0}
$$

como sendo o vetor de transferência de momento no espaço recíproco. Já que, pela primeira aproximação de Born, a onda incidente possui mesma energia que a onda espalhada, isto é, o espalhamento é elástico, então

$$
|\vec{k}|=\left|\vec{k}_{0}\right|=k=\frac{2 \pi}{\lambda}
$$

onde $\lambda$ é o comprimento de onda usado na radiação. Com este fato, podemos escrever o módulo de $\vec{q},|\vec{q}|=q$. Usando a lei dos cossenos aplicada ao triângulo mostrado na Figura 2.7b:

$$
q^{2}=k^{2}+k^{2}-2 k^{2} \cos 2 \theta
$$

Resolvendo, encontra-se a relação entre $q$ e $k$, a saber

$$
q=2 k \sin \theta
$$

Substituindo Eq. 2-13 em Eq. 2-15, 


$$
q=\frac{4 \pi}{\lambda} \sin \theta
$$

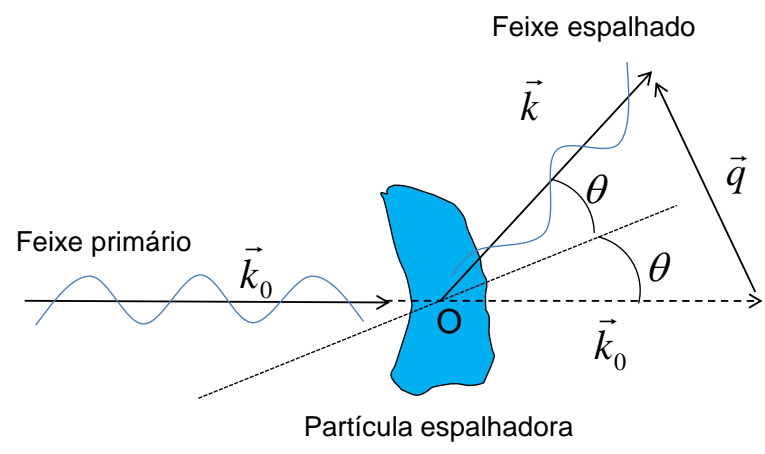

a)

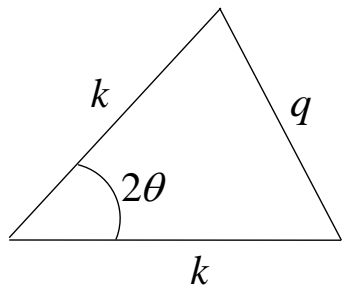

b)

Figura 2.7: a) Feixe de raios $X$ espalhado por uma partícula, fixa no espaço, formando um ângulo em relação ao feixe incidente. b) A partir de considerações geométricas escreve-se o módulo do vetor de transferência de momento no espaço recíproco (q) em função do ângulo de espalhamento e do módulo do vetor de onda.

Se a partícula está fixa no espaço e possui densidade eletrônica $\rho(\vec{r})$, então a amplitude de espalhamento $A(\vec{q})$ será dada pela Transformada de Fourier da densidade eletrônica:

$$
A(\vec{q})=\frac{1}{4 \pi} \int_{V} \rho(\vec{r}) e^{-i \vec{q} \cdot \vec{r}} d \vec{r},
$$

a qual está relacionada com a intensidade espalhada $I_{1}(\vec{q})$, mensurável, por meio de

$$
I_{1}(\vec{q})=A(\vec{q}) \bullet A(\vec{q})^{*}
$$

Em sistemas reais as partículas não estão fixas no espaço. Logo deve-se tomar a média sobre todas as orientações da partícula. No espaço recíproco isso é feito facilmente tomando-se a média sobre o ângulo sólido $\Omega$ :

$$
I_{1}(q)=\left\langle A(\vec{q}) \bullet A(\vec{q})^{*}\right\rangle_{\Omega}=4 \pi \int_{0}^{\infty} p(r) \frac{\sin q r}{q r} d r,
$$


onde a função $p(r)$, chamada distribuição de pares de distâncias, é uma função no espaço real que fornece informações sobre a forma das partículas a partir a partir da intensidade espalhada $I_{1}(q)$. Para tanto usa-se a Transformada Inversa de Fourier:

$$
p(r)=\frac{r}{2 \pi^{2}} \int_{0}^{\infty} q^{2} I_{1}(q) \frac{\sin q r}{q r} d q .
$$

A Figura 2.8 mostra a intensidade espalhada por algumas formas geométricas comuns assim como a função $p(r)$ correspondente.
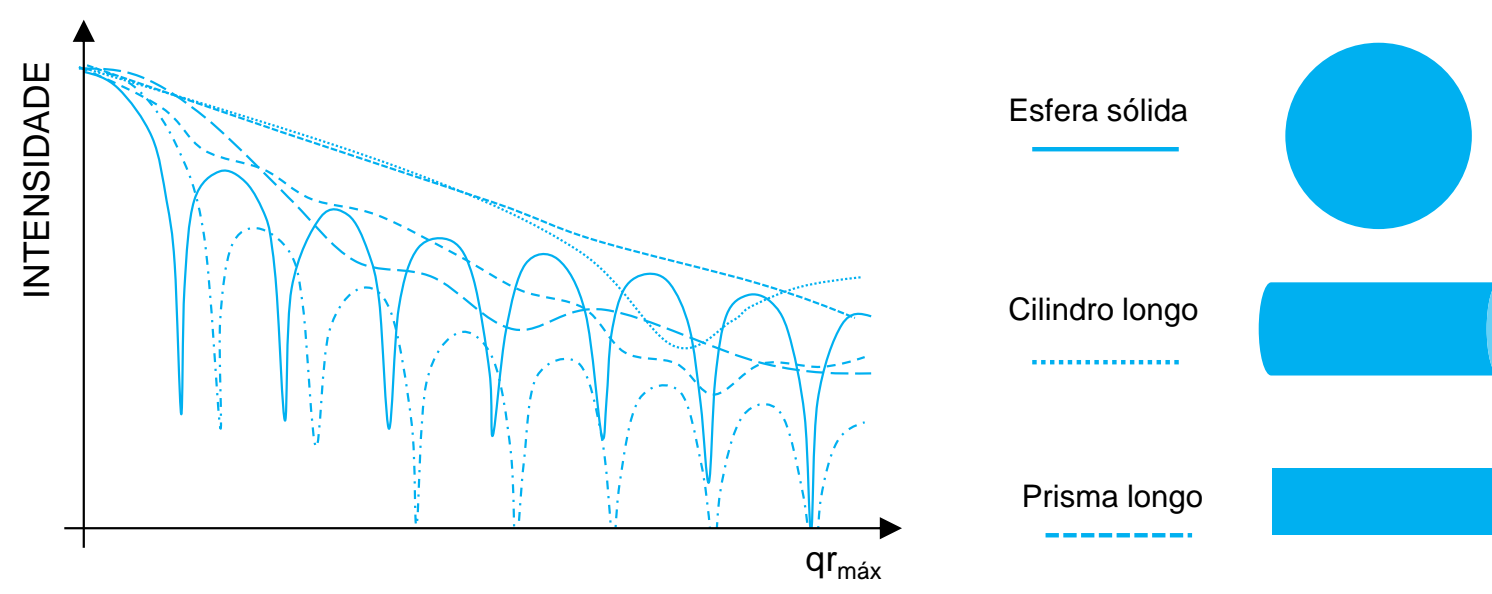

Cilindro longo

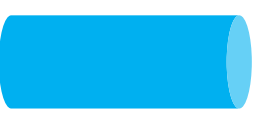

Prisma longo
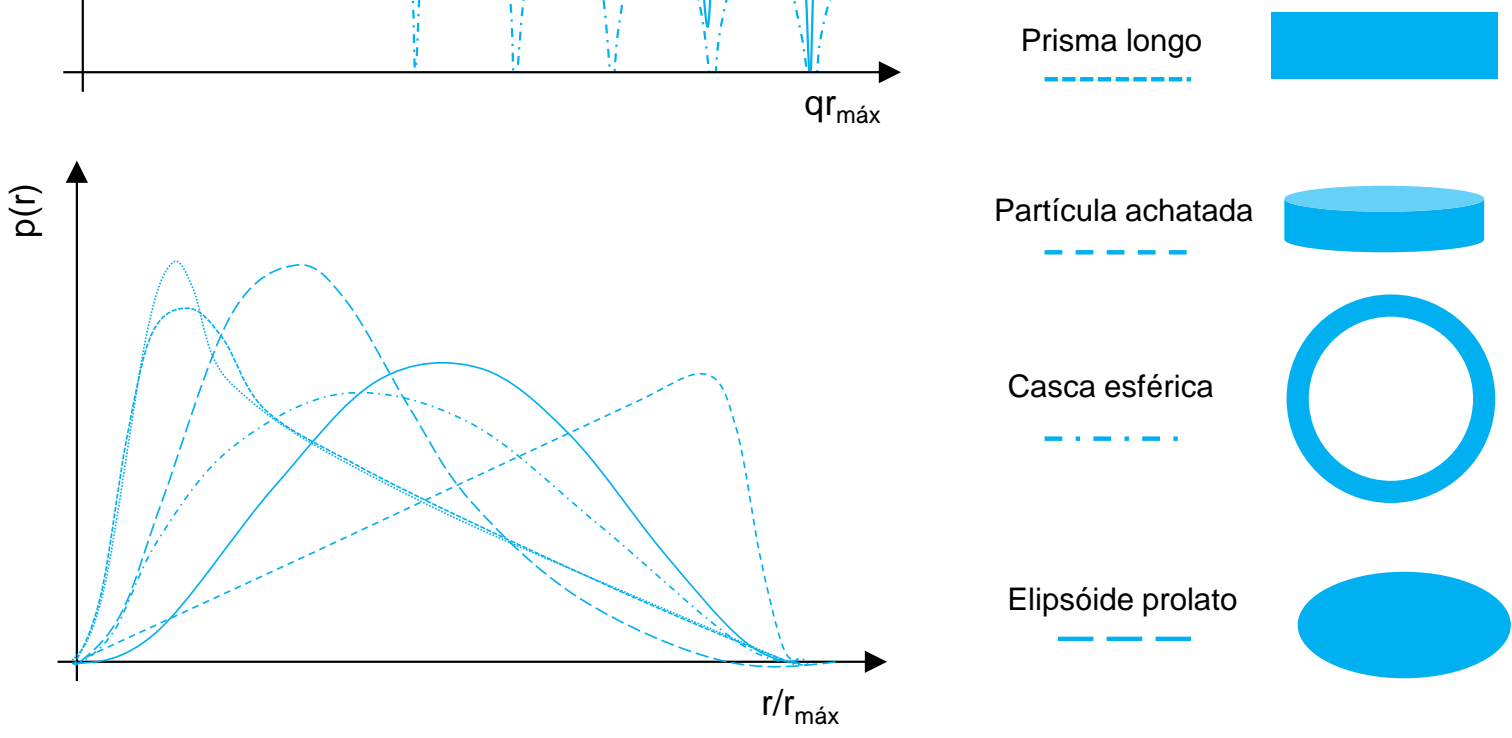

Partícula achatada

$-----$

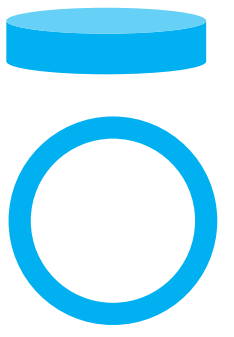

Elipsóide prolato
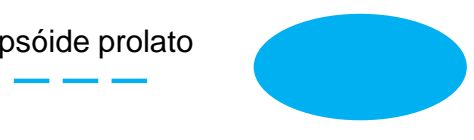

Figura 2.8: Cada estrutura mostrada à direita (esfera, cilindro, prisma...) possui um único perfil de intensidade assim como um único perfil de $\mathbf{p}(\mathbf{r})$. Conhecendo-se esses perfis, pode-se em uma análise inicial dar palpites sobre a forma das partículas em um sistema qualquer assim como o tamanho máximo envolvido $\left(\boldsymbol{r}_{\text {max }}\right)$, informação esta relacionada com a curva $p(\mathbf{r})$. Adaptado de (Oliveira, 2005).

Até agora foi tratado o espalhamento de uma única partícula. Para um sistema de partículas, randomicamente orientadas, a intensidade espalhada pelo sistema é 


$$
I(q)=\aleph\left\langle A(\vec{q})^{2}\right\rangle\langle S(\vec{q})\rangle
$$

onde $\left\langle f(\vec{q})^{2}\right\rangle=P(q)$ é o chamado fator de forma da partícula e $\langle S(\vec{q})\rangle=S(q)$ é o chamado fator de estrutura.
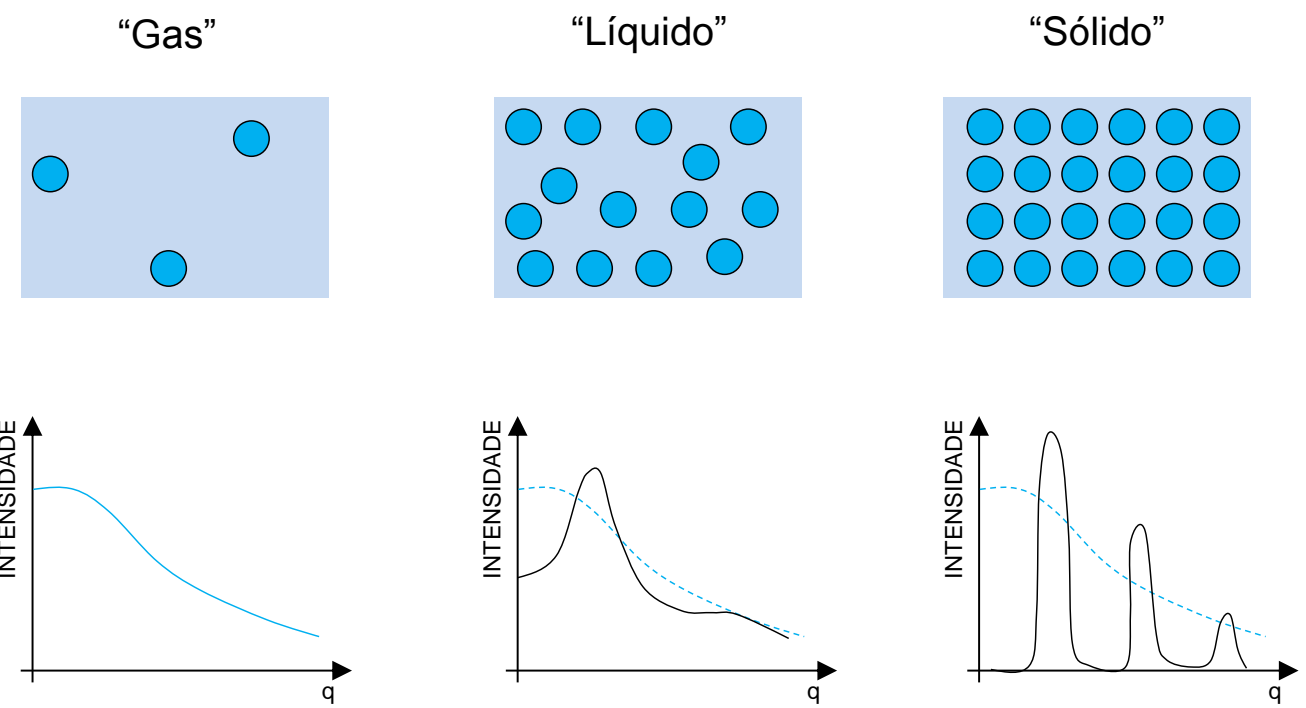

Figura 2.9: Para sistemas diluídos (primeira imagem da esquerda para a direita) nos quais as partículas estão muito distantes umas das outras (como em um gás), apenas o fator de forma (linha azul) é predominante. Para sistemas mais concentrados (como em um líquido) as partículas estão mais próximas umas das outras e passam a interagir, sendo que o fator de estrutura (linha preta) passa a ser importante. Para sistemas muito concentrados (como em um sólido) nos quais as partículas interagem fortemente, ambos o fator de estrutura e fator de forma devem ser levados em conta a fim de que a intensidade espalhada possa ser descrita completamente. Adaptado de (Craievich, 2009).

O fator de forma depende unicamente da forma das partículas. Se o sistema for monodisperso, a forma das partículas não muda e $P(q)=I_{1}(q)$. Se o sistema for polidisperso, o fator de forma incluirá a média sobre todas as possíveis formas, tamanhos e densidades eletrônicas das partículas. O fator de estrutura depende das interações entre as partículas e das possíveis estruturas que elas podem formar devido a isso. Para sistemas diluídos, $S(q) \rightarrow 1$ e a intensidade espalhada só dependerá do fator de forma. Para sistemas concentrados $S(q)$ deve ser levado em conta a fim de que a intensidade espalhada seja perfeitamente entendida. A Figura 2.9 ilustra, por meio de uma analogia, situações que vão desde o estado diluído (tipo "gás") até o estado concentrado (tipo 
"sólido") de um sistema, considerando em cada caso a contribuição dos fatores de forma e estrutura.

\subsubsection{ITC}

A calorimetria surgiu no século XVIII, mesma época em que o desenvolvimento da Termodinâmica ainda estava acontecendo, a atribui-se a Lavoisier e Laplace a construção do primeiro calorímetro. Esse instrumento, ainda usado hoje, mede grandes magnitudes de calor, da ordem de joules. Contudo, várias reações químicas e processos biológicos acontecem liberando quantidades ínfimas de calor. Surgiram então calorímetros mais sensíveis, na década de 1960, que mediam calores da ordem de milijoules. Com isso já era possível estudar termodinamicamente algumas reações, fossem químicas ou não. Somente na década de 1980 a sensibilidade passou a ser da ordem de microjoules, sendo os calorímetros propriamente chamados de microcalorímetros. Com o advento da grande produção e venda de microcalorímetros iniciou-se o estudo de processos biológicos em larga escala. $\mathrm{O}$ primeiro trabalho usando a técnica de calorimetria isotérmica para o estudo de micelas aconteceu no final da década de 1980 (Johnson, Olofsson e Jonsson, 1987). A vantagem da técnica de ITC bem como de outras técnicas calorimétricas, como DSC (calorimetria diferencial de varredura), é que se torna possível a determinação direta de valores de entalpia, além de outros parâmetros como constante de equilíbrio, constantes de ligação e outros.

A sigla ITC vem de Isothermal Titration Calorimetry que significa calorimetria de titulação isotérmica. A ideia básica de um calorímetro é medir o calor gerado ou absorvido em um processo físico ou químico, enquanto um experimento de titulação tem como objetivo o estudo da variação das propriedades físico-químicas de uma solução quando diluída sistematicamente no solvente. A técnica de ITC une esses dois aspectos: o experimento consiste na titulação de uma solução (no caso deste trabalho, apenas de surfactante) em buffer (o solvente), objetivando o estudo do calor gerado ou absorvido pelo sistema durante o processo. No experimento a temperatura é mantida constante e 
observada por meio de sensores ligados às duas células, uma de referência (a qual é preenchida com água) e a outra de amostra (onde é colocada a amostra e ocorre a diluição), como está mostrado na Figura 2.10. Ambas as células estão dentro de uma armadura adiabática que evita trocas de calor das células com o ambiente externo.

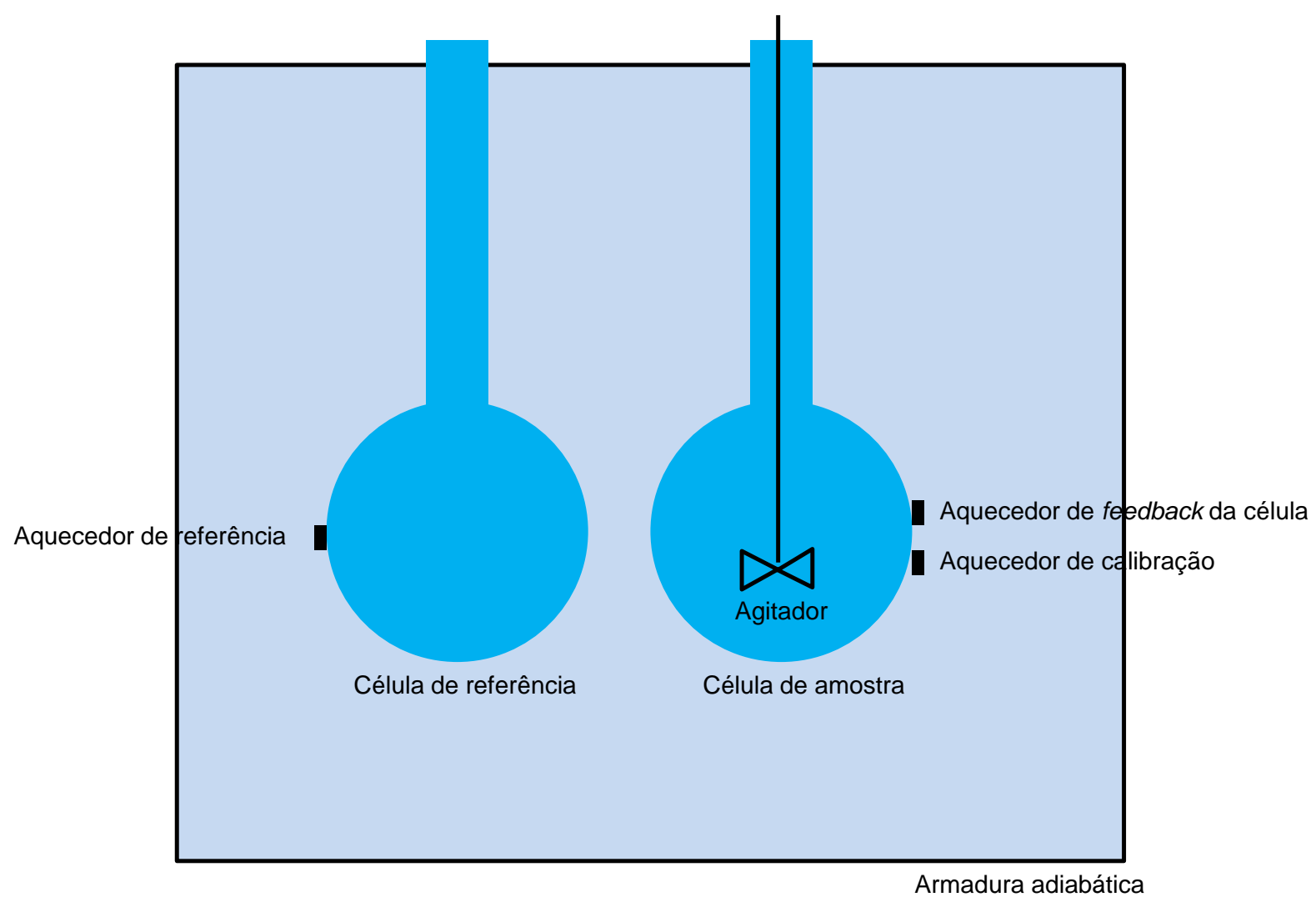

Figura 2.10: Esquema de um equipamento de ITC. Adaptado de (Pierce, Raman e Nall, 1999).

A informação sobre calores trocados vem da medida do fluxo de calor necessário para manter o equilíbrio térmico entre as células. Assim, se o processo libera calor (dito exotérmico) então o fluxo de calor que vai para a célula de amostra deverá diminuir. Do contrário (processo endotérmico, absorvendo calor) o fluxo deverá aumentar. Caso não aconteça a absorção ou liberação de calor, então o fluxo se mantém constante, correspondendo à chamada linha de base (Figura 2.11). 


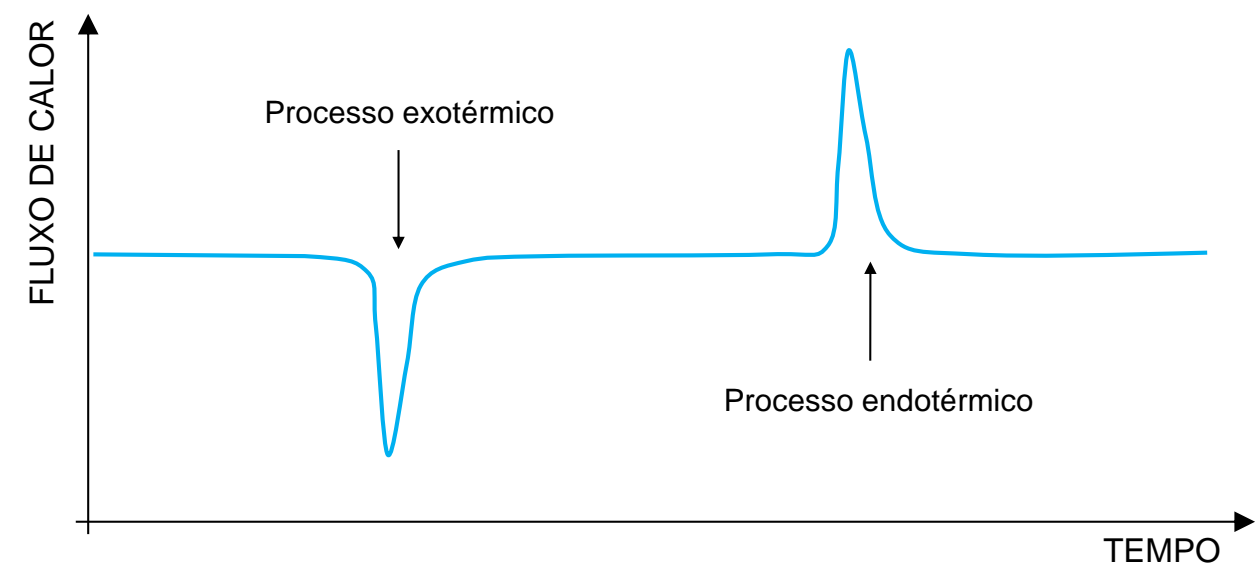

Figura 2.11: No processo exotérmico ocorre a diminuição do fluxo de calor a fim de se manter a temperatura da célula de amostra constante. Em um fluxograma de calor isso é representado por um vale. Para o processo endotérmico é necessário fornecer calor, de modo que o fluxo aumenta. Isso corresponde a um pico no fluxograma. A linha de base, horizontal, corresponde a todo o momento no qual o processo não é exotérmico nem endotérmico. Adaptada de http://www.microcal.com/technology/itc.asp (acessado em janeiro/2013).

O fluxo de calor é observado ao longo do tempo do experimento e o resutado final é um gráfico de fluxo de calor x tempo, chamado de fluxograma (Figura 2.12a). Uma vez tratados os dados, a interpretação do gráfico está diretamente ligado a medidas de mudanças de energia no sistema. Este gráfico é chamado agora de entalpograma (Figura $2.12 b)$, pois os calores, trocados a pressão constante, correspondem a variações de entalpia.

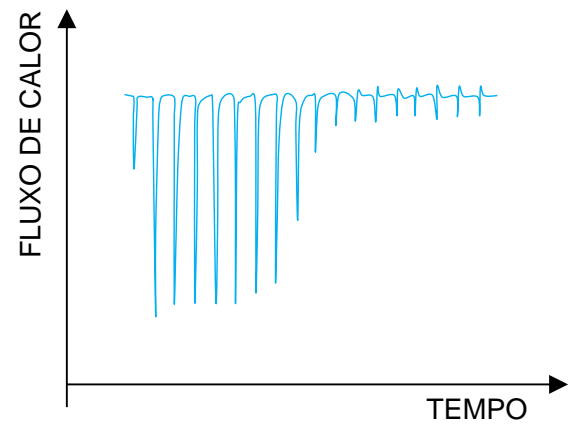

a)

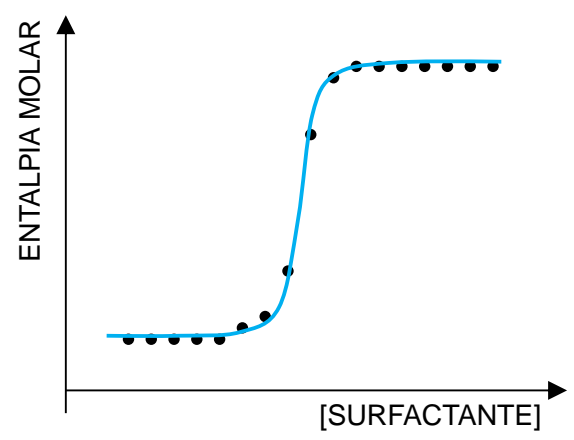

b)

Figura 2.12: a) Fluxograma, mostrando aumentos e diminuições de fluxo de calor ao longo do experimento. b) Entalpograma. A linha azul representa o ajuste dos dados experimentais. 
Cada ponto no entalpograma corresponde a um pico do fluxograma que foi integrado em relação ao tempo. Dispondo-se de um modelo, é possível fazer o ajuste dos dados (representado pela linha azul na Figura 2.12b) e obter informações sobre parâmetros termodinâmicos como constante de equilíbrio, variações de energias livres e variações de entropia.

Nesse trabalho estaremos interessados em entalpogramas relacionados à titulação de uma solução concentrada de surfactante ( 100 mM) em buffer, com perfil típico mostrado na Figura 2.13a. Na literatura em geral são empregados métodos gráficos para a avaliação de parâmetros termodinâmicos do sistema micelar. Por meio da primeira derivada da curva do entalpograma em relação à concentração de surfactante é possível obter o $C M C$ (Figura 2.13b), interpretado nesse caso como o ponto de inflexão da curva do entalpograma (Chatterjee et al., 2001).

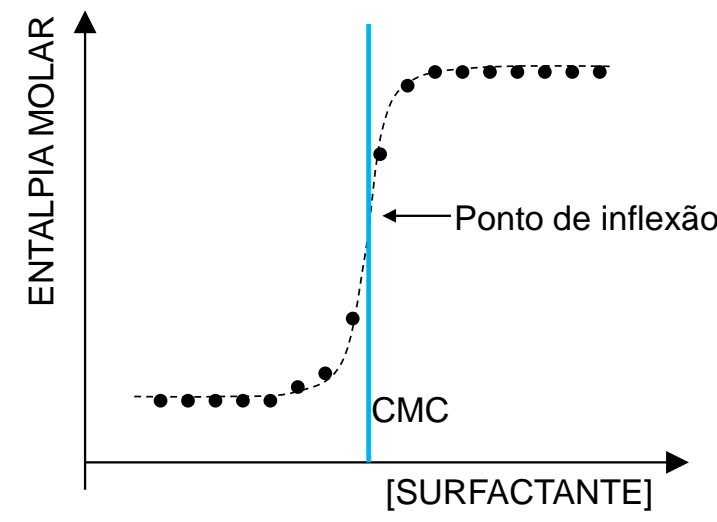

a)

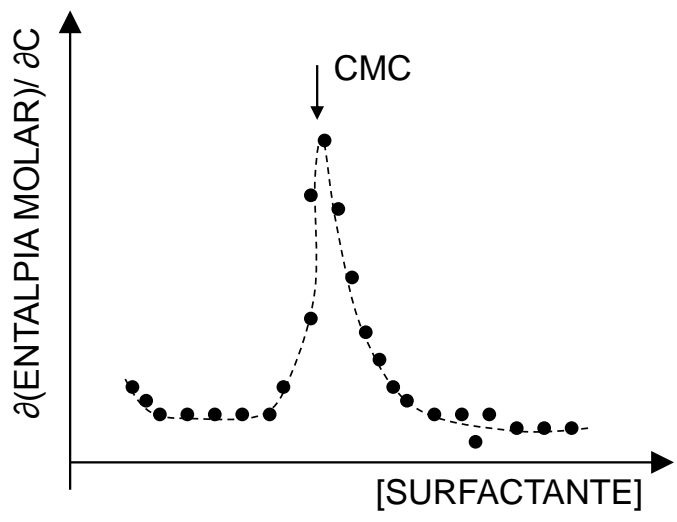

b)

Figura 2.13: a) Entalpograma da titulação de SB3-12 em água, na temperatura de 25C. b) Método gráfico da primeira derivada para a determinação do $C M C$ a partir do entalpograma. Adaptado de (Antonio, 2011).

Para sistemas micelares é comum ser possível a identificação de três regiões, que estão devidamente numeradas na Figura 2.14 (Olofsson e Loh, 2009). A região 1 é chamada região pré-micelar, a qual corresponde a monômeros livres na célula de amostra após a diluição da solução concentrada de surfactante. Após a diluição as micelas são 
desfeitas, sendo esse processo chamado demicelização. Portanto, a variação de entalpia nessa região, $\Delta H_{1}$, é a soma da variação de entalpia correspondente das micelas que são desfeitas, $\Delta H_{\text {demic }}$, com a variação da entalpia devido à diluição dos monômeros, $\Delta H_{\text {dil }}^{1}$, isto é,

$$
\Delta H_{1}=\Delta H_{\text {demic }}+\Delta H_{d i l}^{1}
$$

Na região 2, chamada de região micelar, a concentração de surfactante na cela de amostra já é suficiente para que o processo de micelização ocorra. Nesse sentido a diluição de parte da solução concentrada a ser injetada dará origem a monômeros livres, enquanto a parte restante formará micelas diluídas. A variação de entalpia nessa região, $\Delta H_{2}$, será a soma da variação de entalpia de micelização, $\Delta H_{\text {demic }}=-\Delta H_{m i c}$ e da diluição das micelas, $\Delta H_{\text {dil }}^{2}$, isto é,

$$
\Delta H_{2}=-\Delta H_{m i c}+\Delta H_{d i l}^{2} .
$$

Na região 3, chamada de região pós-micelar, a concentração de surfactante na cela de amostra está muito acima da $C M C$, de modo que as injeções seguintes acarretarão na diluição de micelas. Logo, a variação de entalpia nessa etapa, $\Delta H_{3}$, corresponderá apenas à variação de entalpia de diluição de micelas, $\Delta H_{d i l}^{3}$, isto é,

$$
\Delta H_{3}=\Delta H_{d i l}^{3} .
$$

Subtraindo Eq. 2-22 de Eq. 2-24, vem:

$$
\Delta H_{3}-\Delta H_{1}=\Delta H_{d i l}^{3}-\left(\Delta H_{d i l}^{1}+\Delta H_{\text {demic }}\right) .
$$

A diferença $\Delta H_{3}-\Delta H_{1}$ corresponde à variação de entalpia observada $\left(\Delta H_{o b s}\right)$ entre as formas monomérica e micelar do surfactante (Figura 2.14b). Assim, a Eq. 2-25 fica:

$$
\Delta H_{o b s}=\Delta H_{d i l}^{3}-\Delta H_{d i l}^{1}-\Delta H_{\text {demic }} .
$$

Usando que $-\Delta H_{d e m i c}=\Delta H_{m i c}$ e que $\Delta H_{d i l}^{3}-\Delta H_{d i l}^{1} \approx 0$, vem 


$$
\Delta H_{o b s}=\Delta H_{m i c} .
$$

Portanto, pode-se determinar graficamente a variação da entalpia de micelização (Chatterjee et al., 2001). Idealmente a concentração da solução na seringa é muito alta, mas isso não é razoável na maioria das vezes. Logo, $\Delta H_{o b s}$ precisa ser corrigido usando a seguinte expressão (Olofsson e Loh, 2009):

$$
\Delta H_{m i c}=\Delta H_{o b s} \frac{c_{0}}{c_{0}-C M C},
$$

onde $c_{0}$ é a concentração inicial de surfactante antes da diluição e $c_{0}-C M C$ é a concentração de monômeros livres em solução.

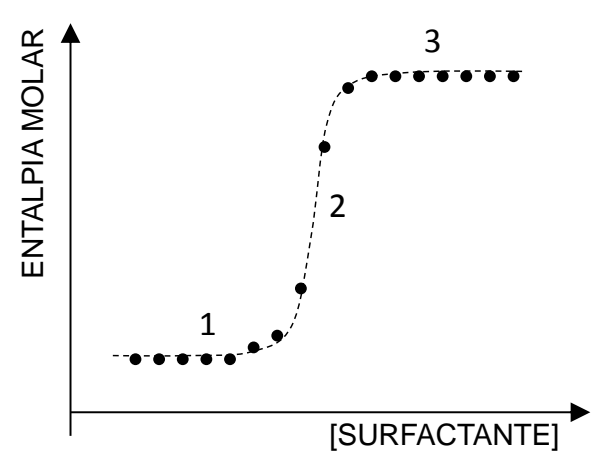

a)

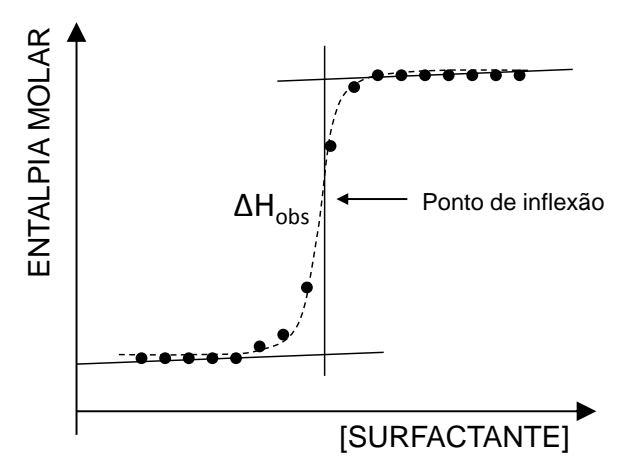

b)

Figura 2.14: a) A região 1 corresponde a região pré-micelar; a região 2 corresponde a região micelar; a região 3 corresponde a região pós-micelar. b) Método gráfico para a determinação da entalpia de micelização, no qual o ponto de inflexão corresponde ao CMC, determinado previamente pelo método gráfico da primeira derivada. Adaptado de (Antonio, 2011).

Às vezes as curvas presentes no entalpograma diferem muito do perfil típico, como é o caso daquele mostrado na Figura 2.15. Para situações assim, e também para os casos comuns, pode-se fazer o ajuste dos dados utilizando (Shimizu, Pires e El Seoud, 2004):

$$
\Delta H=\frac{a_{1} \cdot c+a_{2}}{1+e^{\frac{c-C M C}{\Delta c}}}+a_{4} \cdot c+a_{5},
$$


onde $a_{1}, a_{4}$ e $a_{5}$ são parâmetros de ajuste, $a_{2}=\Delta H_{o b s}, c$ é a concentração molar de surfactante na cela de amostra e $\Delta c$ é a largura de transição, que corresponde até $\pm 15 \%$ do valor $C M C$.

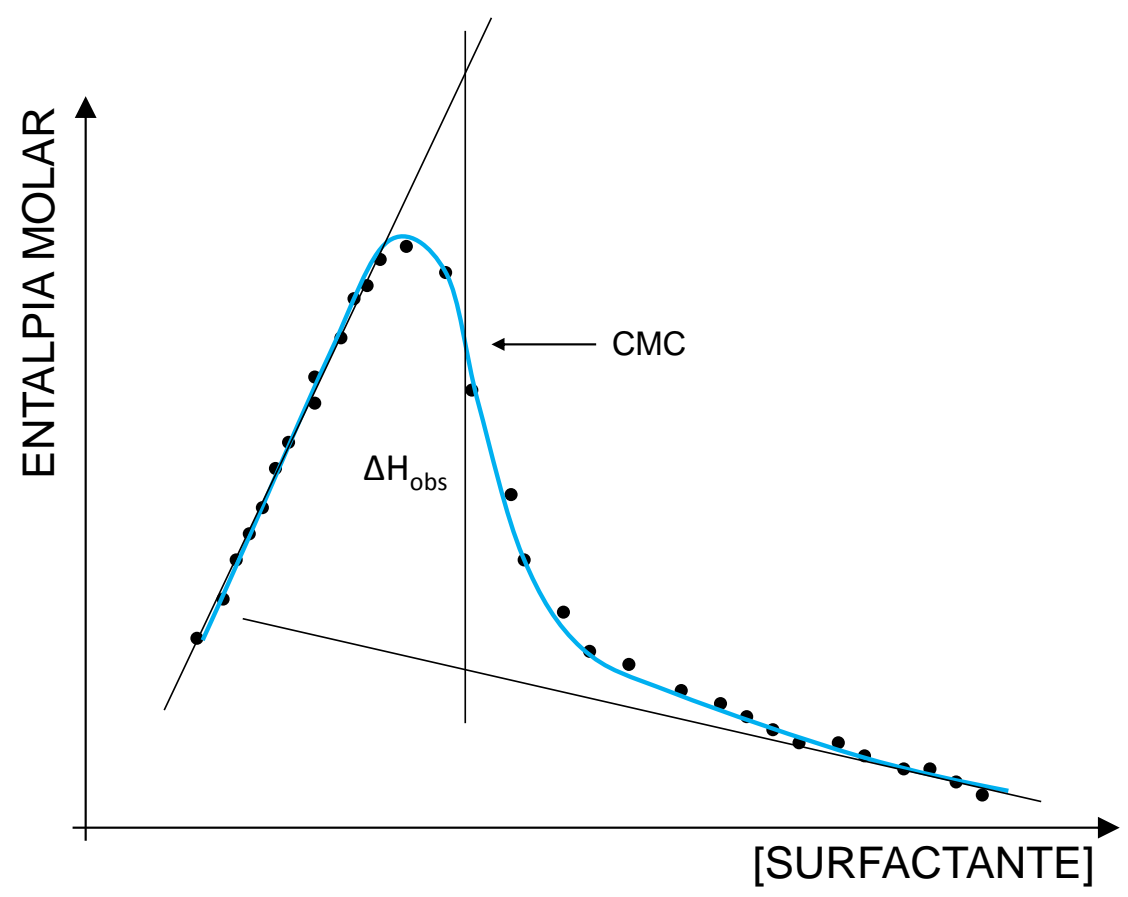

Figura 2.15: Exemplo de ajuste obtido usando-se a Eq. 2-29. Adaptada de (Antonio, 2011).

\subsubsection{Condutividade}

A condutimetria (ou condutometria) é uma técnica que tem sido aplicada desde o século XVIII para a classificação de sólidos e fluidos em bons ou maus condutores. Isso somente foi possível com os estudos de Georg Simon Ohm acerca da proporcionalidade que existe entre corrente e tensão elétrica, e depois continuados por André Marie Ampère. Para líquidos, a interpretação molecular sobre as observações oriundas da condutimetria surgiram apenas um século depois, com a hipótese de Arrhenius sobre a dissociação iônica de sais. As primeiras aplicações da condutimetria para o estudo de micelas data da década de 1940 (Ward, 1940). Essa técnica, diferente de SAXS e ITC, é muito barata e extremamente sensível, fornecendo tanto informações estruturais quanto termodinâmicas (Galgano e El Seoud, 2010). 
Na Figura 2.16 estão mostrados os principais elementos envolvidos na técnica de condutividade. Basicamente são imersas duas placas na solução, ligadas a um gerador de tensão alternada. Medindo-se a tensão $U$ e a corrente elétrica $i$ é possível determinar a resistência elétrica $R$ e, indiretamente, a condutividade elétrica $\kappa$.

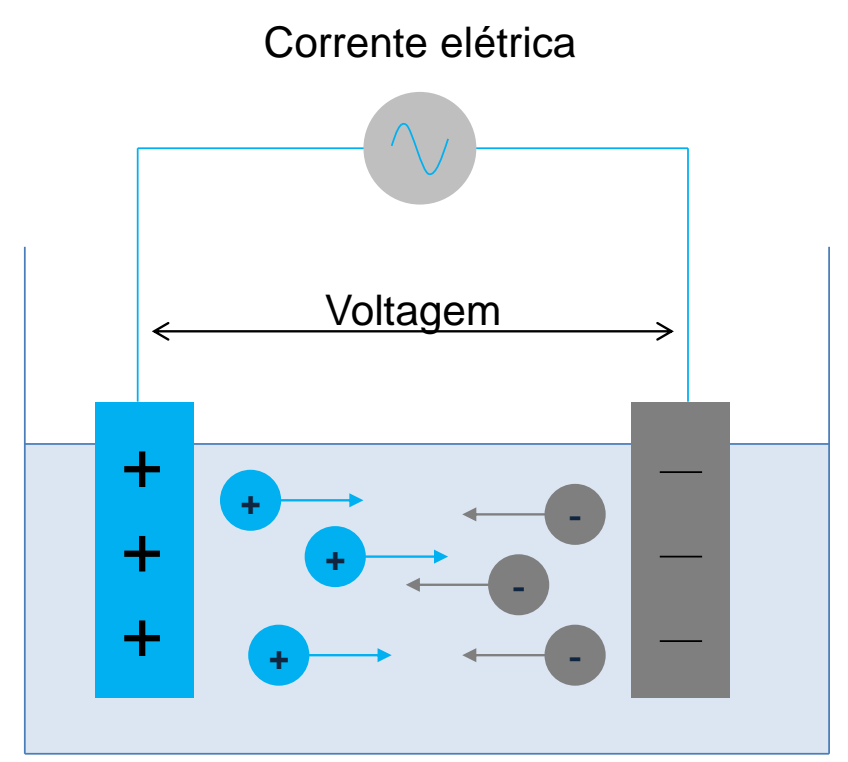

Figura 2.16: Esquema para a determinação da condutividade elétrica de uma solução iônica.

Define-se a resistência elétrica da solução, $R$, pela $1^{\text {a }}$ Lei de Ohm:

$$
R=\frac{U}{i}
$$

Também pode-se definir a condutância elétrica, $\mathrm{K}$, como o inverso da resistência elétrica,

$$
\mathrm{K}=\frac{1}{R}
$$

Das características geométricas do sistema esquematizado na Figura 2.16, isto é, área das placas, $a$, e distância de separação entre elas, $d$, podemos definir o parâmetro $g$ como 


$$
g=\frac{d}{a}
$$

que é chamada constante de célula. Como isso, pode-se definir a condutividade elétrica específica de uma solução, $\kappa$, (que acaba sendo o inverso da resistividade elétrica, $\rho$ ) por meio de:

$$
\kappa=\mathrm{K} \cdot g
$$

A condutividade elétrica específica possui unidade $S \cdot m^{-1}$ no SI, onde $S=\Omega^{-1}$ significa siemens. Como a condutividade de soluções de surfactantes é tipicamente baixa, é conveniente usar a subunidade $\mu S \cdot \mathrm{cm}^{-1}=10^{-5} \mathrm{~S} \cdot \mathrm{m}^{-1}$.

Outra grandeza igualmente usada em experimentos de condutivimetria é a condutividade elétrica molar, $\Psi$, dada por

$$
\Psi=\frac{\kappa_{\text {solução }}-\kappa_{\text {solvente }}}{c},
$$

onde $c$ é a concentração da solução.

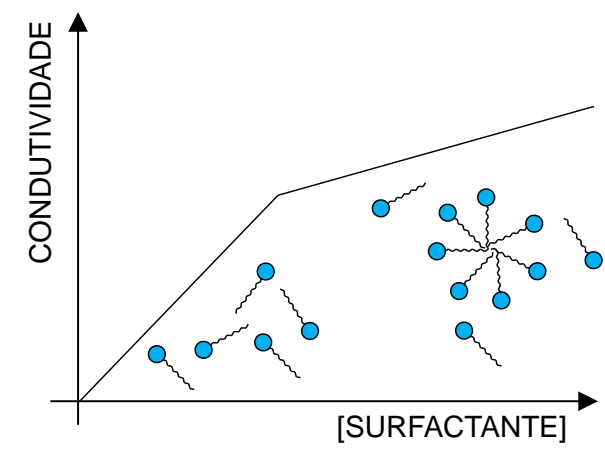

a)

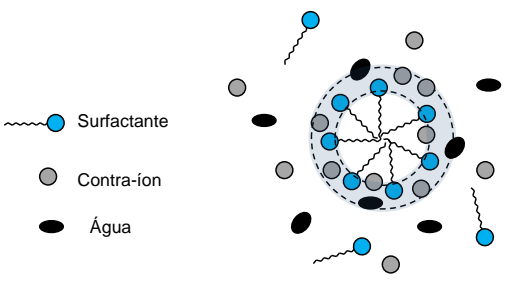

b)

Figura 2.17: a) Perfil típico de dados de condutividade. A mudança do comportamento linear dos dados reflete a passagem do surfactante em estado monomérico para o estado micelar. b) Surfactantes iônicos, quando em solução, dissociam-se dando origem ao íon e contra-íon. Os contra-íons se inserem no meio micelar (coroa circular colorida), a chamada camada de Stern, ajudando na estabilização do agregado formado. Adaptado de (Felippe, 2006). 
A Figura 2.17a mostra um perfil condutividade $\times$ [surfactante] típico para sistemas micelares compostos por surfactantes iônicos. No experimento de condutividade o aumento da concentração de surfactante em solução causa o aumento linear da condutividade, porque a quantidade de íons e contra-íons aumenta. Quando a concentração de surfactante atinge a $C M C$ há a formação de micelas que, como discutido em seções anteriores, possuem contra íons entre os monômeros que ajudam na estabilização elétrica do agregado (Figura 2.17b). A micela possui pouca carga elétrica, e já que a concentração de íons e contra-íons livres em solução diminuiu por causa dela, então a taxa de aumento de condutividade também deve diminuir (Attwood e Florence, 1983; Evans e Wennerström, 1999). Isso explica a mudança do regime linear mostrado na Figura 2.17a.

Partindo do pressuposto de que soluções de surfactante obedecem a lei de Kohlrausch (Atkins e De Paula, 2008), então a condutividade específica $\kappa$ pode ser determinada a partir da condutividade iônica molar dos íons, $\psi_{i}$, dada por

$$
\psi_{i}=z_{i} \cdot u_{i} \cdot F
$$

onde $z$ é a carga do íon, $u$ a sua mobilidade iônica ${ }^{2}$ e $F$ a constante de Faraday. Considerando o caso do surfactante iônico abaixo da $C M C$, tem-se que o valor de $\kappa$ vem das contribuições dos íons e contra íons, de maneira que

$$
\kappa=\left(\psi_{\text {ion }}+\psi_{\text {contra ion }}\right) c=\alpha_{1} c,
$$

onde $c$ é a concentração total de surfactantes, nesse caso na forma monomérica, e $\alpha_{1}=\psi_{\text {ion }}+\psi_{\text {contraion }}$ é a inclinação da curva $\kappa \times c$ abaixo da $C M C$. Uma vez que a micela composta por surfactantes iônicos é parcialmente carregada, é conveniente definir a grandeza fração de carga micelar neutralizada, $\beta$ ou, o que é similar, o grau de ionização

2 É a velocidade adquirida por uma espécie iônica na presença de um campo elétrico, considerando-se também a viscosidade de meio em que ela se encontra. Possui unidade $m^{2} / V \cdot s$. 
micelar, $\alpha=1-\beta$. Logo, a concentração de contra íons livres na solução, $c_{c o n t r a-i o n}$, é dada por

$$
c_{\text {contra-ion }}=C M C-\alpha c_{m} \text {, }
$$

onde $c_{m}=c-C M C$ é a concentração de monômeros na forma micelar. Considerando que na solução de surfactante não exista qualquer eletrólito adicional (por exemplo, $\mathrm{NaCl}$ ), então a condutividade elétrica do sistema acima da $C M C$ pode ser considerada como sendo formada por 3 partes: 1) íons e contra-íons livres em solução; 2) íons e contra-íons que formam a micela eletricamente neutra; 3) contra-íons em excesso na micela, que a tornam parcialmente ionizada. Assim, a condutividade acima da $C M C$ será dada por

$$
\kappa=\left(\psi_{\text {ion }}+\psi_{\text {contra-ion }}\right) C M C+\psi_{\text {contra-ion }} \alpha c_{m}+\psi_{m} c_{\text {mic }},
$$

onde $c_{\text {mic }}$ é a condutividade iônica da micela e $c_{\text {mic }}$ a concentração molar de micelas, dada por $c_{m i c}=(c-C M C) / N_{a g}$. É razoável supor que a contribuição da micela para a condutividade seja a mesma que o dos íons que a formam, de modo que $\psi_{m}=\alpha N_{a g} \psi_{\text {ion }}$. Logo, a equação anterior se torna

$$
\kappa=\left(\psi_{\text {ion }}+\psi_{\text {contra-ion }}\right) \operatorname{CMC}(1-\alpha)+\left(\psi_{\text {ion }}+\psi_{\text {contra-ion }}\right) \alpha c=\kappa_{0}+\alpha_{2} c \text {, }
$$

onde $\alpha_{2}=\alpha_{1} \alpha$ é a inclinação da curva $\kappa \times c$ acima da $C M C$, enquanto $\kappa_{0}$ é o coeficiente linear. Portanto, podemos escrever que

$$
\alpha=\frac{\alpha_{2}}{\alpha_{1}}
$$

conhecido como método de Frahm (Frahm, Diekmann e Haase, 1980) para a determinação do grau de ionização $\alpha$.

Considerando que as retas descritas por Eq. 2-36 e Eq. 2-39 se interceptem no valor particular de concentração $C^{*}$, teremos que 


$$
\kappa_{0}+\alpha_{2} C^{*}=\alpha_{1} C^{*} \Rightarrow C^{*}=\frac{\kappa_{0}}{\alpha_{1}-\alpha_{2}}
$$

Lembrando que $\kappa_{0}$ é, de acordo com Eq. 2-41, dado por $\kappa_{0}=\alpha_{1} C M C(1-\alpha)$, tem-se que a expressão anterior pode ser reescrita como

$$
C^{*}=\frac{C M C\left(\alpha_{1}-\alpha_{1} \alpha\right)}{\alpha_{1}-\alpha_{2}}
$$

Já que $\alpha_{2}=\alpha_{1} \alpha$, vem finalmente que

$$
C^{*}=C M C,
$$

ou seja, em um perfil típico de condutividade, sobre o qual se traçam duas retas representativas dos comportamentos lineares, então a interseção delas irá fornecer o valor da $C M C$, como ilustra a Figura 2.18b. Esse método é conhecido como método de Williams (Williams, Phillips e Mysels, 1955).

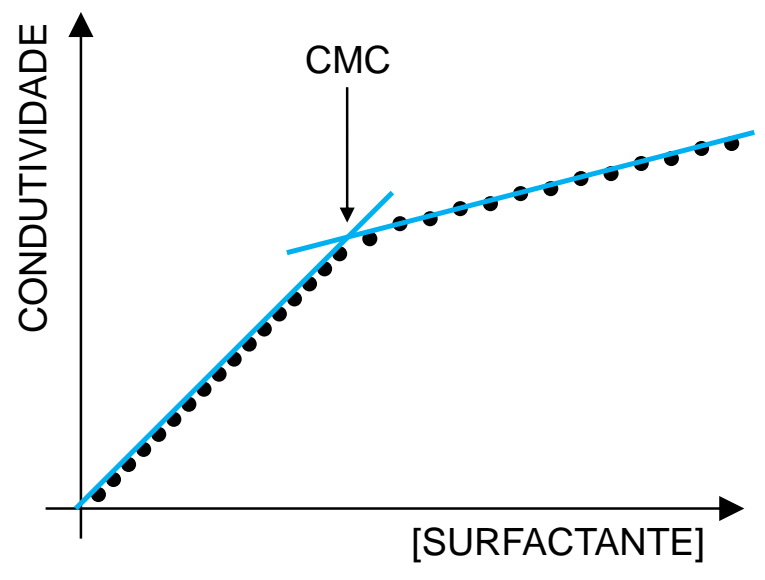

Figura 2.18: Exemplo de dados experimentais mostrando o perfil típico dos dados de condutividade. Método gráfico usual empregado para a análise dos dados experimentais, o qual permite obter a $C M C$ e o grau de dissociação iônica.

Esse método gráfico funciona bem para casos onde a região de transição de um comportamento linear para outro, que contém a $C M C$, é bem definida. Contudo, existem casos onde esse requisito não é satisfeito. Como é mostrado na Figura 2.19, existe a 
incerteza sobre quantos pontos experimentais usar para se traçar as duas retas e, como consequência, a $C M C$ é pouco confiável.

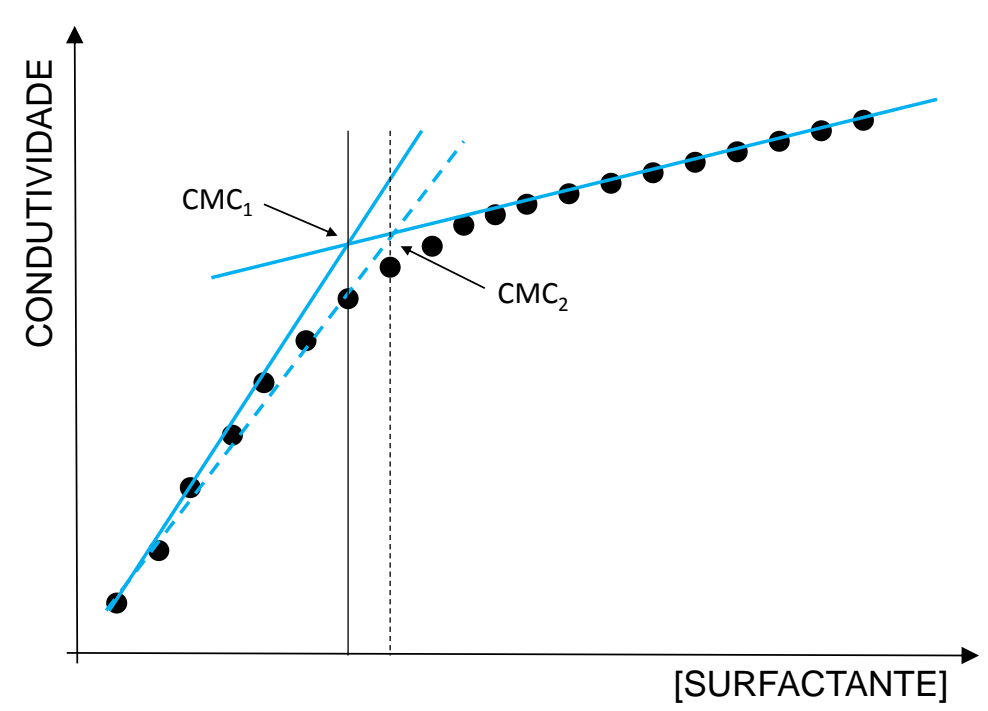

Figura 2.19: Representação do problema do método gráfico para análise dos dados de condutividade. Quando a região de transição não é bem definida, existe grande dificuldade para se traçar as duas retas, levando a um erro grande no valor da $C M C$.

Para resolver esse problema, alguns procedimentos foram criados baseados na análise da curva diferencial (primeira ou segunda ordem) versus a concentração de surfactante, isso porque na curva diferencial as mudanças pequenas são mais visíveis. Sugihara et al. trabalharam com a primeira derivada da condutividade específica versus a raiz quadrada da concentração de surfactante (Sugihara et al., 1997). Já García-Mateos et al. propuseram um método que trabalha com a segunda derivada da curva de condutividade versus concentração de surfactante, aproximando a forma da curva a gaussianas (Garciamateos, Velazquez e Rodriguez, 1990). Pérez-Rodríguez et al. também trabalham com derivadas de segunda ordem e gaussianas, porém usando métodos de análise numérica diferentes (Perez-Rodriguez et al., 1998). Nesse trabalho será usado a abordagem proposta por Carpena et al (Carpena et al., 2002), a qual será discutida em maiores detalhes na seção 3.5.3. 


\section{Capítulo 03}

Materiais e Métodos 


\section{Materiais e Métodos}

Nesse capitulo serão fornecidas informações sobre os materiais que foram utilizados na preparação das amostras bem como o protocolo para tal realização. Para cada técnica usada neste trabalho também será feito um levantamento dos procedimentos experimentais, fornecendo informações gerais sobre a forma de análise dos dados, aspecto que será mais profundamente trabalhado no capítulo concernente aos resultados e discussão.

\subsection{Materiais e reagentes}

Na Tabela 3.1 estão mostrados todos os surfactantes utilizados neste trabalho, assim como o peso molecular e a $C M C$ (obtida em água), ambas as informações disponíveis no site do fornecedor.

Tabela 3.1: Todos os surfactantes usados neste estudo e seus fornecedores.

\begin{tabular}{cccc}
\hline Surfactante & Peso molecular $[\mathrm{g} / \mathrm{mol}]$ & $C M C[\mathrm{mM}]$ & Fornecedor $^{3}$ \\
\hline SDS & 288,38 & $7-10\left(20-25^{\circ} \mathrm{C}\right)$ & Sigma - Aldrich ${ }^{\circledR}$ \\
TTAB & 336,39 & $4-5\left(20-25^{\circ} \mathrm{C}\right)$ & Sigma - Aldrich \\
SB310 & 307,49 & $25-40\left(20-25^{\circ} \mathrm{C}\right)$ & Sigma - Aldrich ${ }^{\circledR}$ \\
DM & 482,56 & $1,6-1,8\left(20-25^{\circ} \mathrm{C}\right)$ & Anatrace ${ }^{\circledR}$ \\
\hline
\end{tabular}

Todos os surfactantes foram adquiridos em forma de pó, e não passaram por processo de purificação adicional. Foi usado também um buffer Tris-EDTA, fornecido pela Sigma-Aldrich ${ }^{\circledast}$, de $\mathrm{pH}$ 8,0, contendo $5 \mathrm{mM}$ de Tris- $\mathrm{HCl}$ e $1 \mathrm{mM}$ de EDTA dissódico.

${ }^{3}$ http://www.sigmaaldrich.com/brazil.html;

http://www.affymetrix.com/estore/index.jsp; acessados pela última vem em 25/04/13. 


\subsection{Protocolos de preparação das amostras}

As amostras foram preparadas sempre seguindo o mesmo protocolo, à temperatura ambiente $\left(22^{\circ} \mathrm{C}\right)$ e dentro de tubos plásticos previamente esterilizados de capacidades 15 e $45 \mathrm{~mL}$, este último usado para a preparação de soluções estoque.

Para a preparação de uma amostra primeiramente se pensava, para cada experimento, na concentração desejada $c$ (em $m M=10^{-3} \frac{\mathrm{mol}}{\mathrm{L}}$ ) e no volume de amostra $V$ (em $m L$ ). Em seguida calculava-se qual a quantidade de surfactante $m$ (em $g$ ) pela seguinte expressão

$$
m=10^{6} \cdot c \cdot M \cdot V
$$

que decorre da definição de concentração molar ou molaridade. Na fórmula, $M$ é o peso molecular, em $\frac{g}{m o l}$. As massas de soluto e solvente foram determinadas usando uma balança analítica.

Para homogeneização passava-se as amostras por processos de agitação mecânica. Este processo era finalizado quando se observava que a solução ficava totalmente transparente. Como efeito da agitação formava-se grande quantidade de espuma. A fim de eliminá-las, o tubo contendo a solução era deixado em repouso por um dia antes do uso.

As concentrações típicas da solução estoque, para SDS, TTAB e DM foram em torno de $100 \mathrm{mM}$, o que corresponde a pelo menos 10 vezes a $C M C$ de cada um. O surfactante SB310 possui uma CMC relativamente alta (veja Tabela 3.1), de modo que para ele foi preparada uma solução estoque de $450 \mathrm{mM}$, o que corresponde também a pelo menos 10 vezes a sua $C M C$. 


\subsection{Experimentos de SAXS}

\subsubsection{Aparato experimental}

Todos os experimentos de SAXS foram realizados no Laboratório Nacional de Luz Síncrotron (LNLS) ${ }^{4}$, na linha SAXS1. A vantagem na utilização de luz síncroton se deve ao alto fluxo de fótons que interagem com a amostra ( $10^{12}$ fótons/segundo) quando comparado com o de fontes convencionais como o Nanostar-Bruker ( 10 fótons/segundo), instalado no Laboratório de Cristalografia do IFUSP, reduzindo consideravelmente o tempo de experimento.

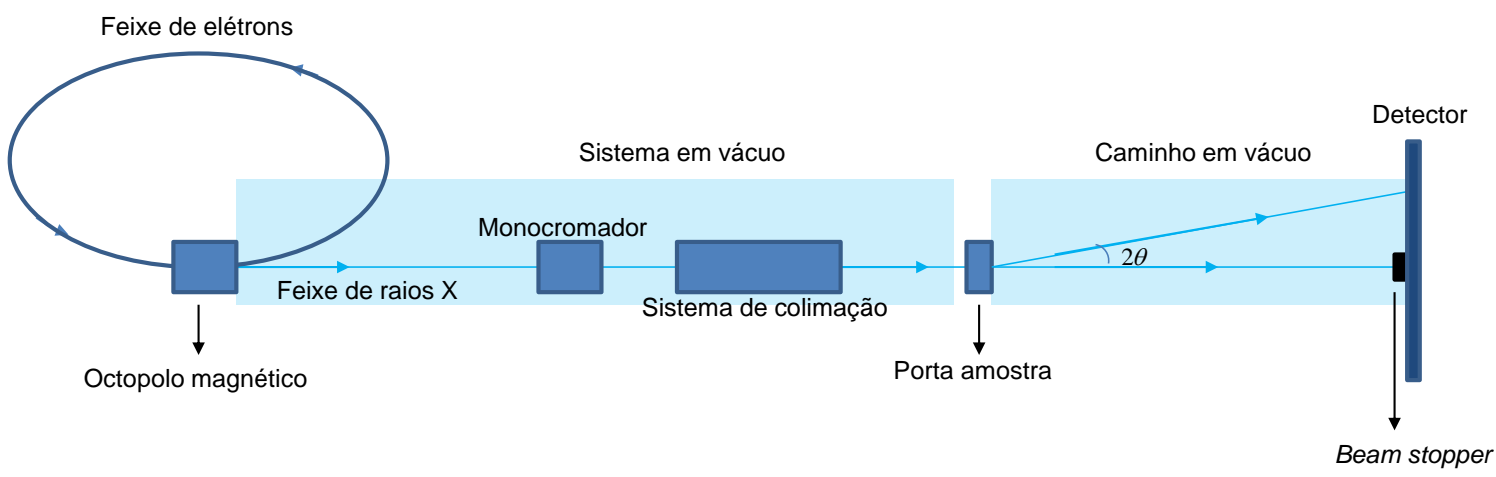

Figura 3.1: Arranjo experimental utilizado para a técnica de SAXS. 0 feixe de elétrons, ao ter sua trajetória desviada por um octopolo magnético, emite radiação (nesse caso, do comprimento de onda de raios $X$ ) que ao passar por um monocromador e sistema de colimação, incide na amostra. Extraído de (Barbosa, 2008).

Na Figura 3.1 é mostrado um esquema simplificado da linha SAXS1 que foi usada para o estudo estrutural proposto neste trabalho. A montagem experimental é basicamente composta de um feixe de elétrons que sofre um desvio de trajetória causado por um octopolo magnético. Isso gera radiação eletromagnética, cujo comprimento de onda permite constatar que se trata majoritariamente de raios $\mathrm{X}$. $\mathrm{O}$ feixe de raios $\mathrm{X}$ passa então por um monocromador, responsável por selecionar o comprimento de onda desejado. Em seguida, um sistema de colimação faz com que o feixe fique o mais próximo de um feixe ponto (diâmetro $\sim 1 \mathrm{~mm}$ ). Todo o caminho que o feixe de raios $X$ faz

\footnotetext{
4 Proposta SAXS1-12386; projeto: “Estudo estrutural de complexos proteína - surfactantes".
} 
encontra-se em vácuo, exceto o porta-amostra, constituído de lâminas de mica prensadas contra uma estrutura metálica, facilitando enormemente a troca de amostra bem como a possibilidade de realização de experimentos que não admitem vácuo.

Logo após incidir na amostra o feixe é espalhado segundo um ângulo $2 \theta$ (veja Seção 2.4.1) e coletado em um detector $2 \mathrm{D}$ do tipo Pilatus ${ }^{5}$. Como grande parte do feixe direto é transmitido sem espalhamento, usa-se um beam stopper para bloqueá-lo antes de chegar ao detector. Como resultado tem-se uma imagem 2D como mostrada na Figura 3.2. A densidade maior de fótons em certas regiões do que outras (padrão de espalhamento) está intimamente relacionada com as características estruturais do sistema estudado.

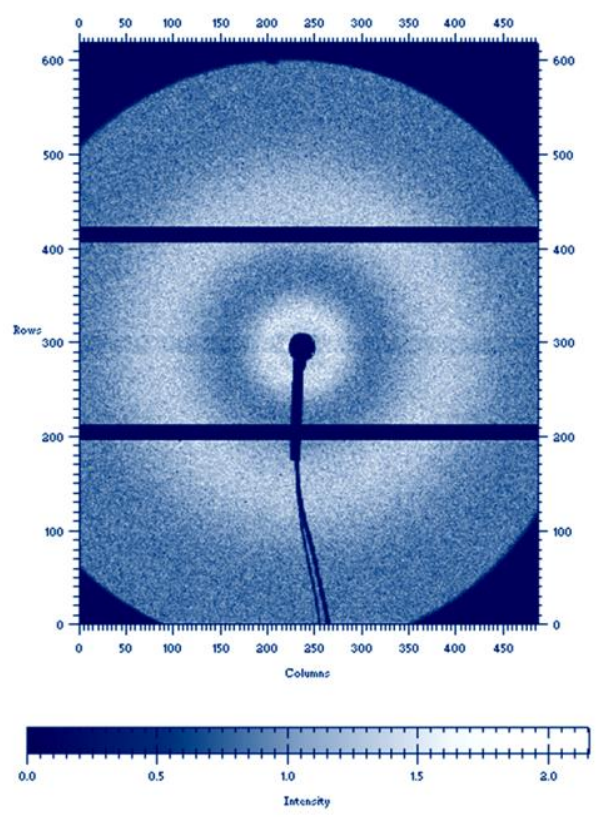

Figura 3.2: Exemplo de difratograma obtido no LNLS. A imagem foi adquirida usando-se programa FIT2D (disponível em http://www.esrf.eu/computing/scientific/FIT2D/).

\subsubsection{Aquisição de dados}

Para a coleta de dados foi necessário medir antes o espalhamento da água, usada para a calibração da intensidade em escala absoluta (isto é, a seção transversal de espalhamento diferencial), já que o espalhamento teórico da água, $I_{\mathrm{H}_{2} \mathrm{O}}$, só depende de

\footnotetext{
${ }^{5}$ http://lnls.cnpem.br/saxs/saxs-1/area-detectors/ - acessado em 25/04/13.
} 
suas propriedades intrínsecas, como mostrado pela expressão a seguir (Orthaber, Bergmann e Glatter, 2000):

$$
I_{\mathrm{H}_{2} \mathrm{O}}=\left(\rho^{\prime}\right)^{2} \cdot k_{B} \cdot T \cdot \chi_{T}
$$

onde $\rho^{\prime}$ é a densidade de comprimento de espalhamento das moléculas de água (ver Seção 3.3.5 para mais informações), $k_{B} \cdot T$ a sua energia térmica na temperatura $T$ e $\chi_{T}$ a compressibilidade isotérmica na temperatura $T$. Para $T=25^{\circ} \mathrm{C}$, que foi a temperatura durante todo o experimento, a intensidade de espalhamento teórica da água é $I_{\mathrm{H}_{2} \mathrm{O}}^{\text {teora }}=0.0162 \mathrm{~cm}^{-1}$ (Oliveira, 2005). Também se mediu o espalhamento devido ao buffer (o qual foi usado na preparação das amostras) e a mica. Esse último elemento servia de janela para o recipiente que continha a amostra e pela qual o feixe também era transmitido. Com isso, uma vez coletados os dados, subtrai-se do espalhamento da amostra o espalhamento do buffer e da mica, além de outros fatores como ruído e espalhamento parasita (devido à montagem do equipamento), resultando no espalhamento apenas dos elementos de interesse, que nesse estudo são as micelas (Figura 3.3).
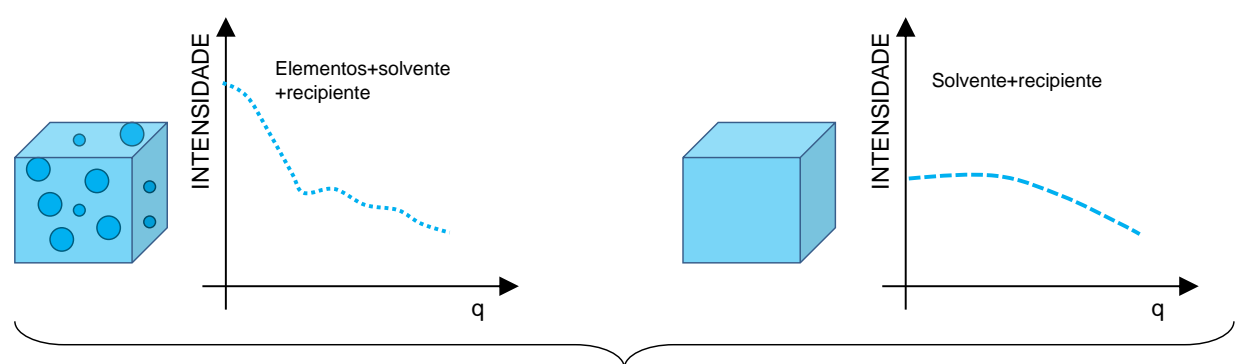

a)
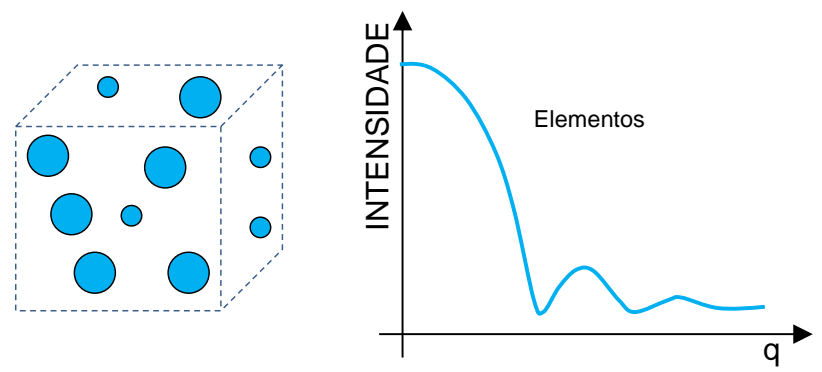

b)

Figura 3.3: Ao final do tratamento dos dados obtém-se o espalhamento apenas dos elementos que compõem sistema. Extraída de (Oliveira, 2005). 
Após esse procedimento, os dados foram convertidos para a escala absoluta usando

$$
I_{\text {absoluto }}(q)=I(q) \frac{I_{\mathrm{H}_{2} \mathrm{O}}^{\text {térico }}}{I_{\mathrm{H}_{2} \mathrm{O}}^{\text {expental }}}
$$

onde $I(q)$ são os dados provenientes da aquisição e $I_{H_{2} \mathrm{O}}^{\text {exprimenal }}$ é o espalhamento da água medido na mesma temperatura que o valor calculado teoricamente pela Eq. 3-2. Vale ressaltar que o processo de renormalização para a escada absoluta deve ser feito de forma correta, pois disso depende a posterior análise dos dados e a confiabilidade dos resultados.

Todo o procedimento de tratamento inicial dos dados foi feito por uma rotina disponível no LNLS. Ela faz o tratamento da imagem 2D descrita acima de forma automatizada, resultando em uma figura 1D (gráfico $I(q) \times q)$ (Figura 3.4a).

Para o tratamento restante utilizou-se o pacote de programas SUPERSAXS (Oliveira e Pedersen, 2009). Um deles, o WCONV, estima os erros nos dados experimentais, visto que a rotina disponível no LNLS não faz isso. Após o tratamento preliminar, os dados estavam prontos para serem analisados.

\subsubsection{Procedimento de análise dos dados}

A análise inicial corresponde ao procedimento de obtenção da função $p(r)$ (ver Seção 2.4.1) a fim de se obter informações no espaço real dos componentes do sistema estudado. Para tanto foi usado o programa WIFT (Oliveira et al., 2009), dentro do pacote SUPERSAXS. O estudo prévio da função $p(r)$ é importante porque fornece uma ideia sobre a forma da partícula, ajudando a decidir sobre o(s) modelo(s) a ser(em) testado(s) posteriormente na etapa da modelagem do sistema.

Na Figura 3.4a está mostrado um exemplo de uma curva de espalhamento para uma partícula do tipo core-shell, isto é, um núcleo e uma casca concêntricos, de contrastes eletrônicos $\Delta \rho$ de sinais opostos (Figura 3.4c). Para qualquer partícula desse tipo, não 
importando as dimensões, a função $p(r)$ será algo muito próximo da curva mostrada na Figura $3.4 b$.

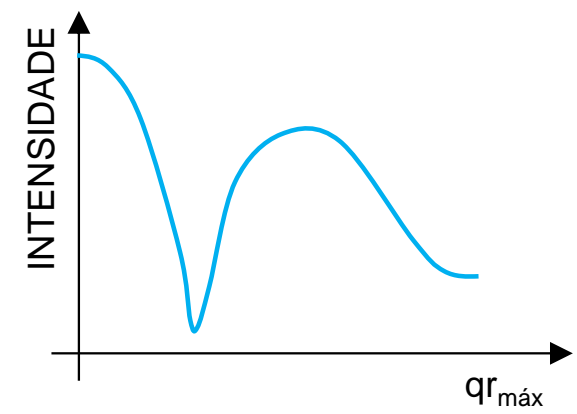

a)

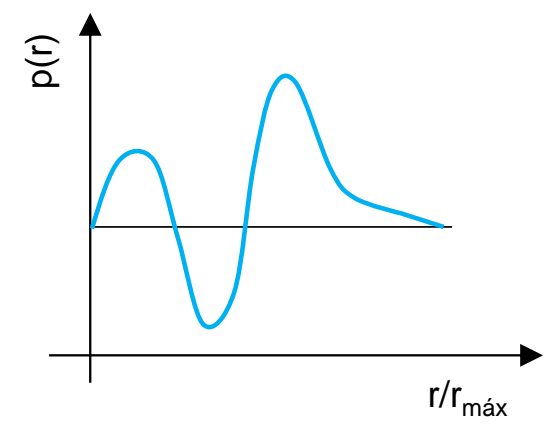

b)

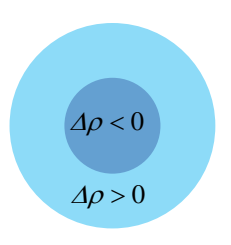

C)

Figura 3.4: A partir da curva de intensidade é possível obter a função distribuição pares de distâncias via a Transformada Inversa de Fourier. Acima está mostrado uma partícula do tipo core-shell, na qual cada uma das partes possui um contraste eletrônico diferente em relação ao solvente. Extraído de (Oliveira, 2011).

Modelos core-shell (abreviadamente, "modelos cs") são bastante usados para descrever sistemas micelares. Isso porque em sistemas não muito concentrados as micelas assumem uma forma próxima da esférica, como mostra a Figura 3.5a, com contrastes eletrônicos da cabeça e da cauda $\Delta \rho_{H}$ e $\Delta \rho_{T}$, respectivamente, em relação ao solvente. Pode-se então modelar esse sistema como um core-shell, onde o core corresponde ao conjunto das caudas e o shell ao conjunto das cabeças (Figura 3.5b). É assumido que tanto o core quanto o shell tenham um contraste eletrônico constante em relação ao solvente. 


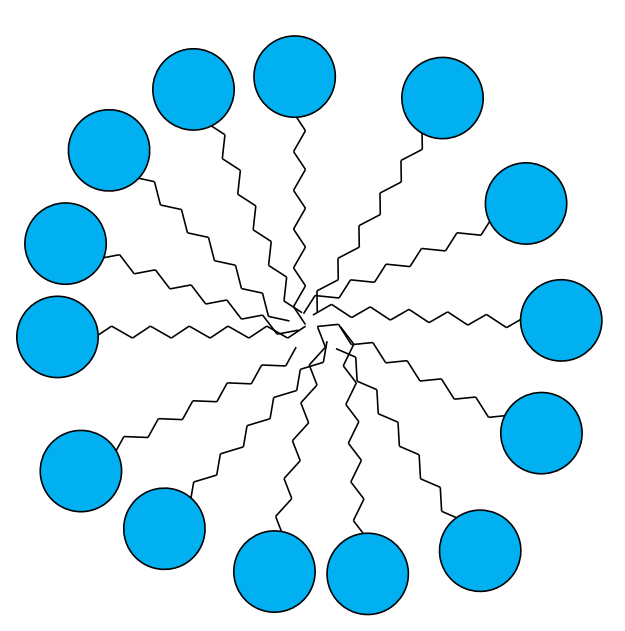

a)

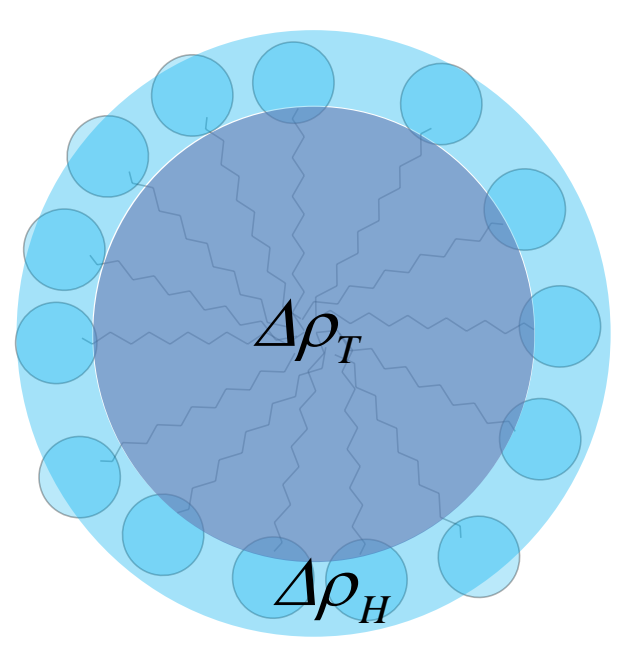

b)

Figura 3.5: a) Esquema de uma micela. b) Modelo esférico tipo core-shell usado para descrever uma micela.

O fator de forma $P(q)$ (Seção 2.4.1) para um core-shell pode ser escrito como (Pedersen, 1997):

$$
P_{\text {core-shell }}(q)=\left(\Delta \rho_{H} V_{\text {shell }} A_{\text {shell }}+\Delta \rho_{T} V_{\text {core }} A_{\text {core }}\right)^{2},
$$

onde $V_{\text {shell }}$ e $V_{\text {core }}$ são os volumes do shell e do core, respectivamente, enquanto $A_{\text {shell }}$ e $A_{\text {core }}$ corresponde às amplitudes de espalhamento normalizadas do shell e do core, respectivamente. Já que as amplitudes gozam da propriedade de aditividade (Castelletto e Hamley, 2002), então

$$
A_{\text {tot }}=A_{\text {shell }}+A_{\text {core }}
$$

onde o índice "tot" indica "total". Assim, Eq. 3-4 pode ser reescrita como

$$
P_{\text {core-shell }}(q)=\left[\Delta \rho_{H} V_{\text {tot }} A_{\text {tot }}+\left(\Delta \rho_{T}-\Delta \rho_{H}\right) V_{\text {core }} A_{\text {core }}\right]^{2}
$$

Para um core-shell esférico (modelo cs-esfera) com raio total $R_{t o t}$ dando um volume total $V_{\text {tot }}$ e um raio de core $R_{\text {core }}$ com volume $V_{\text {core }}$, o fator de forma fica 


$$
P_{\text {cs-esfera }}(q)=\left[\Delta \rho_{H} V_{\text {tot }} A_{\text {esfera }}\left(q R_{\text {tot }}\right)+\left(\Delta \rho_{T}-\Delta \rho_{H}\right) V_{\text {core }} A_{\text {esfera }}\left(q R_{\text {core }}\right)\right]^{2}
$$

onde $A_{\text {esfera }}(q R)$ é a amplitude de espalhamento de uma esfera, dada por (Rayleigh, 1910)

$$
A_{\text {esfera }}(q R)=\frac{3[\sin (q R)-q R \cos (q R)]}{(q R)^{3}} .
$$

Um core-shell elipsoidal de revolução (modelo cs-elipsoide) é bem descrito quando se conhece os raios total $R_{t o t}$ e de core $R_{c o r e}$ e anisotropia $\varepsilon$. Se $\varepsilon<1$, então o elipsoide é dito oblato. Se $\varepsilon>1$, o elipsoide é prolato. Se $\varepsilon=1$, então o elipsoide é na verdade uma esfera. $\mathrm{O}$ fator de forma será desse elipsoide de revolução será (Rogers e Young, 1984)

$$
P_{c s-e l i p s o i d e}(q)=\int_{0}^{\pi / 2}\left[\Delta \rho_{H} V_{\text {tot }} A_{\text {esfera }}\left(q r_{\text {tot }}\right)+\left(\Delta \rho_{T}-\Delta \rho_{H}\right) V_{\text {core }} A_{\text {esfera }}\left(q r_{\text {core }}\right)\right]^{2} \sin \xi d \xi,
$$

onde $r_{\text {tot }}=R_{\text {tot }}\left(\sin ^{2} \xi+\varepsilon^{2} \cos ^{2} \xi\right)^{1 / 2}$ e $r_{\text {core }}=R_{\text {core }}\left(\sin ^{2} \xi+\varepsilon^{2} \cos ^{2} \xi\right)^{1 / 2}$. Nesse trabalho usou-se a Eq. 3-9 em vez de Eq. 3-7 por ser mais geral e também porque é sabido que as micelas dos surfactantes possuem anisotropia, mesmo que pequena. A expressão final que expressa o espalhamento de apenas uma micela nos termos do modelo cs-elipsoide é

$$
I(q)=P_{c s-\text { elipsoide }}(q)+\text { back },
$$

onde back é um parâmetro de background, constante.

\subsubsection{Imposição de vínculos moleculares}

A técnica de SAXS é dita uma técnica de baixa resolução, pois o processo de obtenção da curva unidimensional $I(q) \times q$ a partir do espalhamento de estruturas tridimensionais randomicamente orientadas no espaço é acompanhada de grande perda de informação. Deste modo, pode-se ter casos em que modelos diferentes acabam por ajustar da mesma forma dados experimentais. No entanto, com a inclusão de vínculos moleculares, pode-se obter modelos que condizem melhor com a realidade. De um modo geral, quanto maior 
a quantidade de informações disponíveis sobre o sistema estudado mais confiável será o modelo escolhido para descrever os dados.

Considerando-se o modelo cs-elipsoide descrito anteriormente, o volume do core será dado por $V_{\text {core }}=\frac{4}{3} \pi \varepsilon R_{\text {core }}{ }^{2}$. Entretanto, se a micela possui número de agregação $N_{a g}$ (veja Seção 2.2.3), então $V_{\text {core }}=N_{a g} V_{T}$, onde $V_{T}$ é o volume da cauda de cada molécula do surfactante usado. Assim, pode-se escrever que

$$
R_{\text {core }}=\left(\frac{N_{a g} V_{T}}{\frac{4}{3} \pi \varepsilon}\right)^{1 / 3}
$$

Da mesma forma é possível escrever que

$$
R_{t o t}=\left(\frac{N_{a g}\left(V_{T}+V_{H}\right)}{\frac{4}{3} \pi \varepsilon}\right)^{1 / 3}
$$

Assumindo conhecidos os parâmetros $V_{T}, V_{H}, \Delta \rho_{T}$ e $\Delta \rho_{H}$, então o fator de forma para uma micela no modelo cs-elipsoide será, a partir da Eq. 3-9, dado por

$$
P_{c s-e l i p s o i d e}(q)=\int_{0}^{\pi / 2}\left[\Delta \rho_{H}\left(V_{T}+V_{H}\right) A_{\text {esfera }}\left(q r_{\text {tot }}\right)+\left(\Delta \rho_{T}-\Delta \rho_{H}\right) N_{a g} V_{T} A_{\text {esfera }}\left(q r_{\text {core }}\right)\right]^{2} \sin \xi d \xi,
$$

onde

$$
\begin{gathered}
r_{\text {tot }}=\left(\frac{N_{a g}\left(V_{T}+V_{H}\right)}{\frac{4}{3} \pi \varepsilon}\right)^{1 / 3}\left(\sin ^{2} \xi+\varepsilon^{2} \cos ^{2} \xi\right)^{1 / 2}, \\
r_{\text {core }}=\left(\frac{N_{a g} V_{T}}{\frac{4}{3} \pi \varepsilon}\right)^{1 / 3}\left(\sin ^{2} \xi+\varepsilon^{2} \cos ^{2} \xi\right)^{1 / 2}
\end{gathered}
$$

Até agora foi considerado uma única micela. Entretanto, a curva experimental de SAXS fornecerá informações sobre o espalhamento de $\aleph$ micelas. Logo, a expressão final de ajuste será, de acordo com Eq. 3-10, dada por 


$$
I(q)=\aleph P_{c s-e l i p s o i d e}(q)+\text { back }
$$

O parâmetro $\aleph$ pode ser reescrito como

$$
\aleph=\frac{c-c_{\text {free }}}{N_{a g}},
$$

onde $c$ é a concentração molar total de surfactantes, conhecida para cada amostra, e $c_{\text {free }}$ a concentração molar de surfactantes livres (isto é, não compondo as micelas).

Considerando-se os vínculos moleculares, os parâmetros ajustáveis referentes à estrutura da micela na Eq. 3-16 são apenas $N_{a g}, \varepsilon$ e $c_{\text {free }}$. Só foi possível obter esse conjunto pequeno de parâmetros porque, como comentado anteriormente, a intensidade espalhada foi medida em escala absoluta e também porque se tinha informações moleculares sobre cada surfactante usado, possibilitando a inclusão desses vínculos. Caso isso não fosse satisfeito, a forma de modelagem seria diferente, diminuindo a confiabilidade do modelo porque aumenta o número de conjuntos de valores dos parâmetros que ajustam os dados, tenho em vista que a quantidade de vínculos entre os parâmetros é diminuída.

O fator de estrutura foi desprezado para todos os surfactantes com exceção do SB310, uma vez que a concentração máxima usada foi muito pequena e, portanto, as interações entre as micelas são muito fracas. O caso do SB310 será tratado particularmente no capítulo de resultados e discussões.

\subsubsection{Determinação dos parâmetros moleculares}

O volume da cauda, $V_{T}$, pode ser calculado para cada surfactante de acordo com a presença de compostos $\mathrm{CH}_{3}$ e/ou $\mathrm{CH}_{2}$ na cauda de cada surfactante. Tomando o exemplo do SDS, a cauda é $\mathrm{CH}_{3}\left(\mathrm{CH}_{2}\right)_{11}$, isto é, ela é formada por uma unidade de $\mathrm{CH}_{3}$ e por 11 unidades de $\mathrm{CH}_{2}$. Assim, sabendo que $V_{\mathrm{CH}_{2}}=27,1 \AA^{3}$ e $V_{\mathrm{CH}_{3}}=53,5 \AA^{3}$ (Chevalier e Zemb, 
1990), tem-se que o volume da cauda para o SDS é $V_{T}=1 \times 53,5+11 \times 27,1$, o que fornece $V_{T}=351,6 \AA^{3}$. A Tabela 3.2 contém as informações calculadas aproximadamente para todos os surfactantes.

Tabela 3.2: Informações moleculares dos surfactantes utilizados neste trabalho.

\begin{tabular}{cccccccc}
\hline & $V_{\text {tot }}\left(\AA^{3}\right)$ & $V_{T}\left(\AA^{3}\right)$ & $V_{H}\left(\AA^{3}\right)$ & $N_{e_{-} T}$ & $N_{e_{-} H}$ & $\rho_{T}\left(\mathrm{el} / \AA^{3}\right)$ & $\rho_{H}\left(\mathrm{el} / \AA^{3}\right)$ \\
\hline SDS & $---(6)----$ & 351,6 & 60,53 & 97 & 59 & 0,276 & 0,975 \\
TTAB & 540,1 & 405,8 & 135,1 & 113 & 69 & 0,278 & 0,511 \\
DM & 691,0 & 351,6 & 339,4 & 81 & 181 & 0,230 & 0,533 \\
SB310 & 468,2 & 297,4 & 170,9 & 81 & 89 & 0,272 & 0,521 \\
\hline
\end{tabular}

A partir do conhecimento do parâmetro $V_{T}$ e $V_{\text {tot }}$ (volume total do surfactante), o volume da cabeça, $V_{H}$, é obtido usando-se

$$
V_{H}=V_{\text {tot }}-V_{T}
$$

onde $V_{\text {tot }}$ é retirado da literatura para cada surfactante (Backlund et al., 1989; Sesta, 1989; Dupuy, Auvray e Petipas, 1997; Giehm et al., 2010).

Os parâmetros $\Delta \rho_{H}$ e $\Delta \rho_{T}$ podem ser determinados a partir da composição química de cada surfactante e buffer. Para tanto será necessária a informação sobre o número de elétrons da cauda e da cabeça $\left(N_{e_{-} T}\right.$ e $N_{e_{-} H}$, respectivamente), que são obtidos a partir da composição química de cada surfactante (Oliveira, 2005).

A densidade eletrônica da cauda $\left(\rho_{T}\right)$ ou da cabeça $\left(\rho_{H}\right)$ é dada pela razão entre a soma do número de elétrons dos elementos químicos que compõem a cauda ou a cabeça do surfactante $\left(N_{e_{-} T}\right.$ ou $N_{e_{-} H}$, respectivamente) e o volume da cauda ou da cabeça ( $V_{T}$ ou $V_{H}$, respectivamente). Em termos gerais, a densidade eletrônica, $\rho_{k}$, para a espécie $k$, será

\footnotetext{
${ }^{6}$ Para o SDS foi achado o valor de $V_{H}$, de modo que não foi necessário $V_{t o t}$.
} 


$$
\rho_{k}=\frac{\sum_{i} N_{i, k}}{V_{k}} .
$$

O conceito de densidade de comprimento de espalhamento $\left(\rho^{\prime}\right)$ é ainda mais usual, de unidade $\left[\rho^{\prime}\right]=L^{-2}$, sendo a mais comum $\mathrm{cm}^{-2}$. Para a espécie $k$, essa grandeza é definida como

$$
\rho_{k}^{\prime}=\frac{\sum_{i} f_{i, k}}{V_{k}},
$$

onde $f_{i, k}$ é o fator de espalhamento do i-ésimo átomo que constitui a espécie $k$, dado por

$$
f_{i, k}=N_{i, k} \times r_{T}
$$

onde $N_{i, k}$ é o número de elétrons do i-ésimo átomo que constitui a espécie $k$ e $r_{T}$ é o raio do elétron clássico de Thomson, que vale $2,82 \times 10^{-13} \mathrm{~cm}$ (Oliveira, 2011). Comparando as equações Eq. 3-19 e Eq. 3-20, conclui-se que

$$
\rho_{k}^{\prime}=\rho_{k} \times r_{T} .
$$

A tabela a seguir mostra alguns átomos que aparecem frequentemente na composição de surfactantes e buffers. eles.

Tabela 3.3: Exemplos de átomos constituintes de surfactantes e buffers bem como informações sobre

\begin{tabular}{ccccccccc}
\hline Átomo & $\mathrm{H}$ & $\mathrm{C}$ & $\mathrm{O}$ & $\mathrm{N}$ & $\mathrm{S}$ & $\mathrm{Cl}$ & $\mathrm{Br}$ & $\mathrm{Na}$ \\
\hline Massa atômica & 1,0 & 12,0 & 16,0 & 14,0 & 32,0 & 35,5 & 79,9 & 23,0 \\
$N_{e}$ & 1 & 6 & 8 & 7 & 16 & 17 & 35 & 11 \\
$f\left(10^{-13} \mathrm{~cm}\right)$ & 2,82 & 16,92 & 22,56 & 19,74 & 45,12 & 47,94 & 98,70 & 31,02 \\
\hline
\end{tabular}

A definição do contraste de espalhamento passa pela densidade eletrônica do buffer. Se ele consistisse apenas de água, suposta tão pura quanto possível, a densidade 
eletrônica desse meio seria $\rho_{\mathrm{H}_{2} \mathrm{O}}=0,334 \mathrm{el} / \AA^{3}$. Em termos de densidade de comprimento de espalhamento, $\rho_{\mathrm{H}_{2} \mathrm{O}}^{\prime}=9,44 \times 10^{-10} \mathrm{~cm}^{-2}$.

Conforme dito na Seção 3.1, o buffer que foi usado nesse trabalho consistiu de $10 \mathrm{mM}$ de Tris, $5 \mathrm{mM}$ de $\mathrm{HCl}$ e $1 \mathrm{mM}$ de EDTA. Para levar em consideração a contribuição dos componentes que estão dissolvidos na água (ou, em geral, qualquer solvente), pode-se usar (Oliveira, 2005)

$$
\rho_{\text {buffer }}=\frac{c_{\text {solvente }} \times \rho_{\text {solvente }}+\sum_{i} c_{i} \times \rho_{i}}{c_{\text {solvente }}+\sum_{i} c_{i}},
$$

onde $c_{i}$ e $\rho_{i}$ correspondem, respectivamente, a concentração molar e densidade (eletrônica ou de comprimento de espalhamento) do i-ésimo componente. No nosso caso, $\rho_{\text {solvente }}=\rho_{\mathrm{H}_{2} \mathrm{O}}$ e $c_{\text {solvente }}=c_{\mathrm{H}_{2} \mathrm{O}}=55,6 \mathrm{~mol} / \mathrm{mL}$. Fazendo o cálculo usando as quantidades de Tris, $\mathrm{HCl}$ e EDTA mencionadas acima, a diferença entre $\rho_{\text {buffer }}$ e $\rho_{\mathrm{H}_{2} \mathrm{O}}$ está na quarta casa decimal.

O contraste de densidade (eletrônico ou de comprimento de espalhamento) entre o meio e as partículas espalhadoras, $\Delta \rho$, que efetivamente está relacionada ao espalhamento pelo sistema, é dado por

$$
\Delta \rho=\rho-\rho_{\text {solvente }} .
$$

A Tabela 3.4 a seguir mostra todas as quantidades que foram calculadas a partir das informações da Tabela 3.2 e Tabela 3.3.

Tabela 3.4: Contrastes de densidades eletrônicas e de comprimento de espalhamento da cabeça e das caudas para todos os surfactantes usados neste trabalho.

\begin{tabular}{ccccc}
\hline & $\Delta \rho_{T}\left(\mathrm{el} / \AA^{3}\right)$ & $\Delta \rho_{H}\left(\mathrm{el} / \AA^{3}\right)$ & $\Delta \rho_{T}^{\prime}\left(10^{-11} \mathrm{~cm}^{-2}\right)$ & $\Delta \rho_{H}^{\prime}\left(10^{-11} \mathrm{~cm}^{-2}\right)$ \\
\hline SDS & $-0,058$ & 0,641 & $-0,778$ & 2,749 \\
TTAB & $-0,056$ & 0,177 & $-0,785$ & 1,440 \\
DM & $-0,058$ & 0,152 & $-0,778$ & 1,371 \\
SB310 & $-0,062$ & 0,187 & $-0,768$ & 1,469 \\
\hline
\end{tabular}




\subsection{Experimentos de ITC}

\subsubsection{Aparato experimental}

Os experimentos microcalorimétricos foram realizados utilizando o equipamento VP-ITC, da Microcal (Figura 3.6), no IQUSP.

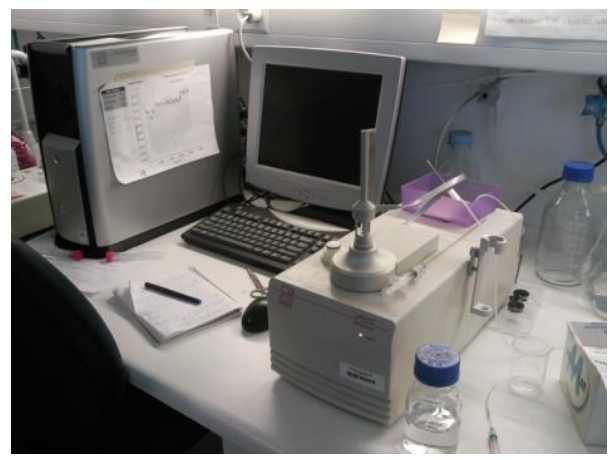

a)

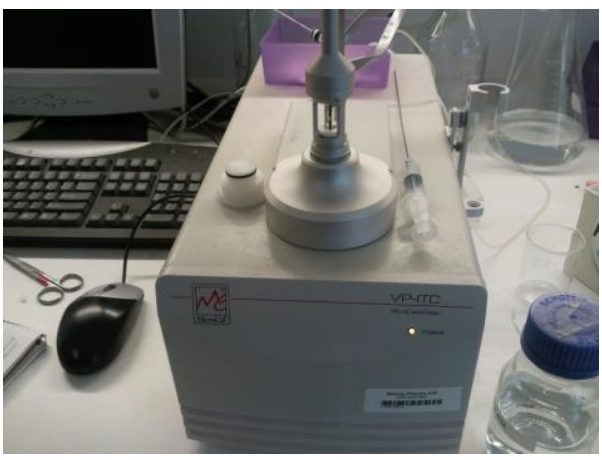

b)

Figura 3.6: a) Equipamento VP-ITC. b) Detalhe da seringa automatizada, na região central.

A célula de referência foi preenchida com água e a célula de amostra foi preenchida com o buffer Tris-EDTA. Na seringa encontrava-se a solução de surfactante concentrada, correspondendo a pelo menos 10 vezes o $C M C$ do surfactante usado. A temperatura de realização dos experimentos foi sempre de $25^{\circ} \mathrm{C}$.

\subsubsection{Aquisição de dados}

É interessante que a curva de ITC seja simétrica, o que corresponde a possuir o mesmo número de pontos antes e depois da $C M C$. Se a $C M C$ não for conhecida, então será necessário realizar um experimento teste que varre um razoavelmente grande intervalo de concentração. Se nesse experimento for observada uma mudança energética significativa em alguma região, então repete-se o experimento apenas nessa região. Isso acontecerá até que a curva de titulação seja satisfatória. Admitindo-se que a $C M C$ de 
cada surfactante seja conhecida, o planejamento do experimento é feito de maneira mais simples. Seja $c_{0}$ a concentração de solução de surfactante na seringa e $c_{f}$ a concentração de surfactante na célula de amostra ao final do experimento. Uma escolha conveniente é $c_{f}=2 \cdot C M C$ a fim de se obter o mesmo número de injeções antes e depois da $C M C$. Além disso pode-se considerar que o volume de surfactante na célula de amostra na nésima injeção é dado por $V_{n}=n \cdot v$, onde $n$ é o número de injeções e $v$ o volume de cada injeção. O volume $V_{n}$ é, no máximo, da ordem de $300 \mu L$, que é a capacidade volumétrica da seringa. Portanto, para uma primeira estimativa, pode-se fazer $V_{\text {célula }}+V_{n} \approx V_{\text {célula }}$, em que $V_{\text {célula }}=1450 \mu L$ é o volume da célula de amostra. Para o experimento programado, o volume inicial a ser injetado será, então, $V_{0}=V_{n}$ e volume final na célula de amostra será $V_{f}=V_{\text {célula }}+V_{n} \approx V_{\text {célula }}$. Assim, pela lei de diluição, tem-se que

$$
c_{0} V_{0}=c_{f} V_{f}
$$

a qual pode ser rescrita como

$$
n=\frac{2 \cdot C M C \cdot V_{\text {célula }}}{c_{0} \cdot v} .
$$

Embora este trabalho tenha usado buffer que pode alterar a $C M C$, foi usado para a estimativa de $n$ os valores de $C M C$ apresentados na Tabela 3.1, medidos usando-se água. No caso dos surfactantes SDS, TTAB e DM, a solução colocada na seringa sempre teve concentração $c_{0}=100 m M$ e, escolhendo-se $v=6 \mu L$, a Eq. 3-26 forneceu a estimativa de $n \approx 40$ injeções. Para o surfactante SB310, que possui CMC mais elevada, a concentração foi $c_{0}=450 \mathrm{mM}$ e, escolhendo-se novamente $v=6 \mu L$, obteve-se $n \approx 40$ injeções.

Para verificar a reprodutibilidade da técnica, os dados foram adquiridos em duplicata, que se mostrou muito boa (Figura 3.7). O teste foi feito com diferença proposital tanto no número de injeções quanto no volume de cada uma. 
O intervalo de tempo entre uma injeção e outra foi de $5 \mathrm{~min}$, suficiente para garantir que a curva de fluxo de calor $x$ tempo voltasse para a linha de base, fazendo com que os picos no fluxograma ficassem bem definidos, o que diminuiria o erro no valor da entalpia molar final devido à integração do fluxo de calor em relação ao tempo.

Além dos experimentos principais foram também realizados os experimentos controle, nesse caso correspondendo à titulação de buffer em buffer. Os calores de diluição provenientes desse processo foram posteriormente subtraídos dos experimentos de interesse.

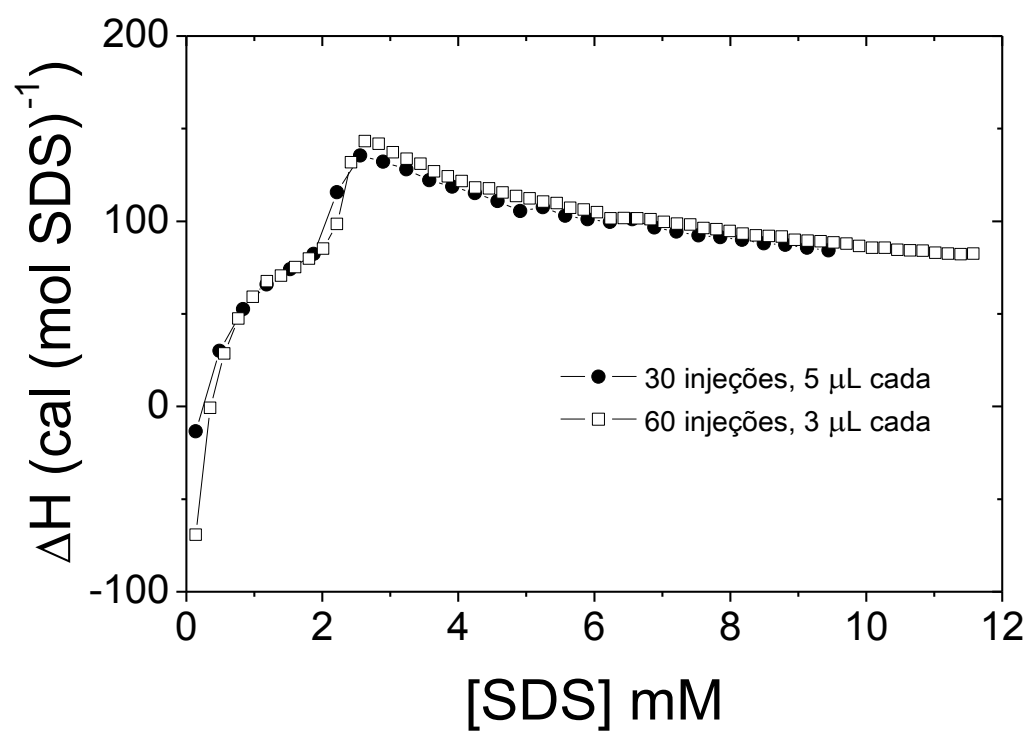

Figura 3.7: Gráfico do fluxo de calor em função da concentração de SDS. Os pontos circulares e quadrados se referem experimentos com diferentes condições que mostram boa reprodutibilidade dos dados obtidos de ITC.

\subsubsection{Análise de dados}

Após a aquisição os dados não sofreram tratamento adicional. A análise foi, em um primeiro momento, inteiramente gráfica, usando o procedimento descrito na Seção 2.4 .2 para a obtenção da $C M C$. Em seguida usou-se a Eq. 2-29 para o ajuste dos dados experimentais. A partir disso foi possível calcular a variação da entalpia de micelização $\Delta H_{m i c}$ e da informação da composição do sistema na CMC (frações molares de surfactante nos estados monomérico e micelar) foi realizado o cálculo da variação da 
energia livre de Gibbs de micelização $\Delta G_{m i c}$ tanto para surfactantes iônicos (Eq. 2-5) quanto para não iônicos (Eq. 2-3) usando o modelo de separação de fases.

Conhecendo-se $\Delta H_{\text {mic }}$ e $\Delta G_{m i c}$ é possível se calcular a variação de entropia de micelização, $\Delta S_{m i c}$, a partir de

$$
\Delta S_{m i c}=\frac{\Delta H_{m i c}-\Delta G_{m i c}}{T},
$$

já que o processo termodinâmico se dá a temperatura constante.

\subsection{Experimento de Condutividade}

\subsubsection{Aparato experimental}

A Figura 3.8 mostra o equipamento usado para a realização dos experimentos de condutividade, executados no laboratório do Grupo de Fluidos Complexos do IFUSP.

O aparato é constituído de um béquer graduado contendo o buffer foi colocado sobre a plataforma de um agitador magnético com aquecimento controlado. A massa de buffer foi medida usando-se uma balança analítica e seu valor $m_{0}$ era anotado. Todos os experimentos foram realizados na temperatura de $25^{\circ} \mathrm{C}$ e a barra magnética, que estava imersa no conteúdo do béquer e girando durante todo o procedimento, ajudava no equilíbrio térmico. No condutímetro é ligada a ponta de prova, contendo os eletrodos, a qual é colocada dentro do béquer a uma distância segura da barra magnética girante a fim de se evitar qualquer dano na ponta. A temperatura foi acompanhada com um termômetro digital acoplado ao próprio agitador magnético.

Antes de qualquer medida é necessária a calibração da ponta de prova. Para tanto usava-se uma solução $10 \mathrm{mM}$ de cloreto de potássio $(\mathrm{KCl})$ como padrão.

Na Tabela 3.5 estão mostrados alguns valores de condutividade para a solução padrão. O procedimento adotado consiste em se medir a temperatura da solução padrão 
e em seguida colocar a ponta de prova submersa nela, ajustando-se o valor do condutímetro para que seja o mesmo da Tabela 3.5 correspondente à temperatura medida. Feito isso a ponta é lavada extensivamente com água MiliQ. O procedimento de calibração foi repetido a cada novo experimento de condutividade.

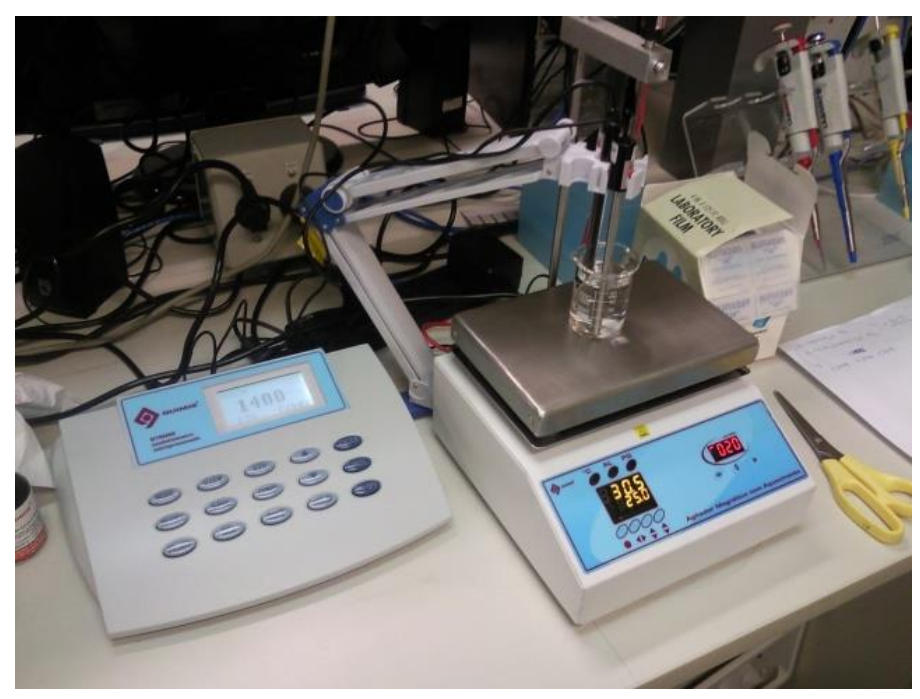

a)

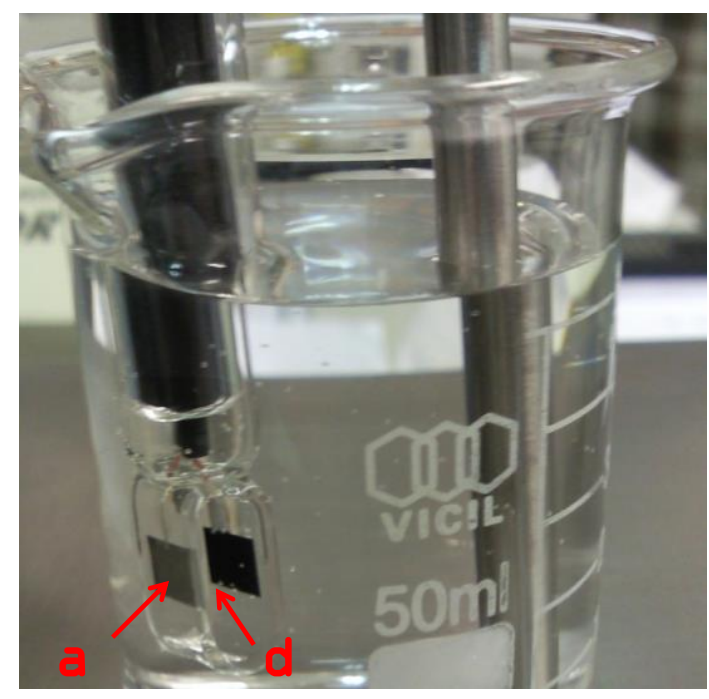

b)

Figura 3.8: a) Condutivímetro (à esquerda) e agitador magnético com aquecimento (à direita). b) Detalhe da ponta do condutivímetro, composta por duas placas metálicas dispostas paralelamente uma à outra. Na figura estão destacados os parâmetros área (a) e distância entre placas (d) usados para o cálculo da constante de célula (Eq. 2-32).

Assim que toda a montagem estava pronta e o buffer na temperatura desejada para o experimento, iniciava-se a titulação da solução concentrada de surfactante com o uso de uma micropipeta. Tal titulação ocorria pausadamente a fim de que o equilíbrio térmico fosse pouco perturbado. Pode-se garantir isso pois usou-se um volume inicial de buffer grande ( $60 \mathrm{~mL}$ ) comparado ao volume de cada injeção ( $200 \mu L)$. Todos os experimentos foram realizados em duplicata, o que mostrou reprodutibilidade dos dados (Figura 3.9). 
Tabela 3.5: Para a calibração da ponta de prova do condutivímetro foi usado cloreto de potássio na temperatura desejada.

\begin{tabular}{cc}
\hline Temperatura $\left({ }^{\circ} \mathrm{C}\right)$ & $\begin{array}{c}\text { Condutividade do } \mathrm{KCl} \\
(\mu \mathrm{S} / \mathrm{cm}), \text { solução } 10 \mathrm{mM}\end{array}$ \\
\hline 15 & 1141.4 \\
16 & 1167.6 \\
17 & 1193.8 \\
18 & 1220.0 \\
19 & 1246.8 \\
20 & 1273.7 \\
21 & 1300.6 \\
22 & 1327.5 \\
23 & 1354.5 \\
24 & 1381.4 \\
25 & 1408.3 \\
26 & 1436.2 \\
27 & 1464.1 \\
28 & 1492.1 \\
29 & 1520.0 \\
30 & 1547.9 \\
31 & 1575.9 \\
32 & 1603.8 \\
33 & 1631.7 \\
34 & 1659.6 \\
35 & 1687.6 \\
\hline
\end{tabular}

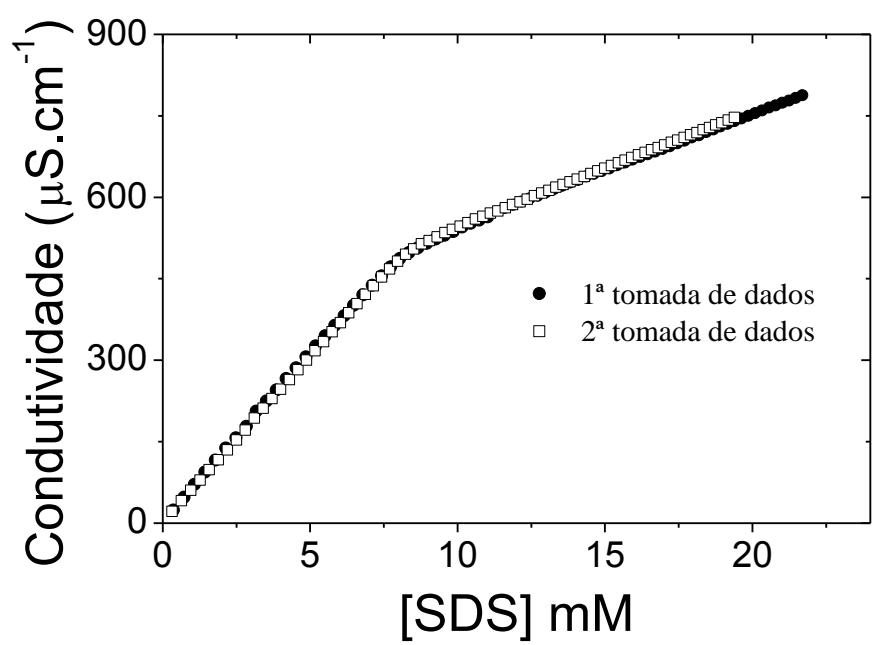

Figura 3.9: Reprodutibilidade dos dados de condutividade. Os dois conjuntos de pontos usados como exemplo apresentam comportamentos muito próximos. 


\subsubsection{Aquisição de dados}

A leitura do condutímetro foi acompanhada e anotada em uma tabela, bem como o número da injeção $n$ e a temperatura de medição. Pequenas variações nesta última grandeza são previsíveis mesmo com todos os cuidados tomados, e influenciam no valor da condutividade informado pelo equipamento. Portanto os valores foram corrigidos usando-se a função de compensação linear a seguir:

$$
\kappa_{T_{r e f}}=\frac{\kappa_{T}}{1+\gamma\left(T-T_{r e f}\right)}
$$

onde $\kappa_{T_{r e f}}$ é a condutividade esperada na temperatura de referência $T_{\text {ref }}$ (temperatura desejada), $\kappa_{T}$ é a condutividade medida na temperatura $T$ e $\gamma$ é o coeficiente linear de compensação de temperatura que em geral assume o valor $\gamma=2 \% /{ }^{\circ} \mathrm{C}$. Neste caso a expressão para a compensação de temperatura é

$$
\kappa_{25^{\circ} \mathrm{C}}=\frac{\kappa_{T}}{1+0,02(T-25)}
$$

para $T$ dado em graus Celsius.

Para saber a concentração $c_{n}$ de surfactante no béquer na $n$-ésima injeção, pode-se usar a lei de diluição dada pela Eq. 3-25:

$$
c_{n}=\frac{c_{0} \cdot V_{0}}{V_{n}}
$$

onde $V_{n}$ é o volume de solução de surfactante na concentração $c_{0}>c_{n}$ na $n$-ésima injeção. Se $\bar{v}$ é o volume médio de solução de surfactante injetado em cada etapa, então $V_{n}=V_{0}+n \cdot \bar{v}$. Logo a expressão anterior pode ser reescrita como

$$
c_{n}=\frac{c_{0} \cdot V_{0}}{V_{0}+n \cdot \bar{v}}
$$

\footnotetext{
${ }^{7}$ Conductivity: Theory and Practice. Manual printed by Radiometer Analytical SAS, France, 2004.
} 
Admitindo-se que a densidade volumétrica $\rho_{V}$ do conteúdo do béquer se altera pouco com a adição da solução de surfactante, $V_{0} \approx m_{0} / \rho_{V}$ e $\bar{v} \approx \bar{m} / \rho_{V}$. Portanto, da Eq. 3-31, vem que

$$
c_{n} \approx \frac{c_{0} \cdot m_{0}}{m_{0}+n \cdot \bar{m}}
$$

A massa média $\bar{m}$ de solução de surfactante correspondente a uma injeção pode ser facilmente encontrada a partir de um experimento de pipetagem do buffer em um béquer que se encontra sobre uma balança analítica.

\subsubsection{Análise de dados}

Para se contornar o problema mostrado na Figura 2.19, neste trabalho faz-se uso da metodologia proposta por Carpena (Carpena et al., 2002), que consiste em admitir que a primeira derivada do perfil típico dos dados de condutividade (Figura 3.10a) segue um comportamento bem descrito por uma função de Boltzman sigmoidal, dada por

$$
f(x)=\frac{A_{1}-A_{2}}{1+e^{\frac{x-x_{0}}{\Delta x}}} .
$$

Partindo desse pressuposto, os dados de condutividade serão então bem descritos pela função integral, $F(x)$, dada por

$$
F(x)=F_{0}+A_{1} x+\Delta x\left(A_{1}-A_{2}\right) \ln \left(\frac{1+e^{\frac{x-x_{0}}{\Delta x}}}{1+e^{\frac{-x_{0}}{\Delta x}}}\right)
$$

A Figura 3.10b mostra ambas as funções $f(x)$ e $F(x)$ e a interpretação gráfica de cada um dos parâmetros. $A_{1}$ e $A_{2}$ representam as inclinações iniciais e finais da curva de condutividade ou, o que é equivalente, aos regimes assintóticos da curva primeira derivada. A grandeza $\Delta x$ representa a largura de transição e $x_{0}$ o ponto de inflexão da 
curva derivada primeira ou, o que é equivalente, ao ponto onde ocorre a mudança do comportamento linear que corresponderá ao valor do $C M C$.

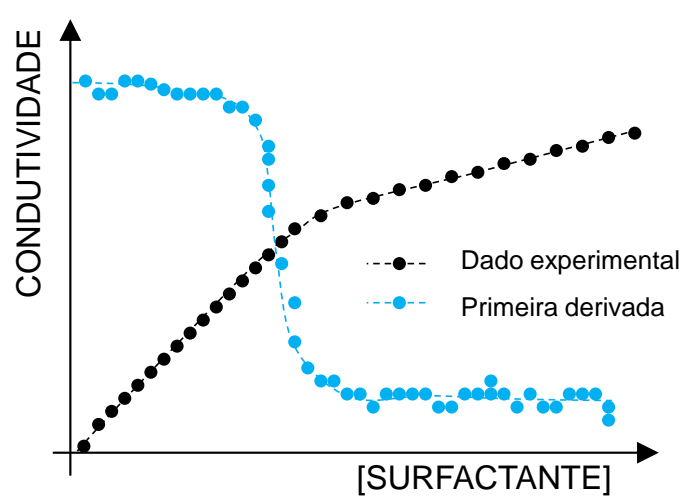

a)

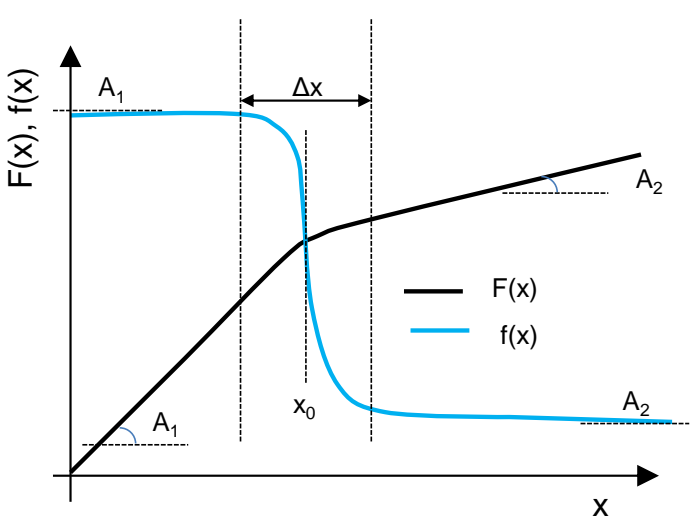

b)

Figura 3.10: a) Pontos experimentais e primeira derivada numérica dos pontos. b) Função sigmoidal de Boltzman (curva azul) e a função integral dela (curva vermelha).

No trabalho de Carpena, ambas as expressões Eq. 2-27 e Eq. 2-28 são utilizadas para ajustar a primeira derivada e curva experimental, respectivamente, sendo que a variação encontrada nos valores assumidos pelos parâmetros de ajuste é pequena. Neste trabalho optou-se por usar apenas a Eq. 3-34 para o ajuste dos dados de condutividade, e a partir dele serão extraídos valores que serão usados para encontrar a $C M C$ e o grau de ionização (Eq. 2-40). 


\section{Capítulo 04}

Resultados e Discussão 


\title{
4 Resultados e Discussão
}

\begin{abstract}
Nesse capitulo serão apresentados os resultados obtidos da aplicação de cada técnica (SAXS, Condutivimetria e ITC) para os sistemas micelares (SDS, TTAB, SB310, DM) tratados neste trabalho. Para organização, optou-se por dividir esta parte em dois momentos: no primeiro será feita uma análise dos dados para cada técnica; no segundo momento será feita a correlação entre os dados das três técnicas.
\end{abstract}

\subsection{ITC}

\subsubsection{Resultados}

Nesta seção serão apresentados os resultados de ITC para os surfactantes utilizados neste estudo. As figuras a seguir (Figura 4.1 à Figura 4.4) foram organizadas em quatro momentos: a) está mostrado o fluxograma, que corresponde ao dado bruto de ITC, como discutido na Seção 2.4.2; em b) está o respectivo entalpograma acrescido do ajuste dos dados usando a Eq. 2-29; em c) a primeira derivada (em relação à concentração de surfactante) da variação de entalpia molar, objetivando a determinação gráfica do $C M C$ de cada surfactante na temperatura trabalhada $\left(25^{\circ} \mathrm{C}\right)$; na parte d) está mostrado o exemplo da curva experimental obtida em trabalhos presentes na literatura, a fim de se investigar a proximidade entre eles e os perfis obtidos neste trabalho. 

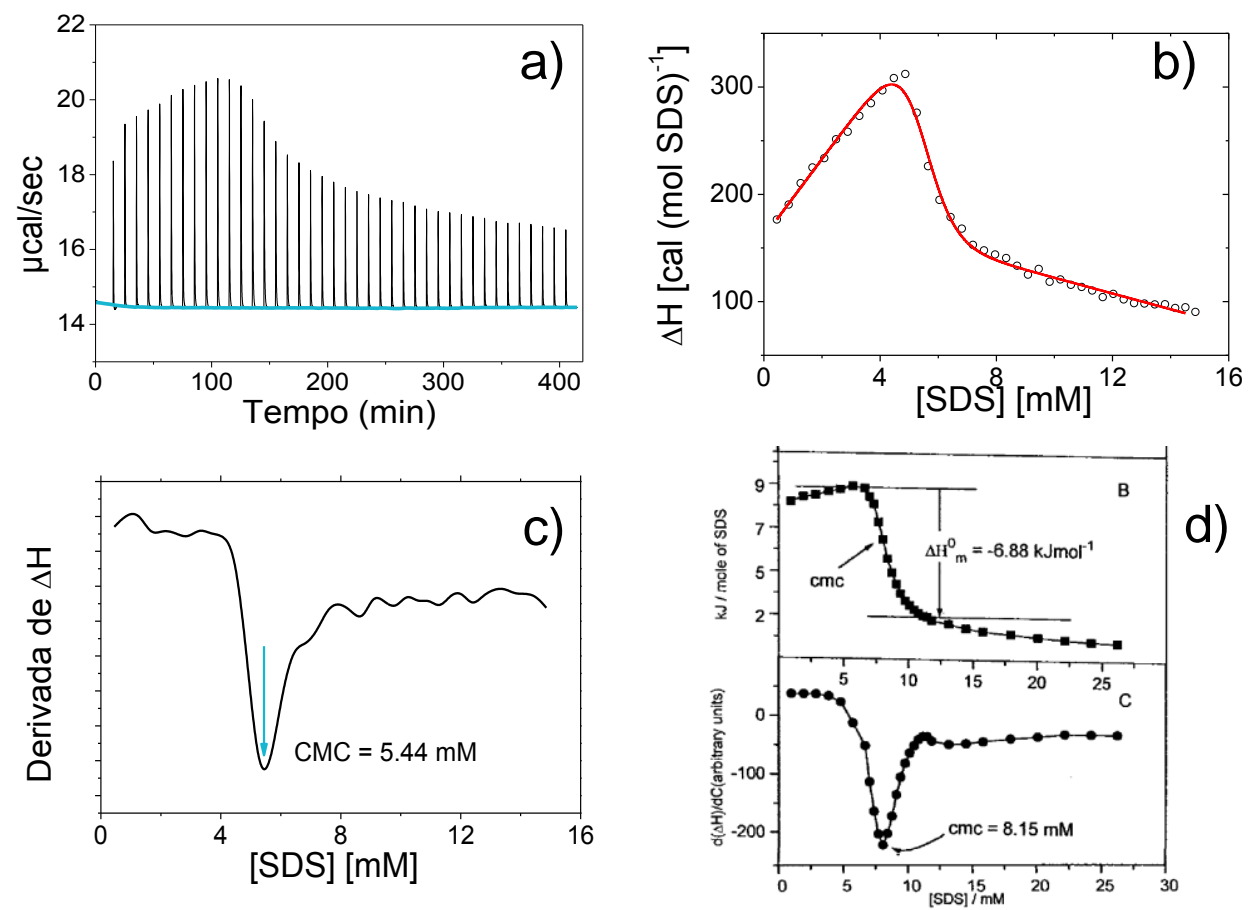

Figura 4.1: a) Fluxograma para a amostra de SDS $100 \mathrm{mM}$ titulada em buffer. b) Entalpograma. c) Primeira derivada do entalpograma em relação à concentração. A seta indica o $C M C$, que nesse caso foi 5,44 mM. d) Perfil obtido na literatura (Chatterjee et al., 2001).
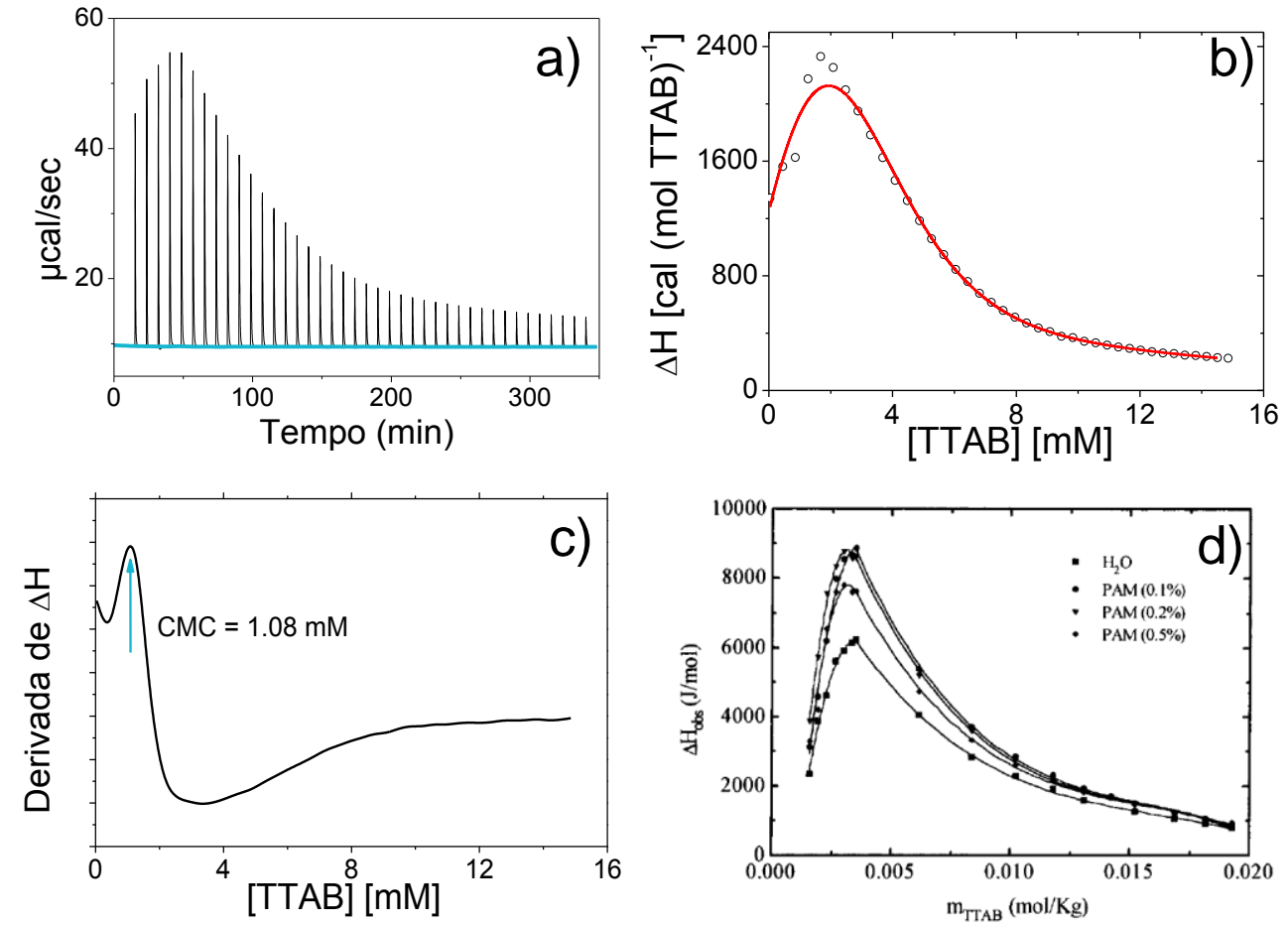

Figura 4.2: a) Fluxograma para a amostra de TTAB $100 \mathrm{mM}$ titulada em buffer. b) Entalpograma. C) Primeira derivada do entalpograma em relação à concentração. A seta indica o $C M C$, que nesse caso foi 1,08 mM. d) Perfil obtido na literatura (Wang et al., 1997). 

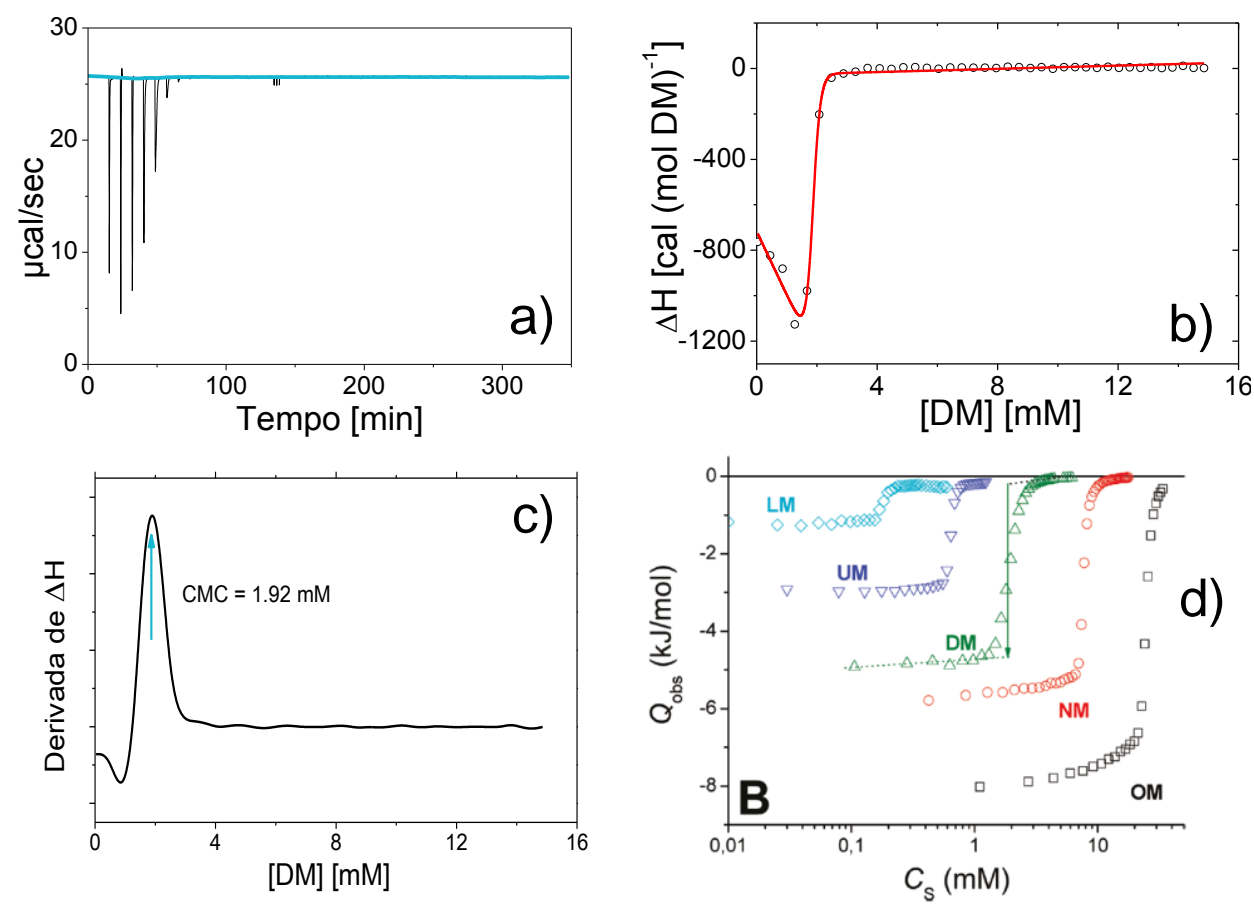

Figura 4.3: a) Fluxograma para a amostra de DM $100 \mathrm{mM}$ titulada em buffer. b) Entalpograma. c) Primeira derivada do entalpograma em relação à concentração. A seta indica o $C M C$, que nesse caso foi 1,92 mM. d) Perfil obtido na literatura (Tsamaloukas, Beck e Heerklotz, 2009).
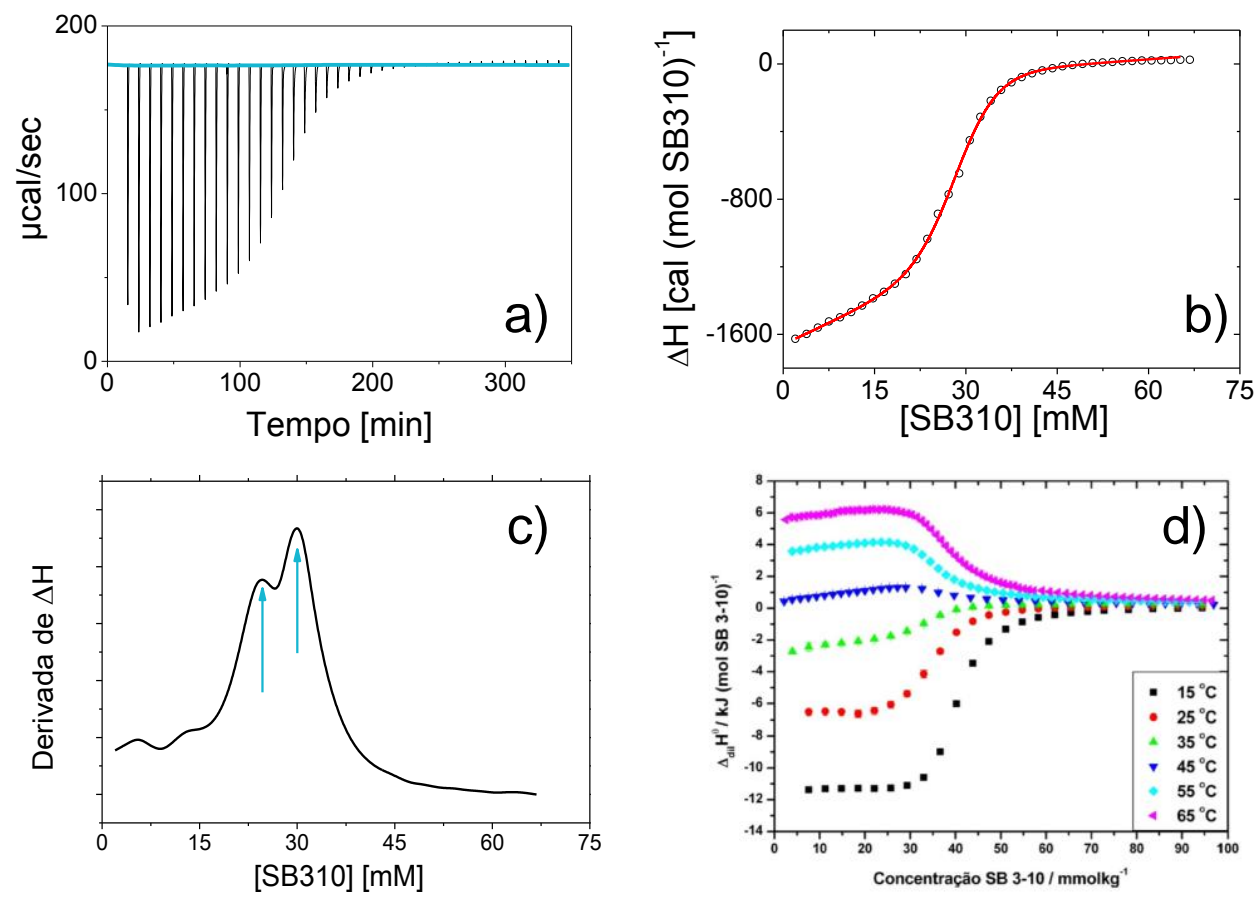

Figura 4.4: a) Fluxograma para a amostra de $S B 310450 \mathrm{mM}$ titulada em buffer. b) Entalpograma. c) Primeira derivada do entalpograma em relação à concentração. As setas indicam as possíveis posições do CMC. d) Perfil obtido na literatura (Antonio, 2011). 
A Tabela 4.1 mostra os parâmetros $a_{2}=\Delta H_{o b s}$ e $a_{3}=C M C$ usados nos ajustes, além do valor de $C M C$ encontrado graficamente.

Tabela 4.1: Parâmetros obtidos no ajuste dos dados experimentais e $C M C$ obtido graficamente.

\begin{tabular}{ccccc}
\hline \multirow{2}{*}{ Parâmetro } & \multicolumn{4}{c}{ Surfactante } \\
\cline { 2 - 5 } & SDS & TTAB & DM & SB310 \\
\hline$a_{2}=\Delta H_{o b s}[\mathrm{cal} / \mathrm{mol}]$ & $-35(6)$ & $-1017(115)$ & $687(23)$ & $1531(66)$ \\
$a_{3}=C M C[\mathrm{mM}]$ & $5,43(7)$ & $1,7(3)$ & $1,87(2)$ & $28,8(2)$ \\
\hline$C M C[\mathrm{mM}]$ & 5,44 & 1,08 & 1,92 & ---- \\
\hline
\end{tabular}

Apesar das diferenças de concentrações, buffers e temperatura usados, as curvas de ITC obtidas neste trabalho possuem perfis parecidos com aqueles presentes na literatura e mostrados na Figura 4.1d, Figura 4.2d, Figura 4.3d e Figura 4.4d, porém os valores de $\Delta H$ observados são diferentes.

Os valores de $C M C$ obtidos pelo ajuste e pelo método gráfico (ver Seção 2.4.2) apresentados na Tabela 4.1 concordam bem entre eles. Para as análises e comparações posteriores será usado, entretanto, apenas o valor de $C M C$ oriundo do ajuste, pois para o caso do surfactante SB310 existem dois picos no gráfico da primeira derivada da entalpia em função da concentração (Figura 4.4c) fazendo com que a determinação do $C M C$ por este método não seja objetiva (Antonio, 2011).

A fim de se obter $\Delta H_{m i c}$, foi usada a Eq. 2-28, e na Tabela 4.2 constam as informações utilizadas no processo de correção.

Tabela 4.2: Parâmetros usados para a correção de 4 Hobs.

\begin{tabular}{ccccc}
\hline Surfactante & $c_{0}[\mathrm{mM}]$ & $C M C[\mathrm{mM}]$ & $c_{0} /\left(c_{0}-C M C\right)$ & $\Delta H_{\text {mic }}[\mathrm{kJ} / \mathrm{mol}]$ \\
\hline SDS & 100 & 5,43 & 1,06 & $-0,15(3)$ \\
TTAB & 100 & 1,7 & 1,02 & $-4,3(5)$ \\
DM & 100 & 1,87 & 1,02 & $2,93(10)$ \\
SB310 & 450 & 28,8 & 1,07 & $6,8(3)$ \\
\hline
\end{tabular}


A fim de se comparar os valores de $\Delta H_{\text {mic }}$ obtidos neste trabalho com aqueles da literatura, a unidade de entalpia molar será alterada para a do Sistema Internacional $(\mathrm{J} / \mathrm{mol})$.

\subsubsection{Discussão}

A Tabela 4.3 reúne informações dos valores de $C M C$ e variações de entalpia obtidos neste trabalho bem como valores disponíveis na literatura. A determinação do $C M C$ no presente estudo foi pelo ajuste dos entalpogramas, que foram muito bons.

Comparando os valores de $C M C$ deste trabalho com os da literatura, é possível concluir que existe uma diferença significativa, exceto para o surfactante não-iônico DM. É razoável assumir que a diferença encontrada entre os valores possa estar relacionada com o uso do buffer, pois os valores encontrados na literatura usam água e, como discutido na Seção 2.2.1, a adição de eletrólitos no solvente tem influência significativa na CMC (Elworthy, Florence e Macfarlane, 1968; Attwood e Florence, 1983).

Tabela 4.3: Comparação entre valores de $C M C$ e $\triangle H$ mic obtidos neste trabalho usando buffer com os da literatura usando água.

\begin{tabular}{ccccc}
\hline & \multicolumn{2}{c}{$C M C[\mathrm{mM}]$ à $25^{\circ} \mathrm{C}$} & \multicolumn{2}{c}{$\Delta H_{\text {mic }}[\mathrm{kJ} / \mathrm{mol}]$ à $25^{\circ} \mathrm{C}$} \\
\hline EDS & Este trabalho & Literatura & Este trabalho & Literatura \\
TTAB & $5,43(7)$ & $7,70^{10} ; 8,2^{11}$ & $-0,15(3)$ & $-0,81^{10} ;-1,72^{11}$ \\
DM & $1,7(3)$ & $3,5^{12}$ & $-4,3(5)$ & $-7,9(4)^{12} ;-4,9^{16}$ \\
SB310 & $1,87(2)$ & $2,1^{13}$ & $2,93(10)$ & $8,9(8)^{14} ; 4,9^{13}$ \\
\hline
\end{tabular}

${ }^{10}\left(\right.$ Chatterjee et al., 2001), ${ }^{11}$ (Seng et al., 2000), ${ }^{12}$ (Wang et al., 1997), ${ }^{13}$ (Tsamaloukas, Beck e Heerklotz, 2009), ${ }^{14}\left(\right.$ Capalbi, Gente e La Mesa, 2004), ${ }^{15}\left(\right.$ Antonio, 2011), ${ }^{16}($ Perger e Bester-Rogac, 2007)

Observou-se uma pequena mudança para os valores de $C M C$ do surfactante DM. Isso se deve ao fato de que eletrólitos usuais ( $\mathrm{LiCl}, \mathrm{NaCl}, \mathrm{NaBr}$, etc) têm pouca influência 
sobre essa classe de surfactante (Zhang, Somasundaran e Maltesh, 1996), fazendo a CMC variar entre $15 \%$ e $20 \%$ do valor que seria obtido sem a adição de eletrólitos.

Comparando as entalpias de micelização, $\Delta H_{m i c}$, deste trabalho com a literatura, conclui-se que elas também são diferentes. Contudo, é difícil avaliar se a diferença é muito significativa uma vez que existe disparidade entre os valores da literatura. Para valores oriundos da aplicação de métodos microcalorimétricos, a diferença entre eles vem da aplicação ou do método gráfico descrito na Seção 2.4 .2 ou do método de van't Hoff, este último levando em conta a dependência do $C M C$ com a temperatura (Chatterjee et al., 2001). Como mencionado anteriormente a $C M C$ deve ter sido alterada devido ao buffer; consequentemente a entalpia micelar foi alterada também porque há dependência entre essas duas grandezas (Elworthy, Florence e Macfarlane, 1968; Attwood e Florence, 1983; Moroi, 1992).

Na Figura 4.1b, Figura 4.2b, Figura 4.3b, Figura 4.4b, onde são apresentados os entalpogramas para cada surfactante, é possível notar que para os não-iônicos DM e SB310 os valores de variação de entalpia observados são negativos, isto é, $\Delta H_{o b s}<0$. Isso significa que na etapa anterior de tratamento dos dados, o fluxograma apresentava valores de fluxo negativos, isto é, abaixo da linha de base, indicando que o processo de demicelização e micelização para esses surfactantes na temperatura estudada (25ํㅡ) liberou calor, ou seja, foi um processo exotérmico. Já para os surfactantes iônicos SDS e TTAB, ocorre o contrário. De acordo com os entalpogramas observa-se $\Delta H_{o b s}>0$, o que indica um processo global que absorve calor, ou seja, um processo endotérmico.

Em uma reação química endotérmica, os produtos possuem mais energia que os reagentes, de modo que a variação de entalpia da reação é positiva. Se for exotérmica, a variação é negativa. Em se tratando de sistemas de surfactantes, não ocorre a reação química, apenas uma organização espontânea das moléculas. Contudo, a interpretação acerca da variação da entalpia, antes e depois da $C M C$ (nesse caso, a $C M C$ sendo um parâmetro de diferenciação entre os "produtos" = monômeros e "reagentes" = micelas) passa por uma consideração parecida. Assim, olhando o perfil dos entalpogramas (a 
forma de $S$ ou $Z$, dependendo do caso), é possível já saber se a variação da entalpia de micelização é positiva ou negativa. Para os não-iônicos SB310 e DM tem-se $\Delta H_{m i c}>0$ (endotérmico) enquanto para os iônicos SDS e TTAB tem-se $\Delta H_{m i c}<0$ (exotérmico).

Ambas interações de origem hidrofóbica e eletrostática contribuem para $\Delta H_{m i c}$ (Shimizu, Pires e El Seoud, 2004). Sobre o primeiro aspecto, tem-se a passagem dos monômeros da solução para a micela. Pensando apenas nas caudas dos monômeros, que são apolares, essa passagem é mais favorável energeticamente, de modo que é esperada ser exotérmica (Shimizu, Pires e El Seoud, 2004). Pensando agora na cabeça polar, a passagem dos monômeros da solução para a micela envolve também a estabilização elétrica do agregado. Os monômeros irão se repelir uns aos outros (tendência de liberar energia e, portanto, é exotérmico) e ao mesmo tempo atraírem os contra-íons (tendência de acumular energia e, portanto, endotérmico). Visto que o agregado iônico possui uma carga não neutralizada, o caráter repulsivo se sobressai em relação ao caráter atrativo, de maneira que a contribuição elétrica para a entalpia é esperada ser exotérmica. Este comportamento foi observado para os surfactantes iônicos SDS e TTAB. Os não-iônicos SB310 e DM apresentam valores de variação de entalpia positivos (endotérmicos) o que indica ligações de hidrogênio são mais intensas entre os monômeros e as moléculas de água para a temperatura estudada (Antonio, 2011).

\subsection{SAXS}

Uma curva de ITC fornece informações sobre mudanças energéticas que acontecem no sistema estudado. Portanto, dispondo-se de um entalpograma, pode-se escolher um intervalo de concentração em que as mudanças energéticas de interesse ocorrem e, com isso, preparar amostras para realizar o estudo estrutural.

Neste trabalho optou-se por varrer toda a região de concentração do entalpograma de cada surfactante. Na Figura 4.5 as concentrações escolhidas estão indicadas por uma barra vertical, associada também a um número que corresponde à ordem da injeção no 
experimento de ITC. Assim, por exemplo, o número 17 faz referência à 17a injeção. Usando Eq. 3-31, pode-se descobrir a exata concentração de surfactante na célula de amostra nesta injeção e, com isso, preparar uma amostra similar em um tubo à parte. Na Tabela 4.4 estão listadas todas as injeções mostradas na Figura 4.5 bem como a concentração de surfactante correspondente.

Tabela 4.4: Injeções escolhidas do experimento de ITC e a correspondente concentração de surfactante.

\begin{tabular}{|c|c|c|c|c|c|c|c|}
\hline \multicolumn{2}{|c|}{ SDS } & \multicolumn{2}{|c|}{ TTAB } & \multicolumn{2}{|c|}{$\mathrm{DM}$} & \multicolumn{2}{|c|}{ SB310 } \\
\hline Injeção & $\mathrm{C}[\mathrm{mM}]$ & Injeção & $\mathrm{C}[\mathrm{mM}]$ & Injeção & $\mathrm{C}[\mathrm{mM}]$ & Injeção & $\mathrm{C}[\mathrm{mM}]$ \\
\hline 3 & 0,9 & 2 & 0,9 & 2 & 0,8 & 3 & 1,5 \\
\hline 6 & 2,1 & 4 & 1,6 & 5 & 1,2 & 12 & 4,7 \\
\hline 10 & 3,9 & 6 & 2,4 & 7 & 2,7 & 18 & 34 \\
\hline 13 & 5,1 & 10 & 3,8 & 10 & 3,8 & 23 & 43,4 \\
\hline 17 & 6,5 & 14 & 5,5 & 20 & 7,4 & 32 & 58,9 \\
\hline 21 & 7,9 & 21 & 7,8 & 31 & 11,2 & 41 & 75,9 \\
\hline 25 & 9,2 & 31 & 11,1 & 41 & 14,4 & & \\
\hline 30 & 10,9 & 41 & 14,3 & & & & \\
\hline 33 & 12 & 50 & 16,8 & & & & \\
\hline 36 & 12,7 & & & & & & \\
\hline 41 & 14,4 & & & & & & \\
\hline 50 & 17 & & & & & & \\
\hline
\end{tabular}



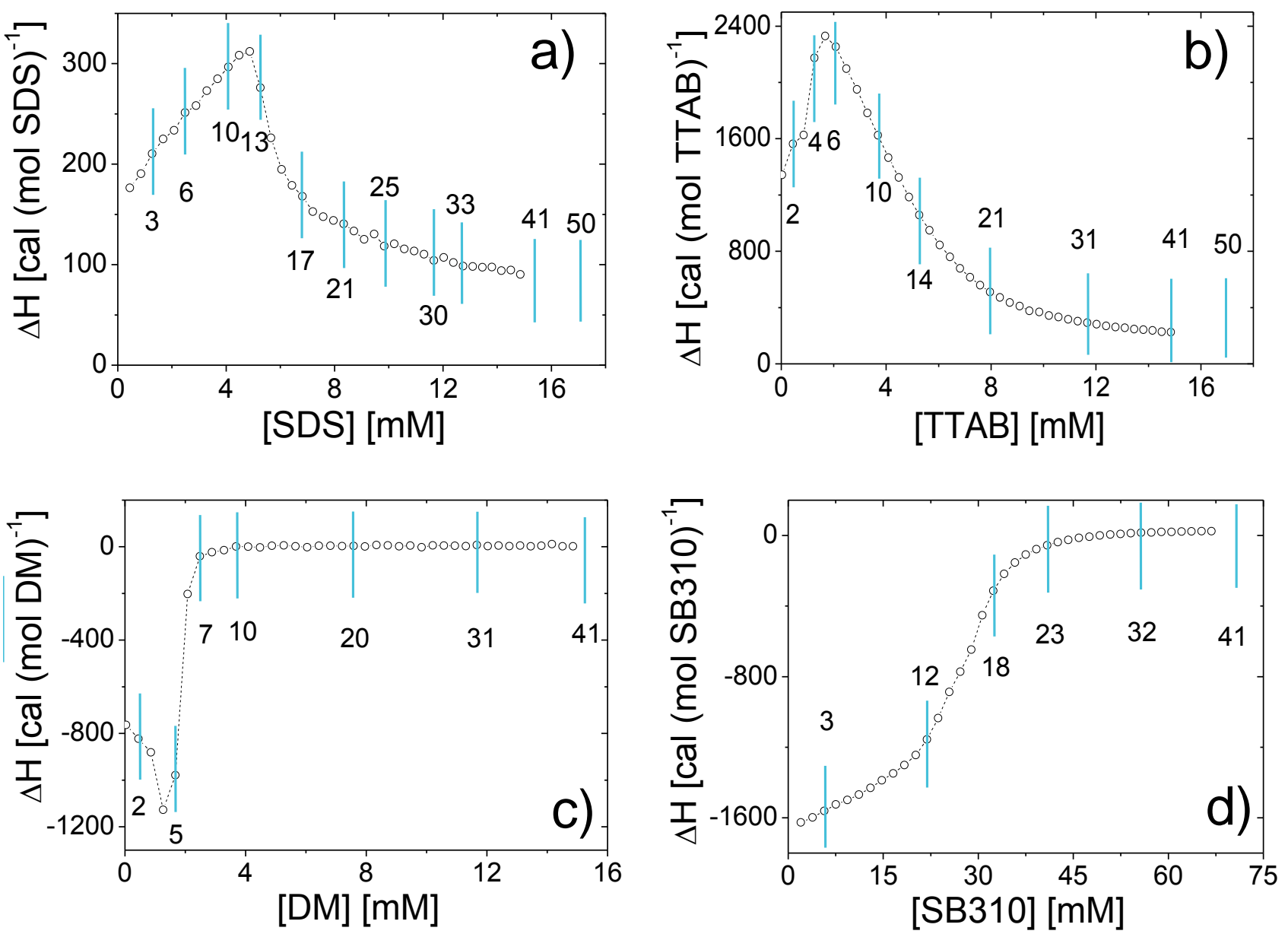

Figura 4.5: Para o entalpograma de cada surfactante foram escolhidas concentrações indicadas por meio de barras verticais, em relação às quais foram realizados experimentos de SAXS.

\subsubsection{Resultados}

Nesta seção serão apresentados os resultados do estudo estrutural para os surfactantes estudados neste trabalho. Para cada surfactante foram preparadas amostras em nas concentrações indicadas na Tabela 4.4. Nas figuras Figura 4.6 à Figura 4.9 são apresentadas as curvas de intensidade espalhada $I(q)$ em função do vetor de espalhamento $q$ para cada surfactante, obtidas a partir do processo de tratamento descrito na Seção 3.3.2.

Para cada curva foi feita uma análise inicial dos dados obtidos. O primeiro passo foi realizar o ajuste dos dados que pela Transformada Inversa de Fourier, a partir da qual 
pode-se determinar a função de distribuição de pares de distância, $p(r)$ (Seção 3.3.3). Os pontos que se encontram no início de cada curva apresentaram uma disposição linear com um alto coeficiente angular. Isso indica a presença de compostos muito grandes, provavelmente frutos de uma não dissolução total do soluto (surfactantes em pó) no solvente. Portanto, esses pontos, que estão no intervalo $q<0,03 \AA^{-1}$, não foram considerados no ajuste para a determinação da função $p(r)$.

As curvas $p(r)$ fornecem informações no espaço real, e viabilizam, entre outros parâmetros, a determinação do diâmetro máximo das micelas. A partir da Figura 4.6b, Figura $4.7 \mathrm{~b}$,

Figura $4.8 \mathrm{~b}$ e Figura $4.9 \mathrm{~b}$, observou-se o valor da abscissa onde a $p(r) \rightarrow 0$ e neste ponto pode-se determinar $r_{\max }$, como representado na Figura 3.4b. Os valores de diâmetro máximo variam em torno de 50 à 80 Å dependendo da composição da micela.

Na Figura 4.10 e Figura 4.11 são apresentados os dados ajustados usando a Eq. 3-10.
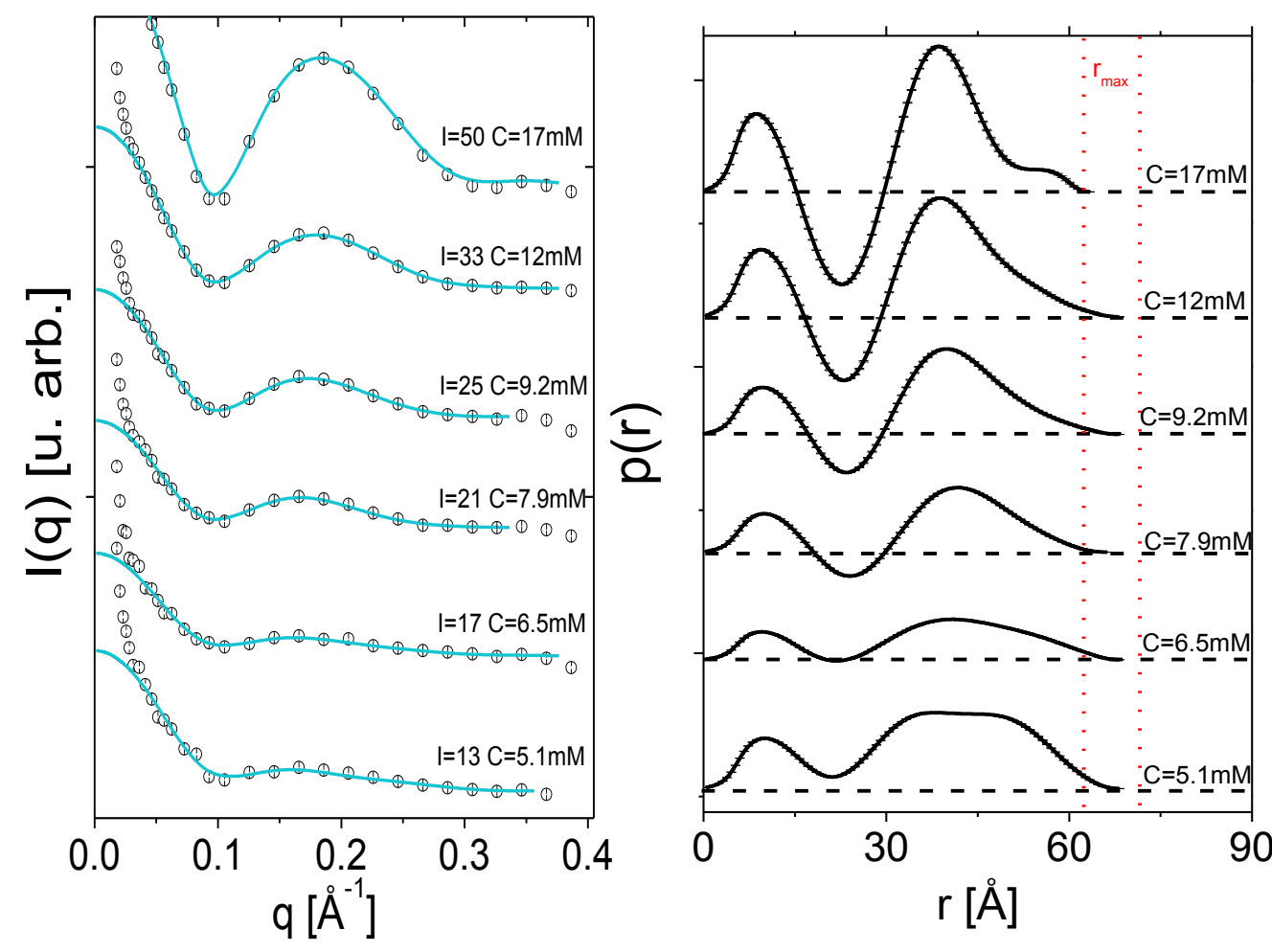

Figura 4.6: a) Curvas de intensidade para cada concentração escolhidas para o surfactante SDS. b) Curvas p(r). 


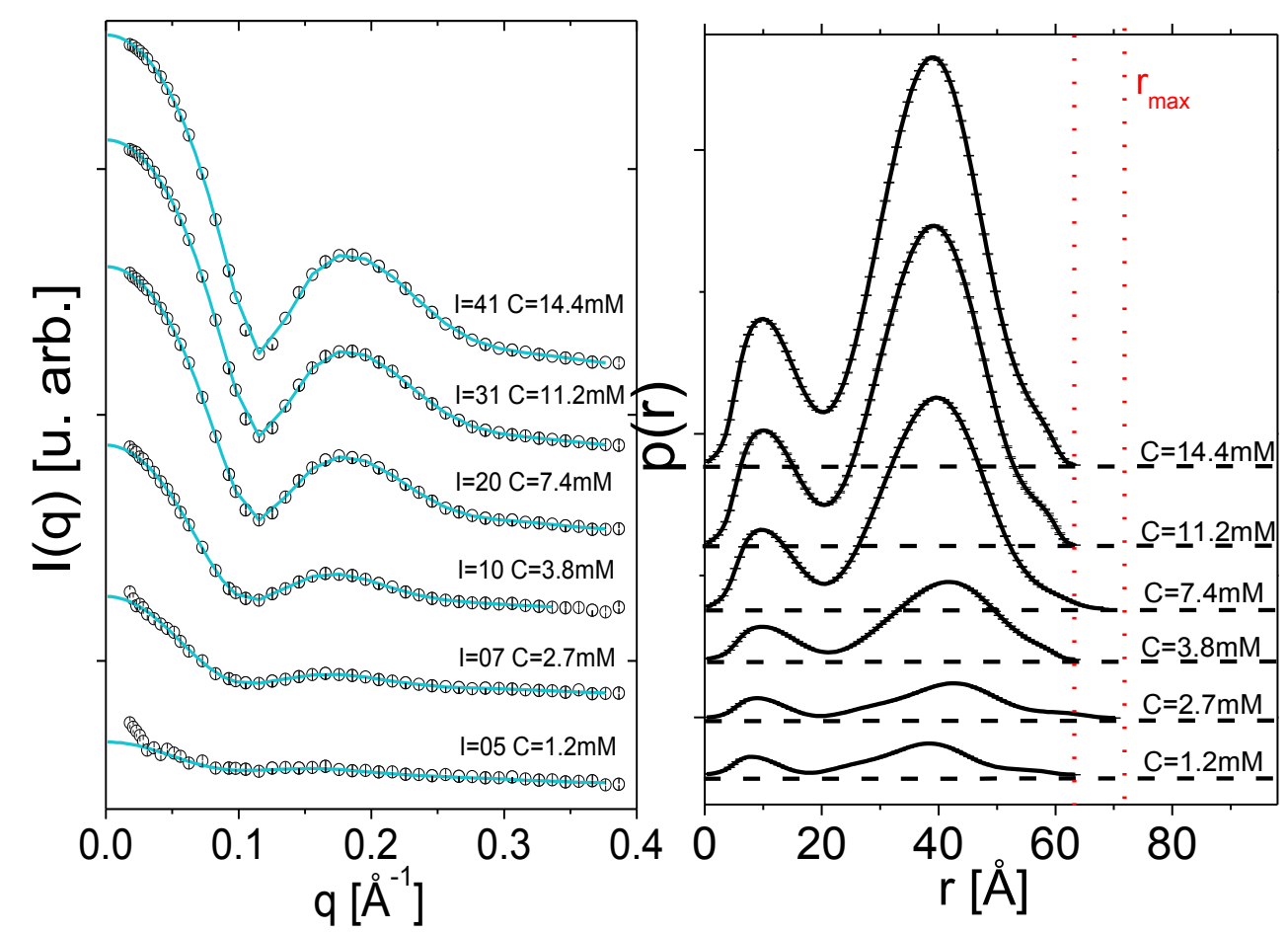

Figura 4.7: a) Curvas de intensidade para cada concentração escolhidas para o surfactante TAB. b) Curvas p(r).
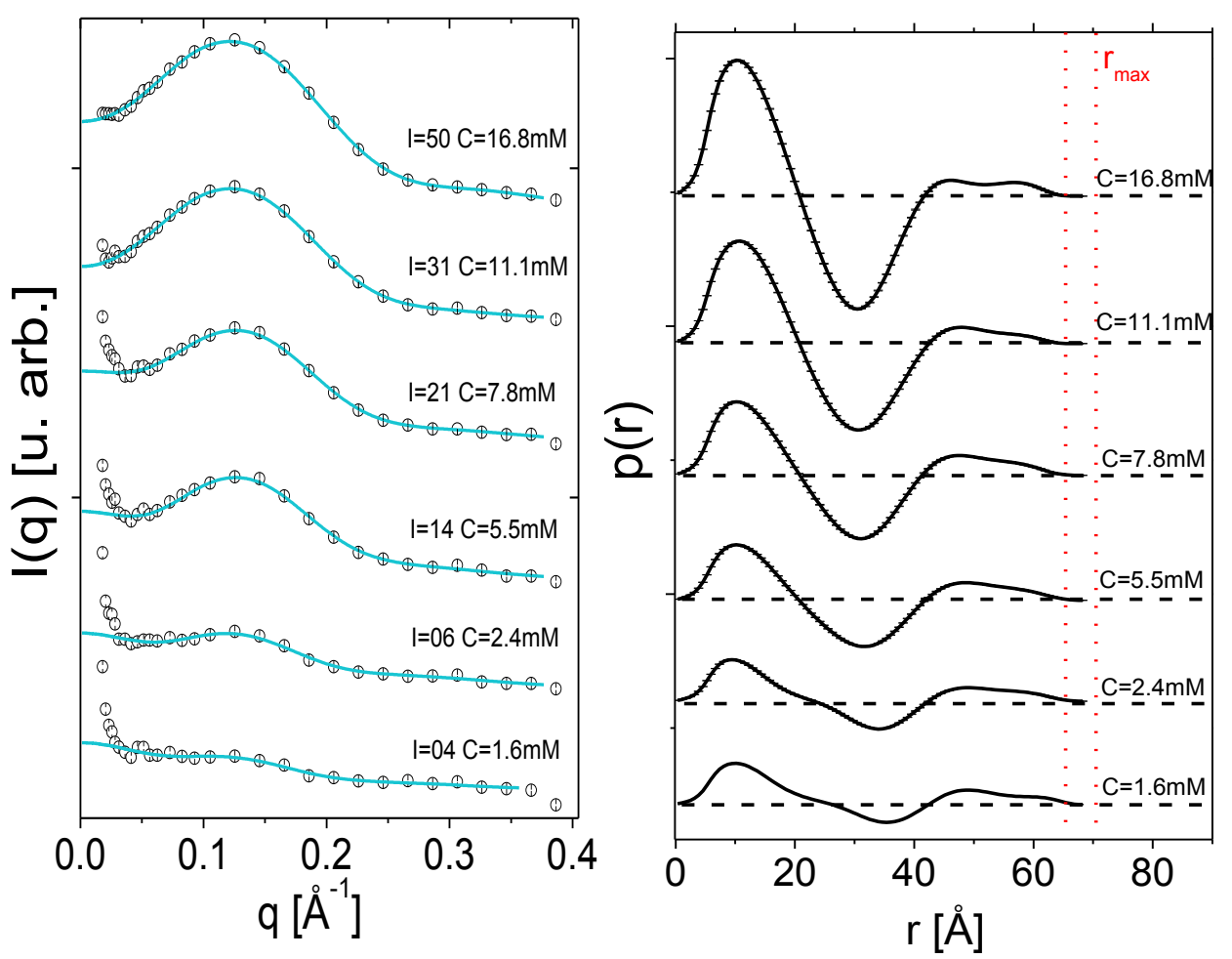

Figura 4.8: a) Curvas de intensidade para cada concentração escolhidas para o surfactante DM. b) Curvas p(r). 

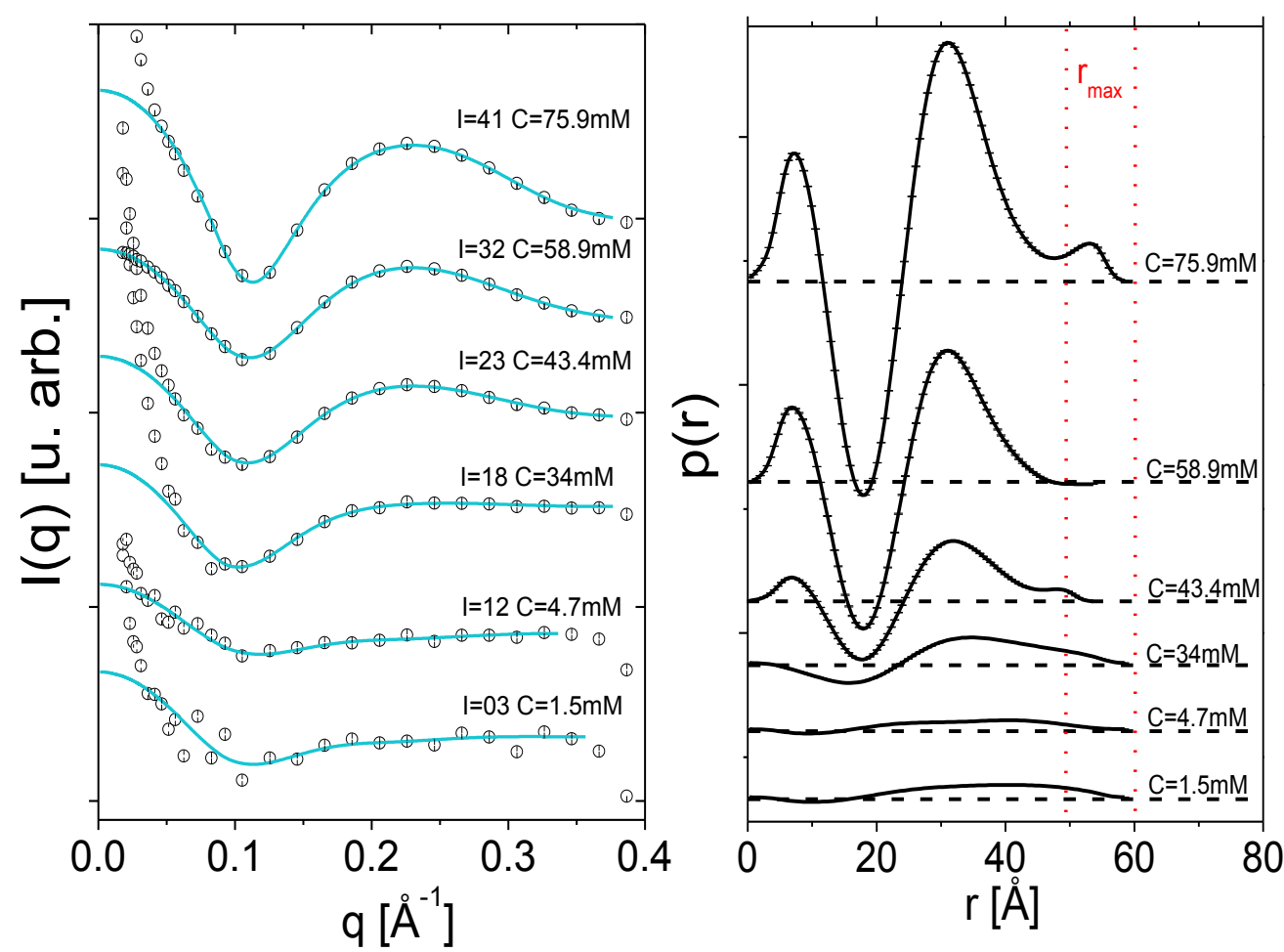

Figura 4.9: a) Curvas de intensidade para cada concentração escolhidas para o surfactante SB310. b) Curvas p(r).

Convém ressaltar que foi usado o mesmo modelo cs-elipsoide de revolução para as micelas dos quatro tipos de surfactantes estudados neste trabalho, além da imposição de vínculos moleculares (Seção 3.3.4), pois pode-se utilizar ao mesmo tempo o fato dos dados experimentais estarem em escala absoluta. Além disso, para o ajuste dos dados de SDS, TTAB e DM, foi usado apenas o fator de forma dado pela Eq. 3-9, pois a concentração usada é muito pequena, fazendo com que a interação entre as micelas (expressa pelo fator de estrutura) seja fraca e, portanto, desprezível. Porém, para as curvas de SB310, o fator de estrutura foi levado em conta já que se tratam de concentrações maiores.

Pelo mesmo motivo comentado anteriormente, alguns pontos do começo de cada curva foram desprezados para se realizar o ajuste.

Os ajustes feitos para as curvas de SDS, TTAB e DM reproduzem muito bem o comportamento das curvas experimentais em todo intervalo de $q$ estudado. Para o 
ajuste das curvas experimentais do surfactante SB310 foi usado um fator de estrutura leva em conta a contribuição de grandes agregados (Sorensen e Wang, 1999) pois a concentração desse tipo de surfactante nas amostras é elevada porque a $C M C$ dele é elevada. Este procedimento permitiu ajustar de forma razoável a curva na regiões de baixo ângulo e intermediária. Contudo, a região de alto ângulo não foi ajustada bem, mesmo com um modelo que já tinha sido aplicado de forma bem sucedida para sulfobetaínas de comprimentos de cauda maiores que a SB310 (D'andrea et al., 2011), indicando que esse tipo de surfactante deva ser melhor estudado, já que existem poucos trabalhos que o incluem.
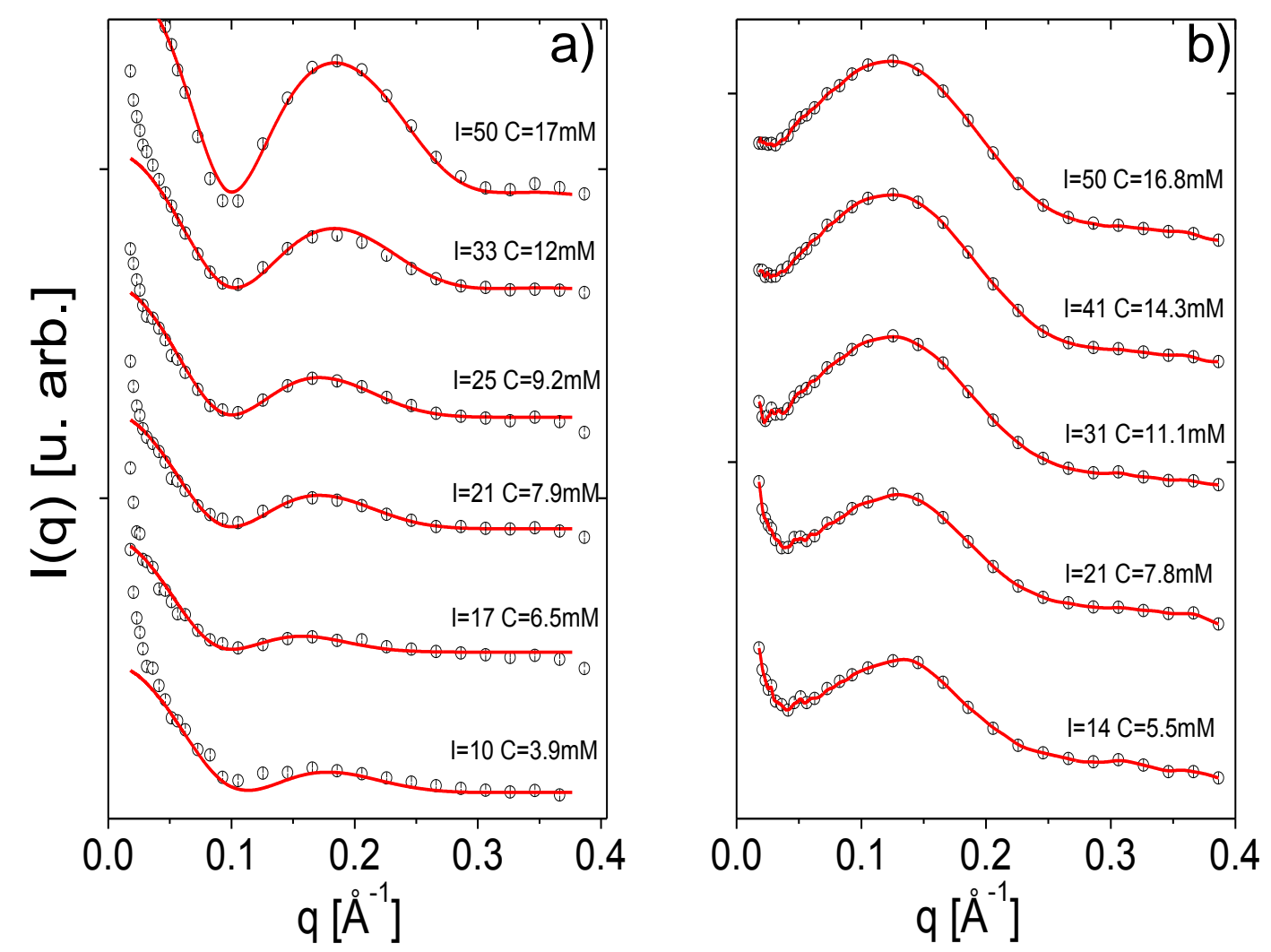

Figura 4.10: Ajuste dos dados experimentais para o surfactante SDS (a) e TAB (b). 

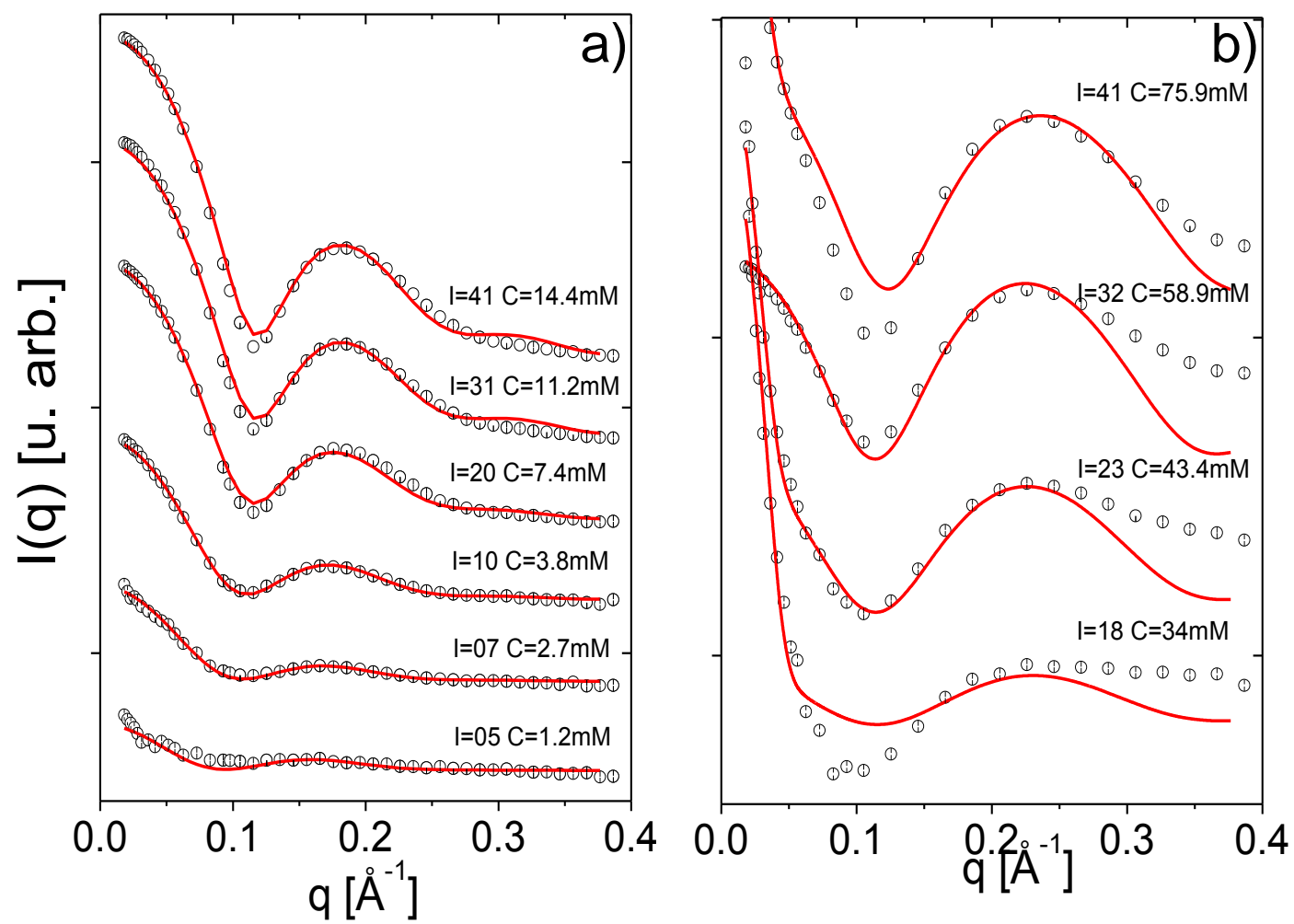

Figura 4.11: Ajuste dos dados experimentais para o surfactante DM (a) e SB310 (b).

Tabela 4.5: Valores do parâmetros de ajuste das curvas experimentais.

\begin{tabular}{|c|c|c|c|c|c|}
\hline & Injeção & $c[m M]$ & $N_{a g}$ & $\varepsilon$ & $c_{\text {free }}[m M]$ \\
\hline \multirow{9}{*}{ SDS } & 13 & 5,1 & $66,0(5)$ & $1,28(17)$ & $4,0(7)$ \\
\hline & 17 & 6,5 & $66,0(5)$ & $1,49(15)$ & $5,0(2)$ \\
\hline & 21 & 7,9 & $65,9(3)$ & $1,28(19)$ & $4,0(3)$ \\
\hline & 25 & 9,2 & $65,8(9)$ & $1,3(2)$ & $4,0(5)$ \\
\hline & 30 & 10,9 & $65,0(3)$ & $1,36(12)$ & $5,5(6)$ \\
\hline & 33 & 12 & $66,0(8)$ & $1,30(17)$ & $6,0(4)$ \\
\hline & 36 & 12,7 & $62,1(4)$ & $1,3(5)$ & $5,0(6)$ \\
\hline & 41 & 14,4 & $63,8(2)$ & $1,20(5)$ & $5,0(4)$ \\
\hline & 50 & 17 & $64,5(6)$ & $1,19(17)$ & $5,5(2)$ \\
\hline \multirow{5}{*}{ TTAB } & 14 & 5,5 & $45,1(9)$ & $0,46(5)$ & $1,74(1)$ \\
\hline & 21 & 7,8 & $44,8(3)$ & $0,45(2)$ & $1,64(1)$ \\
\hline & 31 & 11,1 & $45,0(3)$ & $0,43(3)$ & $1,73(3)$ \\
\hline & 41 & 14,3 & $45,0(7)$ & $0,43(2)$ & $1,64(1)$ \\
\hline & 50 & 16,8 & $45,0(8)$ & $0,44(9)$ & $1,65(1)$ \\
\hline \multirow{4}{*}{$\mathrm{DM}$} & 7 & 2,7 & $72,3(9)$ & $1,48(18)$ & $1,5(2)$ \\
\hline & 10 & 3,8 & $72,0(3)$ & $1,46(14)$ & $1,0(2)$ \\
\hline & 20 & 7,4 & $63,8(7)$ & $1,53(11)$ & $1,51(19)$ \\
\hline & 31 & 11,2 & $65,1(4)$ & $1,42(6)$ & $1,6(2)$ \\
\hline
\end{tabular}




\begin{tabular}{l|ccccc} 
& 41 & 14,4 & $65,1(6)$ & $1,40(4)$ & $1,5(2)$ \\
\hline & 18 & 34 & $41,0(3)$ & $1,3(2)$ & $32,2(4)$ \\
SB310 & 23 & 43,4 & $40,0(4)$ & $1,4(4)$ & $35,0(2)$ \\
& 32 & 58,9 & $45,1(5)$ & $1,2(2)$ & $35,1(6)$ \\
& 41 & 75,9 & $40,2(7)$ & $1,4(3)$ & $32,0(8)$ \\
\hline
\end{tabular}

Os ajustes das curvas experimentais fornecem parâmetros como número de agregação $\left(N_{a g}\right)$, anisotropia $(\varepsilon)$ e a concentração de monômeros livres $\left(c_{\text {free }}\right)$. Os valores obtidos para todos os ajustes são apresentados na Tabela 4.5. Por conveniência, estão mostrados os valores dos parâmetros apenas para as amostras cuja concentração molar de surfactante está acima da sua $C M C$ indicada na Tabela 4.3.

\subsubsection{Discussão}

Foram selecionadas amostras com concentração pré-determinada onde observou-se utilizando a técnica de ITC mudanças energéticas significativas. Uma primeira análise permitiu observar o comportamento da função $p(r)$, onde observou-se para todos os surfactantes que as curvas apresentam um mesmo comportamento. Como mostrado na Seção 3.3.3, tal comportamento indica que todas elas se tratam de micelas do tipo coreshell. Comparando as curvas para cada surfactante, observa-se que os perfis da $p(r)$ mudam com a concentração. Precisamente, as "cristas" (parte positiva) e "vales" (parte negativa) ficam mais acentuados a medida que se aumenta a concentração. Isso acontece porque sendo a função $p(r)$ um histograma de distâncias, se o número de micelas aumenta com o aumento da concentração, então a frequência de ocorrência de uma mesma distância também aumentará. Mesmo assim, a forma da curva se mantém praticamente a mesma em toda a extensão de concentração estudada, indicando que a forma das partículas também se mantém a mesma.

Na Figura 4.12 estão mostradas curvas $p(r)$, uma para cada surfactante, relacionadas a uma concentração próxima de $\sim 14$ mM (exceto para SB310, cuja concentração molar está acima desse valor). As curvas foram multiplicadas por um fator constante a fim de 
que todas ficassem com a mesma altura. Da comparação entre elas é possível perceber o perfil é semelhante ao de uma partícula do tipo core-shell (Seção 3.3.3) porém as dimensões são diferentes para cada surfactante. Essas diferenças são atribuídas ao contraste eletrônico, ao tamanho do core, ao tamanho do shell e à anisotropia da micela.

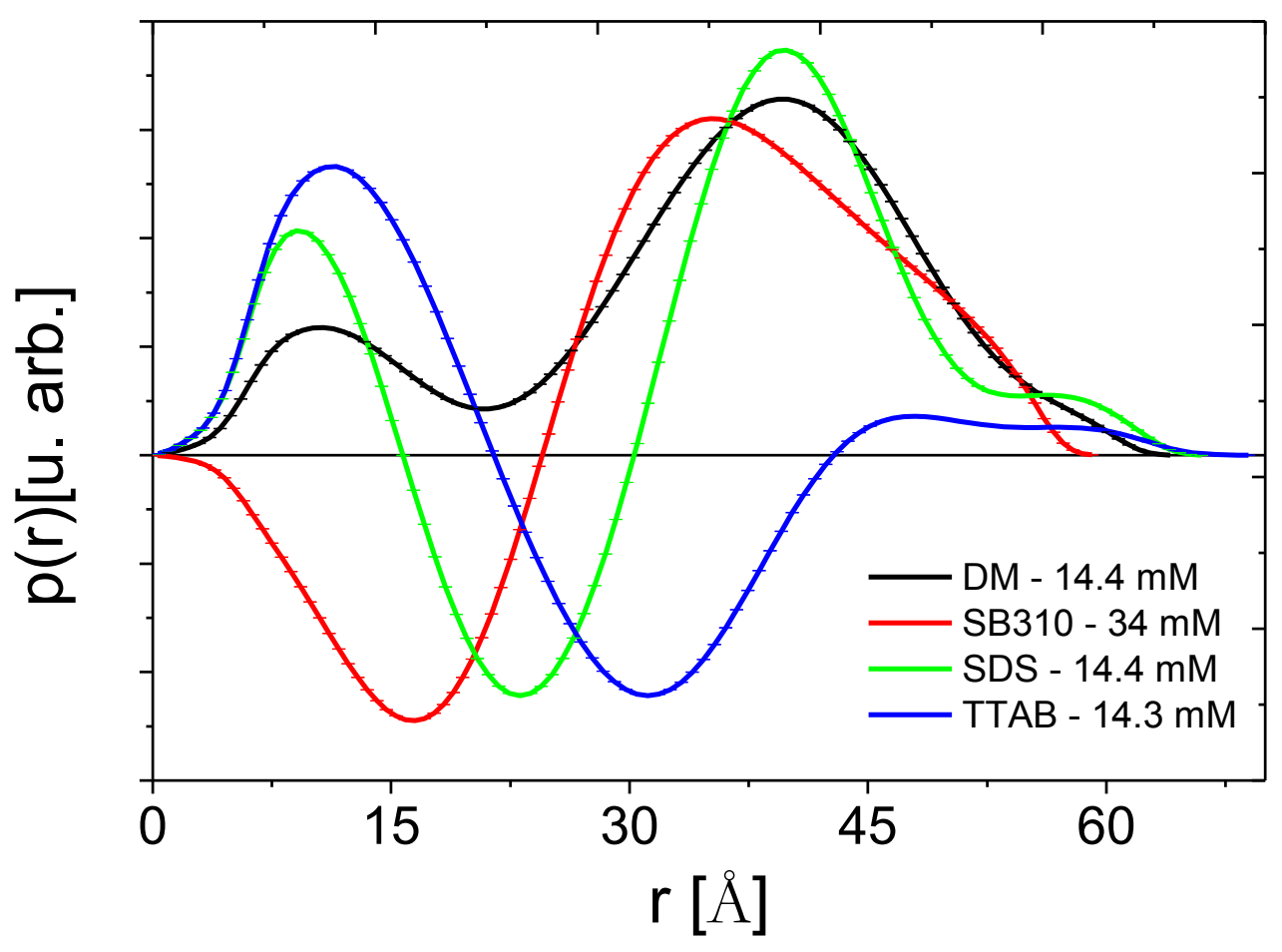

Figura 4.12: Comparação da forma da curva $p(r)$ para cada surfactante.

Para cada perfil de $p(r)$ de cada surfactante foram encontrados os valores de $r_{\max }$, que são apresentados na Figura 4.13. Ajustou-se, para cada conjunto de valores de $r_{\max }$, uma função constante, representada pelas linhas trecejadas, e isso forneceu para cada surfactante um valor médio de $r_{\max }$ (Tabela 4.6). É interessante observar que os valores de $r_{\max }$ são menores para o surfactante SB310 do que para o surfactante DM, mesmo que o volume total deste último (volume da cabeça polar + volume da cauda apolar) seja maior que o do primeiro, de acordo com a Tabela 4.6. Da mesma forma, apesar do surfactante TTAB possuir maior volume total do que o surfactante SDS, os valores de $r_{\text {máx }}$ são próximos para os dois. As diferenças e proximidades encontradas se devem ao 
fato de que o equilíbrio termodinâmico para cada surfactante é diferente, favorecendo um tamanho e forma para a micela. O efeito do buffer sobre este equilíbrio termodinâmico pode ser um fator importante para o entendimento dos resultados obtidos, porém pode não ser o único fator. A dimensão da micela esta correlacionada não apenas com o volume da cabeça e cauda, mas também com o número de agregação e a anisotropia (Eq. 3-11 e Eq. 3-12), de maneira que a análise sobre o comportamento desse parâmetro não é trivial.

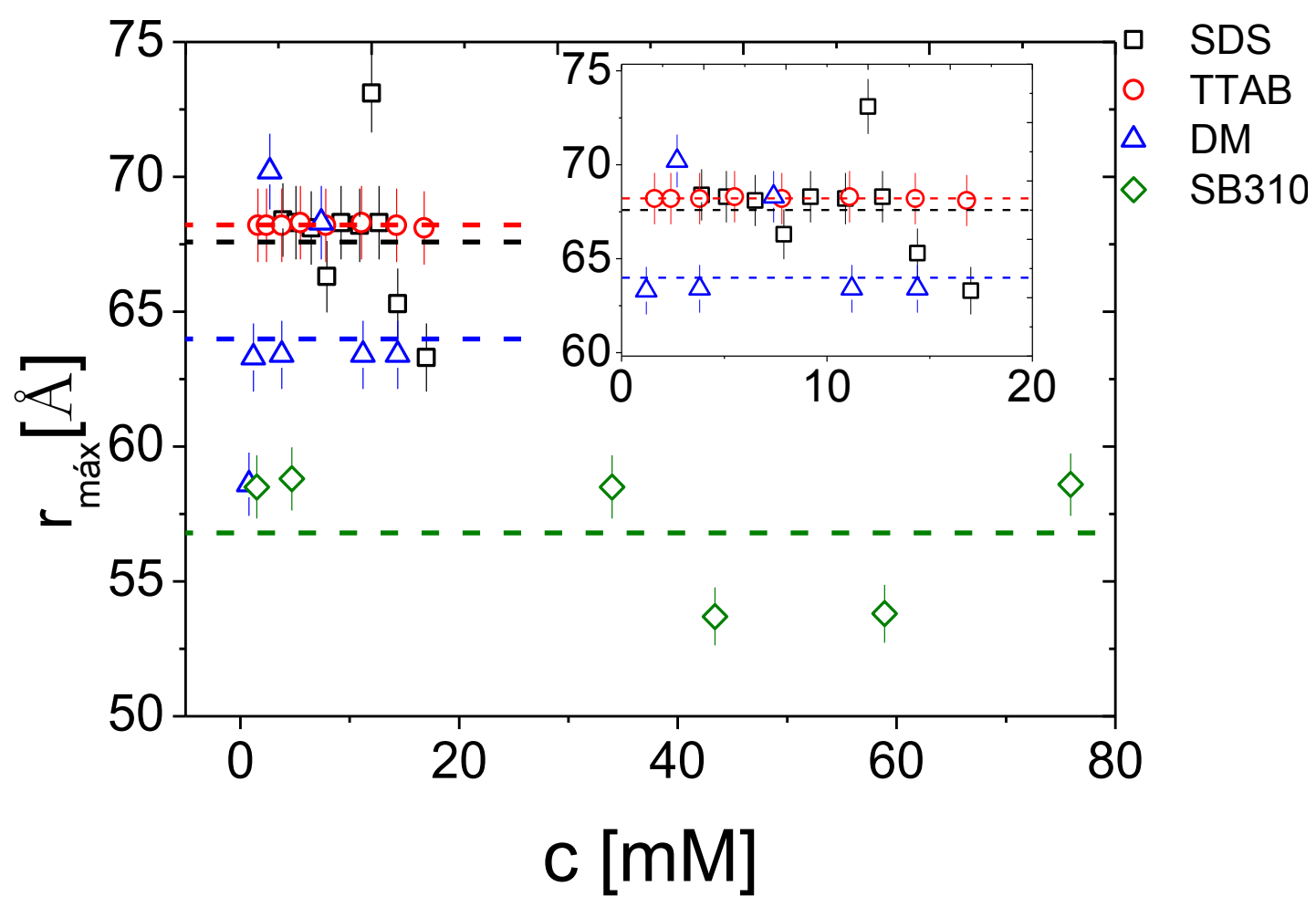

Figura 4.13: Valores de $r_{\max }$ para cada surfactante obtidos da curva $p(r)$. Para melhor visualização estão mostrados no canto superior direito os valores de $\boldsymbol{r}_{\text {max }}$ no intervalo de concentração de 0 à 20 mM.

Tabela 4.6: Volumes da cauda e da cabeça e valores de $r_{\operatorname{mix}}$ para cada surfactante.

\begin{tabular}{cccc}
\hline & $V_{T}\left[\AA^{3}\right]$ & $V_{H}\left[\AA^{3}\right]$ & $r_{\text {máx }}[\AA]$ \\
\hline SDS & 351,6 & 60,53 & $67,6(5)$ \\
TTAB & 405,8 & 135,1 & $68,2(5)$ \\
DM & 351,6 & 339,4 & $64,0(5)$ \\
SB310 & 297,4 & 170,9 & $56,8(5)$ \\
\hline
\end{tabular}


Em relação aos ajustes com o modelo cs-elispsoide, houve uma boa concordância do comportamento previsto com os dados experimentais. É interessante destacar que foi usado o mesmo modelo de fator de forma para todos os quatro surfactantes, com imposição de vínculos moleculares (Seção 3.3.4). Somente para o surfactante SB310 foi usado um fator de estrutura que leva em conta as interações inter-micelares que surgem devido à alta concentração usada na preparação das amostras. Os únicos parâmetros de ajuste foram $N_{a g}, \varepsilon$ e $c_{\text {free }}$, aumentando a confiabilidade dos resultados.

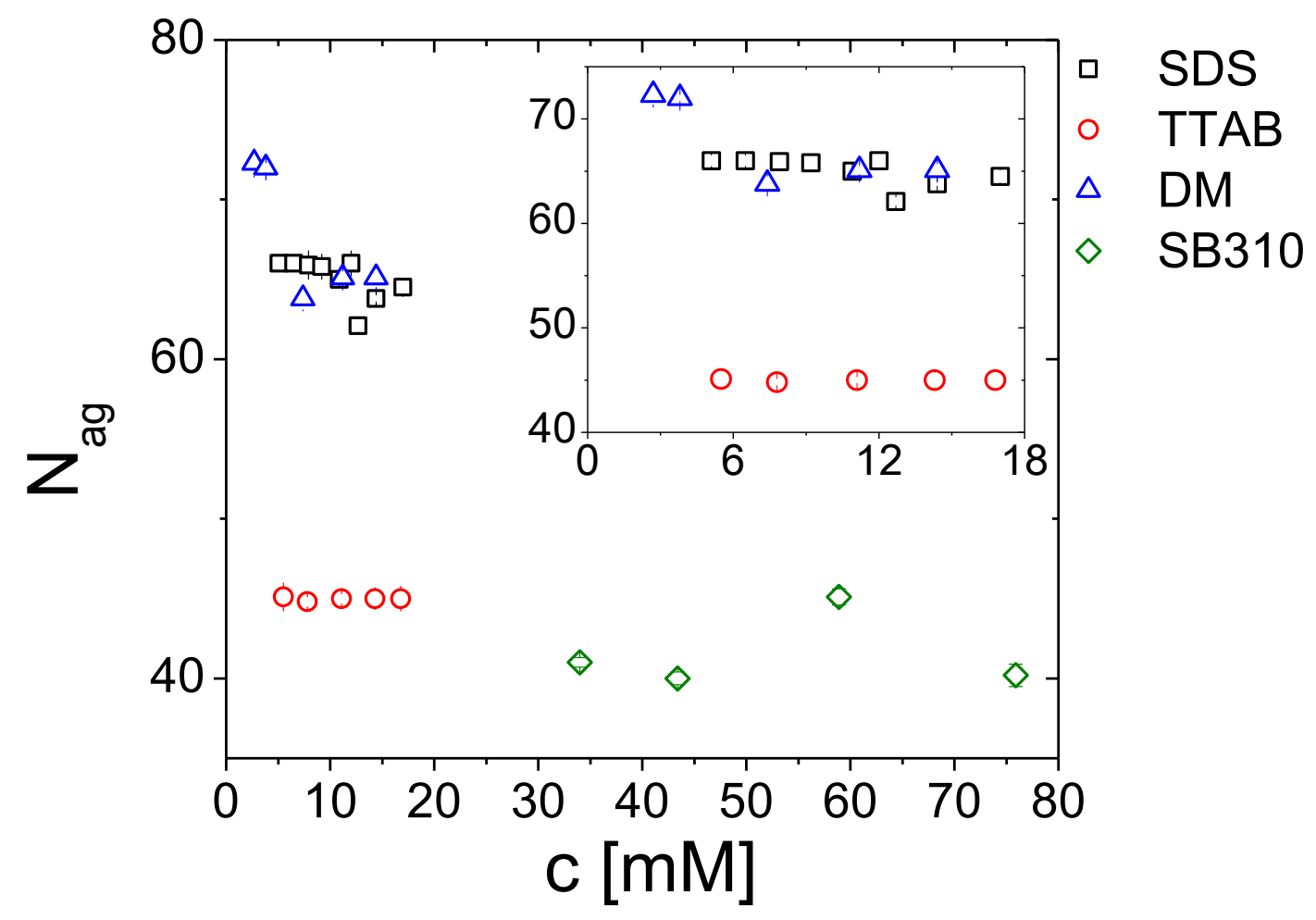

Figura 4.14: Valores de número de agregação obtidos nos ajustes para cada surfactante em função da concentração. Para melhor visualização estão mostrados no canto superior direito os valores de $\mathbf{N}_{a s}$ compreendidos no intervalo de concentrações de 0 à 20 mM.

Na Figura 4.14 está representado o comportamento do parâmetro $N_{a g}$ em função da concentração $(c)$ dos surfactantes usados. Como discutido na Seção 2.2.3, esse parâmetro fornece uma informação média sobre as micelas em solução. Logo, já seria esperado uma flutuação desse valor, como observado na Figura 4.14. O valor médio pode ser calculado realizando um ajuste linear dos dados experimentais, e os valores obtidos são apresentados na Tabela 4.7 . 
Na Figura 4.15 está mostrado o comportamento dos valores da concentração de monômeros livres em solução $\left(c_{\text {free }}\right)$ em função da concentração das amostras. Esse parâmetro fornece uma aproximação para o valor de $C M C$ (Andersen et al., 2009). No gráfico o valor obtido de $C M C$ encontrado pela técnica de ITC está indicado pela reta tracejada, que respeita o código de cores para cada surfactante. É interessante perceber que os valores desse parâmetro, oriundos do ajuste das curvas experimentais para cada um dos surfactantes, foram obtidos de forma totalmente independente das informações reveladas pelas outras técnicas e estão muito próximos daquele encontrado com a técnica de ITC e Condutimetria. Isso mostrando que o modelo cs-elipsoide é auto consistente com uma informação que já se tinha sobre o sistema.

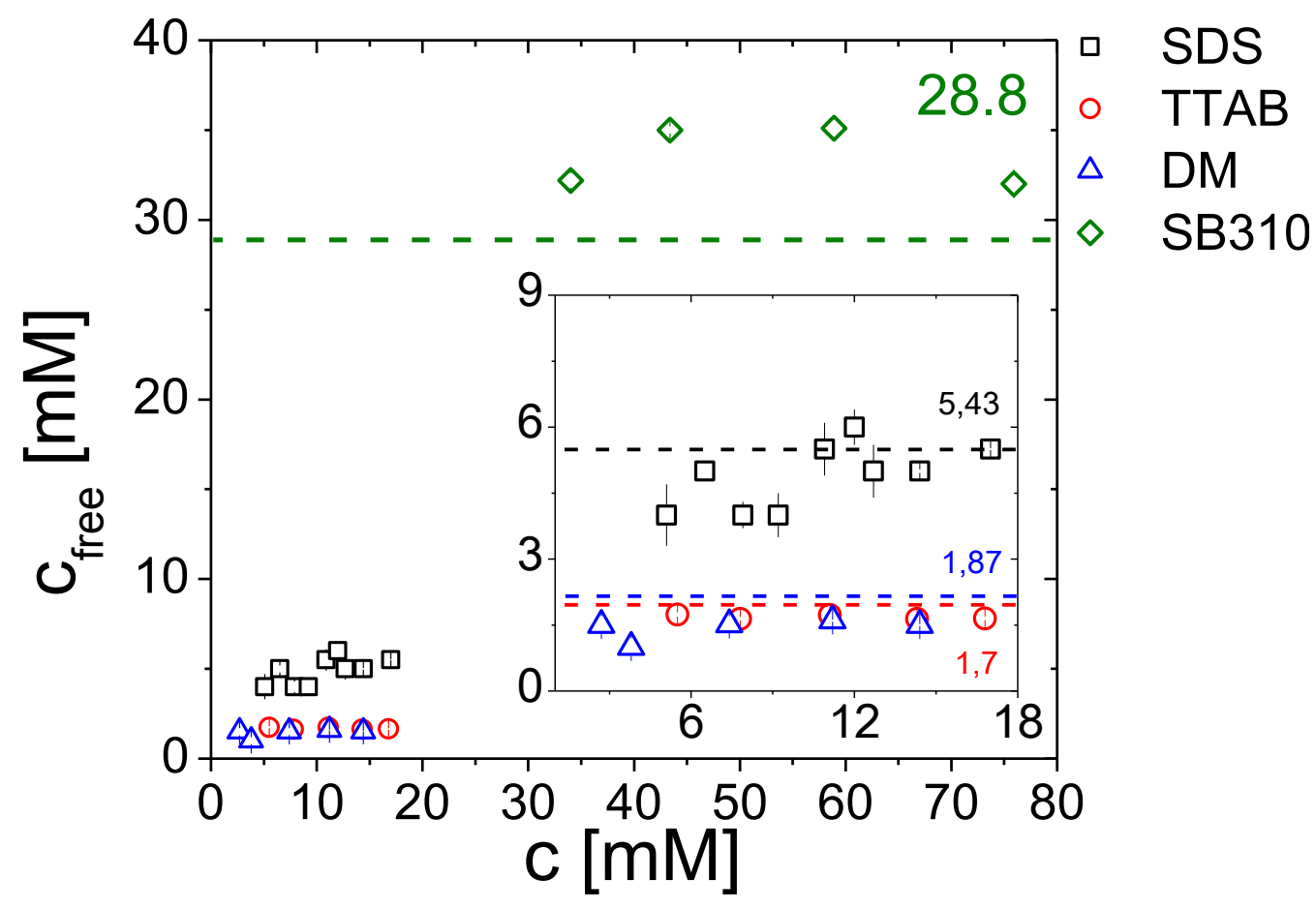

Figura 4.15: Valores de concentração de monômeros ("free") obtidos dos ajustes. Para cada conjunto de dados está indicado o valor de CMC encontrado nos experimentos de ITC. Para melhor visualização estão mostrados, no detalhe, os valores de $C_{\text {rree }}$ compreendidos no intervalo de concentrações de 0 à $18 \mathrm{mM}$.

O comportamento do parâmetro de anisotropia em função da concentração dos surfactantes está mostrado na Figura 4.16. Para cada conjunto de dados não existe dúvida quanto à anisotropia das micelas, mesmo que as incertezas, principalmente de 
SB310, sejam relativamente altas quando comparados com os valores dos outros parâmetros discutidos anteriormente. Assim sendo, nas condições experimentais estudadas, as micelas de SDS, DM e SB310 apresentam-se como prolatas $(\varepsilon>0)$, enquanto as de TTAB são oblatas $(\varepsilon<0)$. É importante ressaltar que essas anisotropias foram bem determinadas pelos ajustes, não havendo a possibilidade de descrever os dados com outras anisotropias (devido à inclusão dos vínculos moleculares). No entanto existem discrepâncias na literatura quanto ao fato de uma micela ser considerada estritamente "prolata" ou "oblata". Como mostrado por (Vass et al., 2008), uma forma oblata ou prolata de micelas de alquil sulfato alcalinos conseguiu ajustar igualmente os mesmos dados experimentais.

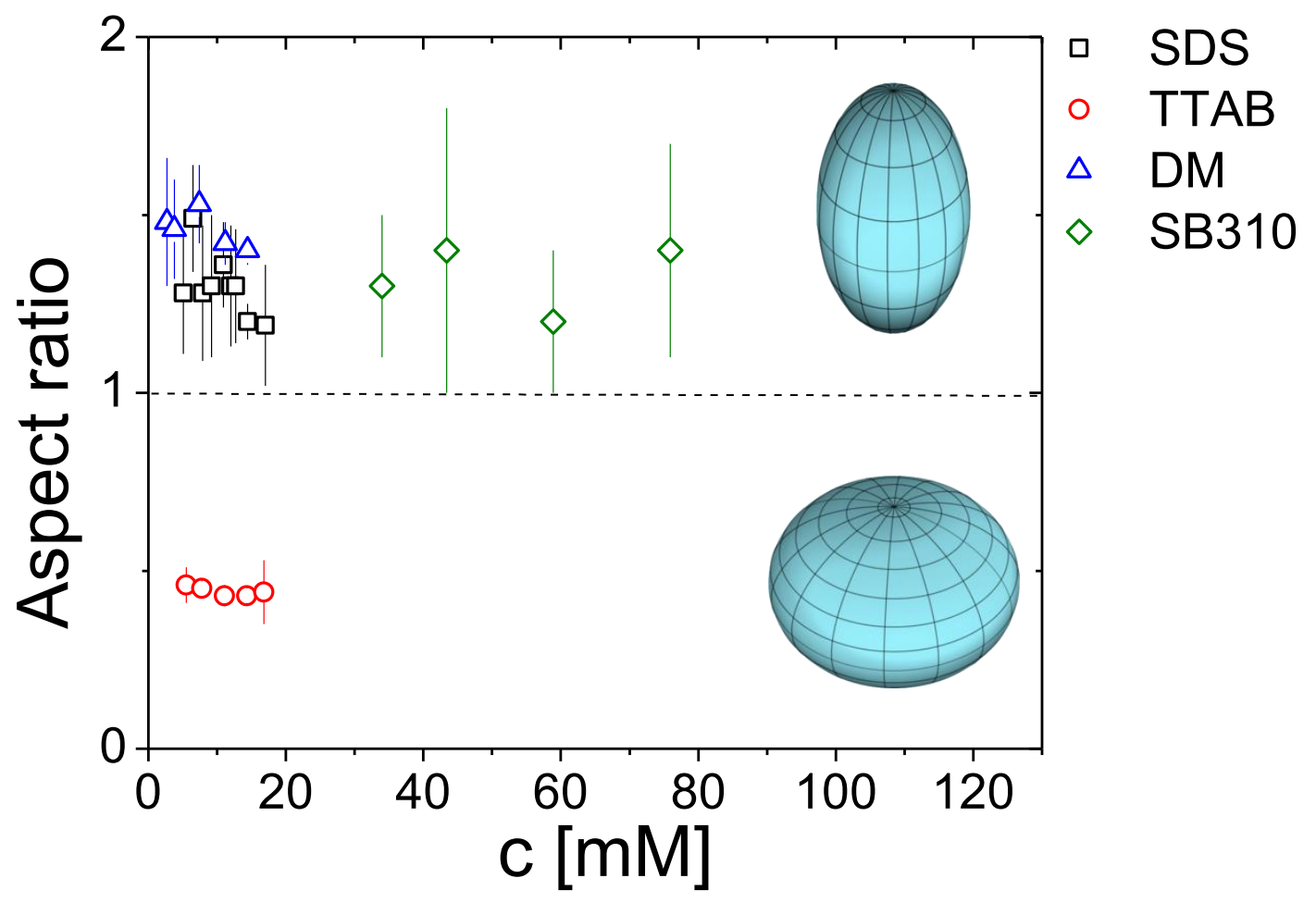

Figura 4.16: Valores dos dados de anisotropia obtidos dos ajustes para cada surfactante.

A Tabela 4.7 contém os valores médios de $N_{a g}, \varepsilon$ e $c_{\text {free }}$, bem como os valores da literatura esperados para os surfactantes em água. 
Tabela 4.7: Valores médios dos parâmetros de ajuste.

\begin{tabular}{ccccccc}
\hline & \multicolumn{2}{c}{$N_{a g}$} & \multicolumn{2}{c}{$\varepsilon$} & \multicolumn{2}{c}{$C M C \approx c_{\text {free }}[\mathrm{mM}]$} \\
\hline & Este trabalho & Literatura & Este trabalho & Literatura & Este trabalho & Literatura \\
\hline SDS & $63,1(2)$ & $66(1)^{1}$ & $1,36(8)$ & $0,663(5)^{1}$ & $5,78(17)$ & $7,70^{2} ; 8,2^{5}$ \\
TTAB & $45,0(3)$ & $99^{4}$ & $0,44(2)$ & $2,2^{4}$ & $1,68(2)$ & $3,51^{6}$ \\
DM & $67,7(3)$ & $132^{3}$ & $1,49(15)$ & $0,59^{3}$ & $2,02(18)$ & $2,1^{7}$ \\
SB310 & $41,6(2)$ & ------ & $1,33(14)$ & ------- & $33,6(3)$ & $34,5^{8}$ \\
\hline
\end{tabular}

1(Andersen et al., 2009), 2(Moller et al., 1998), 33(He et al., 2002), 4(Koshy et al., 2011), 2(Chatterjee et al., 2001), ${ }^{5}$ (Seng et al., 2000), ${ }^{6}$ (Wang et al., 1997), ${ }^{7}$ (Tsamaloukas, Beck e Heerklotz, 2009), ${ }^{8}$ (Antonio, 2011)

Na composição do buffer existem eletrólitos diluídos, e já seria esperado a diminuição dos valores de $C M C$, bem como o aumento dos valores de $N_{a g}$ (Evans e Wennerström, 1999). Entretanto só observamos o primeiro fato. Essa discrepância pode estar ligada a diversas fontes. Uma dela consiste no fato de que as técnicas usadas para a obtenção dos valores de $N_{a g}$ listados na Tabela 4.7 são diferentes. Além disso, mesmo para uma única técnica, o método escolhido para analisar um conjunto de dados pode fornecer resultados diferentes (Elworthy, Florence e Macfarlane, 1968). Particularmente para os dados de SAXS, a inclusão dos dados em escala absoluta acrescido da existência de vínculos entre os parâmetros conferem grande confiabilidade dos dados (Cantu et al., 1998).

\subsection{Condutimetria}

\subsubsection{Resultados}

Nesta seção serão apresentados os resultados de Condutimetria para os surfactantes iônicos SDS e TTAB. A Figura 4.17 e Figura 4.18 mostram os dados para SDS e TTAB. Para ambos foi realizado o ajuste usando a Eq. 3-34. Também é mostrada a função derivada do ajuste (linha tracejada). 


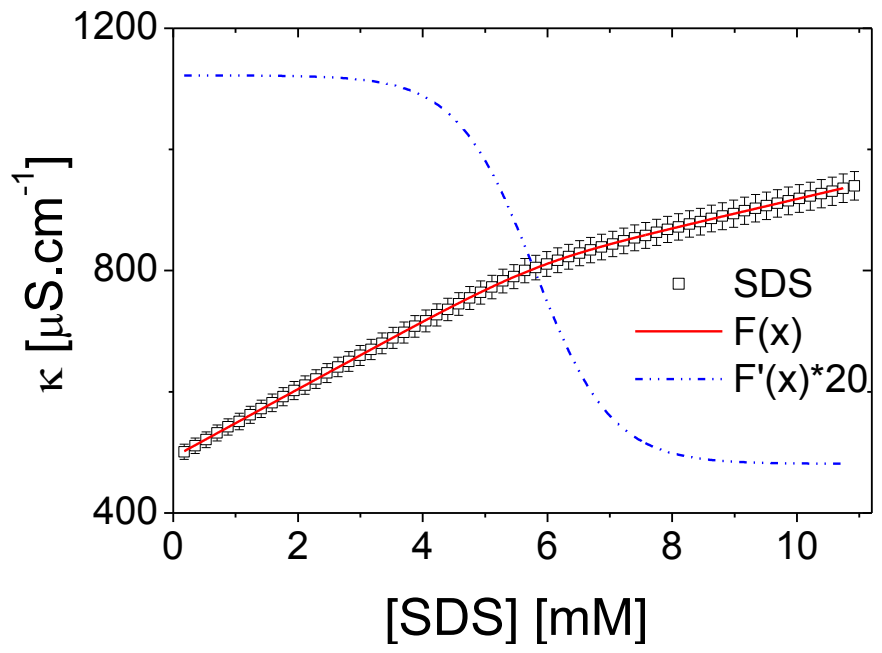

Figura 4.17: Ajuste dos dados experimentais (linha vermelha) e a função derivada (linha azul) multiplicada por um fator 20 para melhor visualização.

O comportamento dos dados experimentais é o esperado para esse tipo de sistema (Carpena et al., 2002), sendo que a mudança de um regime linear para outro é bastante visível nos dois casos.

Os valores dos parâmetros ajustados são apresentados na Tabela 4.8. Como os experimentos foram feitos em duplicidade, o valor médio foi calculado a partir da média aritmética, sendo que o resultado está apresentado na coluna "Valor final".

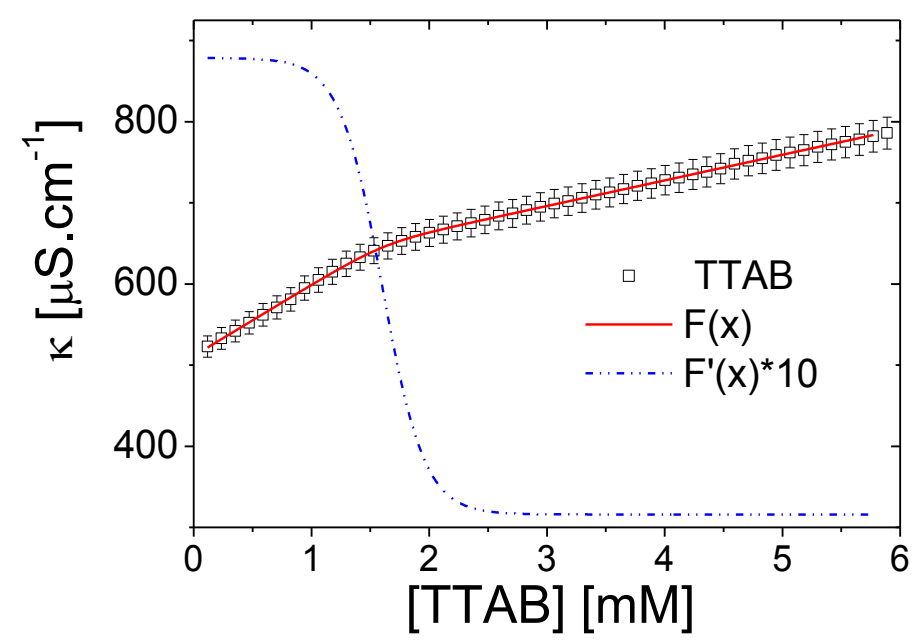

Figura 4.18: Ajuste dos dados experimentais (linha vermelha) e a função derivada (linha azul) multiplicada por um fator 10 para melhor visualização. 
Tabela 4.8: Valores dos parâmetros de ajuste das curvas de condutividade para SDS e TAB.

\begin{tabular}{ccccccc}
\hline \multirow{2}{*}{ Parâmetros } & \multicolumn{3}{c}{ SDS } & \multicolumn{3}{c}{ TTAB } \\
\cline { 2 - 7 } & Valor 01 & Valor 02 & Valor final & Valor 01 & Valor 02 & Valor final \\
\hline$A_{1}\left[\mu S \cdot \mathrm{cm}^{-1}\right]$ & $56,12(14)$ & $55,68(15)$ & $55,9(9)$ & $81,8(9)$ & $87,1(1,1)$ & $84,8(1,4)$ \\
$A_{2}\left[\mu S \cdot \mathrm{cm}^{-1}\right]$ & $24,1(2)$ & $24,3(3)$ & $24,2(3)$ & $30,50(19)$ & $31,6(2)$ & $31,0(3)$ \\
$x_{0}[\mathrm{mM}]$ & $5,79(3)$ & $5,81(3)$ & $5,80(3)$ & $1,71(2)$ & $1,60(2)$ & $1,66(3)$ \\
$\Delta x[\mathrm{mM}]$ & $0,62(3)$ & $0,60(3)$ & $0,61(4)$ & $0,21(2)$ & $0,18(2)$ & $0,19(3)$ \\
\hline
\end{tabular}

\subsubsection{Discussão}

A partir dos ajustes dos dados experimentais de Condutimetria pode-se determinar os parâmetros mostrados na Tabela 4.8. A partir deles foi possível a determinação dos valores de $C M C$ e grau de ionização $\alpha$ ( Tabela 4.9), este último calculado usando a Eq. 2-40.

Tabela 4.9: Valores de $C M C$ e grau de ionização para os surfactantes SDS e TTAB.

\begin{tabular}{ccccc}
\hline \multirow{2}{*}{ Parâmetro } & \multicolumn{2}{c}{ SDS } & \multicolumn{2}{c}{ TTAB } \\
\cline { 2 - 5 } & Este trabalho & Literatura & Este trabalho & Literatura \\
\hline$C M C[m M]$ & $5,8(3)$ & $7,75^{1} ; 8,38^{2}$ & $1,66(10)$ & $3,74^{3} ; 3,62^{4}$ \\
$\alpha$ & $0,433(9)$ & $0,41^{1} ; 0,368^{2}$ & $0,366(7)$ & $0,250(3)^{3} ; 0,23^{4}$ \\
\hline
\end{tabular}

${ }^{1}$ (Chatterjee et al., 2001), ${ }^{2}$ (Goddard e Benson, 1957), ${ }^{3}$ (Das e Das, 2009), ${ }^{4}$ (Graciani et al., 2005)

A incerteza no valor de $\alpha$ foi estimada usando a metade do valor da largura de transição informada pela Tabela 4.8 , isto é, $\sigma_{\alpha}=\Delta x / 2$. Comparando os valores de $C M C$ e $\alpha$ encontrados para SDS e TTAB com aqueles disponíveis na literatura, conclui-se que novamente o buffer possui grande efeito sobre eles. De maneira geral o $C M C$ diminui no caso deste experimento, possivelmente porque ocorre o efeito de blindagem eletrostática (Evans e Wennerström, 1999) devido à presença de mais íons positivos e negativos no buffer, diminuindo a repulsão eletrostática entre os monômeros e favorecendo assim a formação de micelas. O grau de ionização apresenta um aumento quando comparado com informação da literatura. Uma explicação possível se deve ao fato de que os íons 
provenientes dos sais, agora não apenas em solução mas também compondo a micela e ajudando na estabilização elétrica da mesma, possuam tamanhos e cargas diferentes, isto é, ocorre uma substituição parcial dos contra-íons usuais de cada surfactante iônico ( $\mathrm{Na}^{+}$, no caso do SDS, e Br-, no caso do TTAB) pelos íons dos sais, diferentes, alterando assim a carga líquida da micela. Situação parecida foi observada em trabalho recente ${ }^{8}$, no qual se estudou o surfactante brometo de dodeciltrimetilamônio (DTABr) na presença do cossoluto iônico hexanitrocobaltato (III) de sódio $\left(\mathrm{Na}_{3}\left[\mathrm{Co}\left(\mathrm{NO}_{2}\right)_{6}\right]\right)$. Em solução, parte dos contra-íons $\mathrm{Br}^{-}$do surfactante presentes na micela foram substituídos pelos ânions $\left[\mathrm{Co}\left(\mathrm{NO}_{2}\right)_{6}\right]^{3-}$, causando o aumento do grau de ionização da micela de DTABr.

\subsection{Discussão geral}

Até agora os dados, obtidos de cada técnica, foram olhados e comentados separadamente. O objetivo nessa seção será fazer um retrospecto dos principais resultados, comparando uns aos outros, e também relacionando-os para se extrair mais informações deles.

Na técnica de ITC partiu-se dos entalpogramas, que são diferentes para cada surfactante, refletindo portando diferenças energéticas nos processos de demicelização e micelização. Da análise deles foi possível encontrar a $C M C$ e as entalpias de micelização, concluindo que para TTAB e SDS elas são exotérmicas, como esperado para iônicos, enquanto para os não iônicos elas são endotérmicas, indicando uma forte interação entre os monômeros e as moléculas de água. Observando-se o comportamento dos entalpogramas, pode-se determinar pontos onde ocorrem variações energéticas interessantes. Para estas concentrações foi realizado o estudo estrutural utilizando-se a técnica de SAXS.

8 Ortega , P. F. R. et. al., Efeito do cossoluto $\mathrm{Na}_{3}\left[\mathrm{Co}\left(\mathrm{NO}_{2}\right)_{6}\right]$ na termodinâmica de micelização do brometo de dodeciltrimetilamônio, 34를 Reunião anual da Sociedade Brasileira de Química. 
Da análise da função $p(r)$, obtida a partir da curva de intensidade espalhada, conclui-se que todas apresentam uma estrutura do tipo core-shell, porém são diferentes para cada surfactante em função do tamanho do core, do shell e dos contrastes eletrônicos existentes entre a cabeça e a cauda do surfactante. Os valores de diâmetro máximo estão entre $\sim 52$ e $\sim 75$ Å. Os ajustes usando o modelo cs-elipsoide foram muito satisfatórios. Mesmo usando um modelo bastante simplificado, o modelo conseguiu descrever bem a maior parte dos dados. Melhorias no modelo podem ser feitas de modo a poder descrever melhor os dados que não tiveram um bom ajuste. Um exemplo seria a inserção de interfaces difusas entre o core e o shell, entre outras. No entanto, vale ressaltar novamente, que esse modelo ajusta bem os dados com poucos parâmetros. Por meio dos ajustes foram obtidas as informações estruturais de $N_{a g}, \varepsilon$ e $c_{f r e e}$, este último fornecendo uma estimativa para o valor da $C M C$. O parâmetro $N_{a g}$ apresenta uma flutuação razoavelmente pequena, como já esperado, pois é definido como um valor médio (Seção 2.2.3). Nas condições deste trabalho, as micelas de SDS, DM e SB310 apresentam-se como prolatas, enquanto as de TTAB apresentam-se como oblatas. O comportamento médio do parâmetro $c_{\text {free }}$ para cada surfactante é próximo da $C M C$ deles obtida por ITC.

Os dados de Condutimetria permitiram encontrar $\alpha$ e $C M C$. Os valores de grau de ionização, de maneira geral, se mostraram maiores do que aqueles obtidos na literatura usando água. A explicação dessa observação pode ser atribuída ao fato de que os íons do buffer, de tamanhos e cargas diferentes dos contra-íons dos surfactantes, se intercalam entre os monômeros, alterando a ionização da micela.

Na Tabela 4.10 estão mostrados os valores de $C M C$ obtidos pelas três técnicas. Observa-se que eles apresentam boa concordância entre si, mesmo que a incerteza não seja suficiente para compensar a diferença. Os valores de CMC para os surfactantes, quando comparados com a literatura que utiliza água, foram alterados, conforme discussões anteriores, pois o buffer contém sais dissolvidos que promovem mudança na estabilização micelar. 
Tabela 4.10: Comparação dos valores de $C M C$ obtidos pelas três técnicas.

\begin{tabular}{cccc}
\hline & ITC & SAXS & Condutividade \\
\hline SDS & $5,43(7)$ & $5,78(17)$ & $5,80(3)$ \\
TTAB & $1,7(3)$ & $1,68(9)$ & $1,66(3)$ \\
DM & $1,87(2)$ & $2,02(18)$ & ----- \\
SB310 & $28,8(2)$ & $33,6(3)$ & ----- \\
\hline
\end{tabular}

A concordância das várias técnicas sobre o valor da $C M C$ é um ótimo indicativo de que o resultado sobre o valor dos outros parâmetros seja confiável.

A fim de se ter uma caracterização termodinâmica mais completa, foi usada a Eq. 2-3 para se encontrar a variação da energia livre de Gibbs $\left(\Delta G_{m i c}\right)$ de surfactantes não-iônicos e a Eq. 2-5 para surfactantes iônicos. Ambas as equações usam a fração molar de surfactante na $C M C\left(x_{C M C}\right)$ dada pela Eq. 2-4. Ela foi calculada assumindo-se que o número de moles de água é muitíssimo maior que o número de moles de surfactante e os íons presentes no buffer, isto é, $n_{\mathrm{H}_{2} \mathrm{O}} \gg n_{\text {suffactantes }} \gg n_{\text {ions } / \text { buffer }}$, e está mostrada na Tabela 4.11, assim como o valor da energia livre de Gibbs. Como pode-se notar, ela é negativa para todos os tipos de surfactante, indicando que o processo de micelização é espontâneo. Os surfactantes não-iônicos apresentam uma maior magnitude de $\Delta G_{\text {mic }}$, que está associada a uma maior espontaneidade (nesse caso, de formação de micelização). Isso está relacionado com o fato de eles pouco sofrerem influência elétrica do meio, já que são neutros. Interessantemente, devido ao fato de que SB310 possui um dipolo elétrico, a influência do meio sobre ele é ligeiramente maior quando comparada ao DM, fazendo com que sua energia livre seja menor em magnitude do que para DM.

Relacionando os valores de $\Delta H_{\text {mic }}$, presentes na Tabela 4.3 com os valores de $\Delta G_{\text {mic }}$ (Tabela 4.11), foi possível calcular o valor de $T \Delta S_{\text {mic }}$ usando a Eq. 3-27 (Tabela 4.12). 
Tabela 4.11: Variação da energia livre de Gibbs.

\begin{tabular}{cccc}
\hline & $C M C_{I T C}[\mathrm{mM}]$ & $x_{C M C}\left[10^{-5}\right]$ & $-\Delta G_{m i c}[\mathrm{~kJ} / \mathrm{mol}]$ \\
\hline SDS & $5,43(7)$ & $9,77(16)$ & $12,97(12)$ \\
TTAB & $1,7(3)$ & $3,1(5)$ & $16,33(11)$ \\
DM & $1,87(2)$ & $3,36(4)$ & $25,52(12)$ \\
SB310 & $28,8(2)$ & $51,8(4)$ & $18,74(16)$ \\
\hline
\end{tabular}

Tabela 4.12: Parâmetros termodinâmicos para o sistema estudado e comparação com dados da literatura.

\begin{tabular}{ccccccc}
\hline & \multicolumn{2}{c}{$\Delta H_{m i c}[\mathrm{~kJ} / \mathrm{mol}]$} & \multicolumn{2}{c}{$-\Delta G_{m i c}[\mathrm{~kJ} / \mathrm{mol}]$} & \multicolumn{2}{c}{$T \Delta S_{\text {mic }}[\mathrm{kJ} / \mathrm{mol}]$} \\
\hline & $\begin{array}{c}\text { Este } \\
\text { trabalho }\end{array}$ & Literatura & $\begin{array}{c}\text { Este } \\
\text { trabalho }\end{array}$ & Literatura & $\begin{array}{c}\text { Este } \\
\text { trabalho }\end{array}$ & Literatura \\
\hline SDS & $-0,15(3)$ & $-0,81^{1} ;-1,72^{2}$ & $12,97(12)$ & $35^{1} ; 22,1^{2}$ & $12,82(12)$ & $34,27^{1} ; 20,3^{2}$ \\
TTAB & $-4,3(5)$ & $-7,9(4)^{3} ;-4,9^{7}$ & $16,33(11)$ & $25,2^{3} ; 44^{7}$ & $12,0(5)$ & $56^{3} ; 39,19^{7}$ \\
DM & $2,93(10)$ & $8,9(8)^{5} ; 4,9^{4}$ & $25,52(12)$ & ----- & $28,45(16)$ & ----- \\
SB310 & $6,8(3)$ & $6,5^{6}$ & $18,74(16)$ & $9,5^{6}$ & $25,5(3)$ & $15^{6}$ \\
\hline
\end{tabular}

${ }^{1}$ (Chatterjee et al., 2001), '2(Seng et al., 2000), 3(Wang et al., 1997), 4(Tsamaloukas, Beck e Heerklotz, 2009), 5(Capalbi, Gente e La Mesa, 2004), 6(Antonio, 2011), 7 (Perger e Bester-Rogac, 2007)

A variação da entropia está, no contexto da formação de micelas segundo a interpretação termo-estatística, associada à desordem espacial e energética das moléculas de água e do surfactante. Assim, quanto maior o termo $T \Delta S_{m i c}$, maior a desordem. Na literatura existe grande discrepância quanto aos valores de $\Delta H_{m i c}$ e $\Delta G_{m i c}$, o que, por consequência, gera grande discrepância no valor de $T \Delta S_{m i c}$, como podemos observar na Tabela 4.12.

É interessante observar pela Tabela 4.12 que $\left|T \Delta S_{\text {mic }}\right|>\left|\Delta H_{\text {mic }}\right|$, o que indica que o processo de micelização é dirigido predominantemente pelo efeito hidrofóbico (Antonio, 2011). Além disso, foi observado neste trabalho que os valores de $T \Delta S_{\text {mic }}$ para os iônicos SDS e TTAB são muito parecidos, sendo que o mesmo acontece entre os não-iônicos DM e SB310. 
Mesmo o sistema de interesse sendo complexo e estando em solução, foi possível a obtenção das informações $C M C, \alpha, N_{a g}, \varepsilon$ e $r_{\text {máx }}$, que são de cunho estrutural, e $\Delta H_{\text {mic }}$, $\Delta G_{m i c}, \Delta S_{m i c}$, que são de cunho termodinâmico, todas obtidas na temperatura de $25^{\circ} \mathrm{C}$ (Tabela 4.13).

Em linhas gerais, a metodologia utilizada neste estudo possibilitou a determinação de parâmetros estruturais e termodinâmicos independentes, complementares e consistentes, permitindo a realização de um estudo robusto e reprodutível, que pode ser usado como um procedimento para o estudo de sistemas similares, variando-se ou não parâmetros como temperatura, $\mathrm{pH}$, concentração de sais, entre outros.

Tabela 4.13: Resumo de todos os parâmetros obtidos neste trabalho.

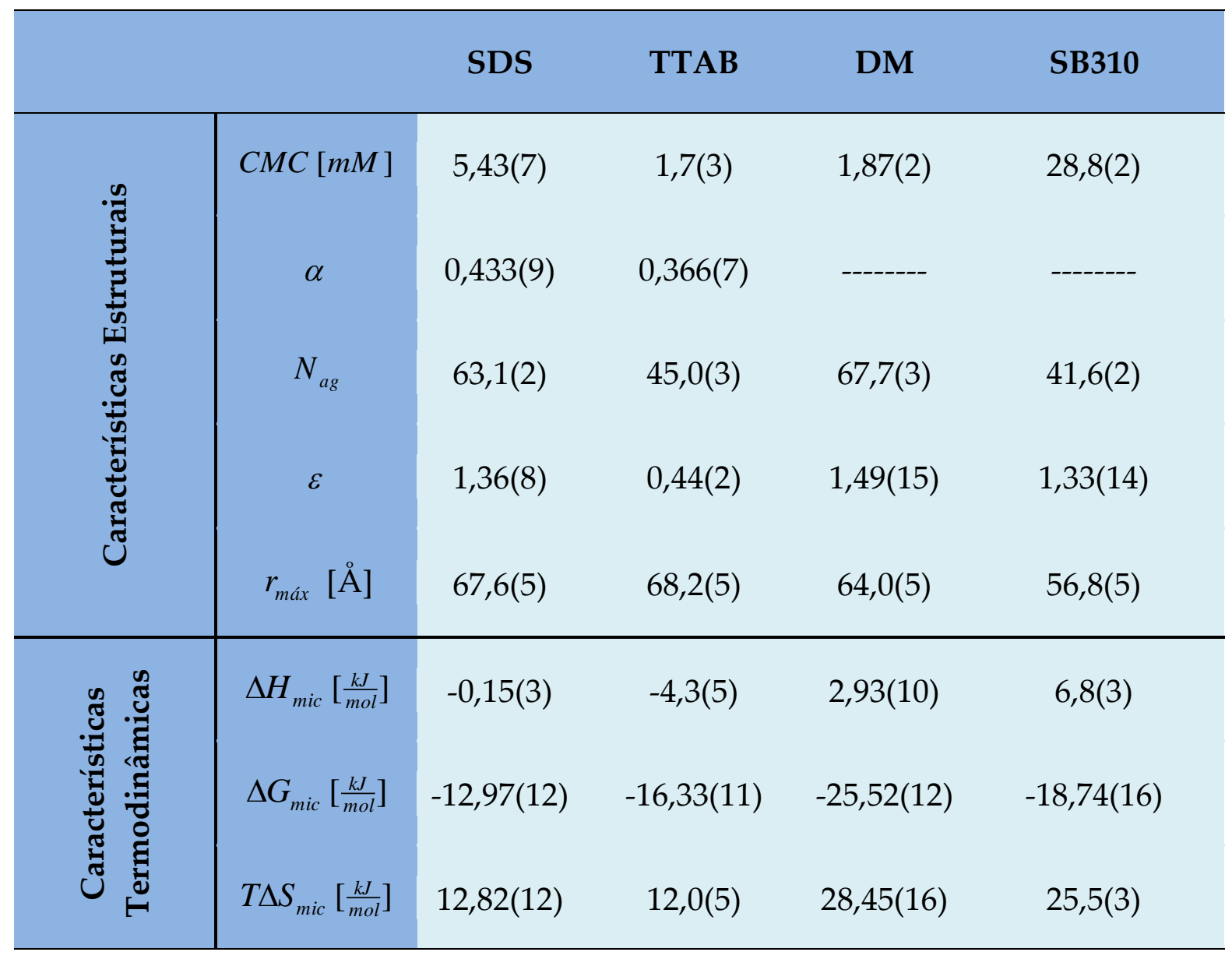




\section{Capítulo 05}

\section{Considerações Finais}

e Bibliografia 


\section{Considerações finais e bibliografia}

Neste capítulo serão ressaltados os principais pontos da discussão geral realizada no capítulo anterior, além de comentários sobre perspectivas de trabalhos futuros e informações da bibliografia consultada durante a composição deste manuscrito.

\subsection{Conclusões}

Um estudo mais completo e amplo de sistemas constituídos por surfactantes necessita da abordagem estrutural e termodinâmica, além da correlação de técnicas associadas a cada visão. Um diferencial deste trabalho vem justamente da abordagem de análise dos dados que possibilitou estudar simultaneamente aspectos estruturais e termodinâmicos no processo de formação de agregados.

Os experimentos de ITC permitiram a determinação da entalpia micelar, que caracteriza interações energéticas do sistema (monômero - monômero; monômero solvente), assim como a determinação da concentração micelar critica. Observou-se que a natureza das interações para a estabilização da micela foi diferente para dois grupos distintos: para os surfactantes aniônicos a principal interação teve caráter eletrostático, enquanto para os surfactantes não iônicos a principal interação foi entre os monômeros e as moléculas do solvente. Globalmente observou-se a diminuição dos valores de entalpia de formação das micelas em buffer quando comparados aos dados disponíveis na literatura.

A partir dos experimentos de SAXS, por meio da análise das curvas de função de distribuição de pares de distâncias, pode-se concluir que todas as micelas formadas por diferentes surfactantes apresentaram uma estrutura do tipo "core-shell", porém de tamanhos diferentes dependendo da composição da micela. Da análise destas curvas obteve-se informação sobre o diâmetro máximo dos agregados, que variou entre $50 \AA ̊$ e 
80 Å dependendo da composição da micela. A partir do ajuste das curvas de intensidade espalhada pode-se determinar o comportamento de parâmetros como o número de agregação, anisotropia de forma e concentração micelar crítica. Em geral o número de agregação diminuiu quando comparado aos valores da literatura, que usam água e outras metodologias de análise. Futuramente a diminuição desse valor será estudado à luz da forma de análise proposta nesse trabalho, variando-se também as condições do solvente.

Pelo ajuste dos experimentos de Condutimetria pode-se determinar parâmetros como o grau ionização, que caracteriza a fração de carga micelar, bem como a concentração crítica micelar. O grau de ionização apresentou um aumento significativo quando comparado aos dados disponíveis na literatura, o qual foi atribuído à inserção de íons do buffer à micela.

Os valores de $C M C$ obtidos pelas diferentes técnicas apresentaram ótima concordância entre si. Esses valores, quando comparados aos dados disponíveis na literatura, que usa água e outras metodologias de análise, apresentam uma diminuição, atribuída possivelmente à presença de íons no buffer.

A partir dos valores de $C M C$ obtidos da técnica de ITC e os valores de grau de ionização oriundos da técnica de condutimetria, pode-se calcular o valor da energia livre de Gibbs micelar. Todos os valores obtidos foram negativos, indicando a espontaneidade da micelização. Comparando-se com a literatura observou-se que os surfactantes iônicos formam micelas menos espontaneamente quando comparado aos surfactantes nãoiônicos. Utilizando os valores da energia livre de Gibbs e a entalpia pode-se calcular a entropia de micelização para cada surfactante. Em relação à literatura os processos envolvidos na micelização dos não iônicos são mais entrópicos do que para os iônicos. 


\subsection{Perspectivas}

Este trabalho certamente pode ser complementado. Nesse sentido, um estudo sistemático será feito à luz do procedimento proposto neste manuscrito para investigar a influência de outros solventes, de pH próximo das condições fisiológicas, na formação dos agregados micelares. Esta nova parte será incluída na escrita de artigos científicos.

Uma das principais contribuições deste trabalho é o desenvolvimento de uma metodologia de análise de dados de SAXS, ITC e Condutimetria, obtendo resultados independentes e complementares. Ele será também expandido, servindo como base para a realização de estudos específicos sobre a interação entre surfactantes e diversas proteínas, objetivando a caracterização estrutural e termodinâmica dos complexos formados. 


\subsection{Apêndice}

Nesta seção será discutido brevemente aspectos termodinâmicos que fornecerão base teórica para parâmetros apresentados a partir da Seção 2.3. Para maiores informações, o leitor pode consultar, entre outras bibliografias, o texto de (Callen, 1985), sobre o qual foi baseada a singela exposição abaixo.

\subsubsection{Postulados da Termodinâmica}

A ciência Termodinâmica surgiu antes da descrição atômica da matéria. Por esse motivo ela é baseada em parâmetros macroscópicos, como volume, temperatura e outros. Abaixo são apresentados os postulados da Termodinâmica sobre os quais se baseia toda a estrutura lógica dessa parte da Física Clássica.

Postulado I. Existem estados particulares (chamados de estados de equilíbrio) de sistemas simples que, macroscopicamente, são caracterizados completamente pela energia interna $U$, o volume $V e$ os números molares $N_{1}, N_{2}, \cdots, N_{r}$ dos componentes químicos.

Postulado II. Existe uma função (chamada de entropia $S$ ) de parâmetros extensivos de um sistema, definidos para todos os estados de equilíbrio e tendo a propriedade a seguir. Os valores assumidos pelos parâmetros extensivos na ausência de vínculos internos são aqueles que maximizam a entropia sobre estados de equilíbrio vinculados.

Postulado III. A entropia de um sistema é aditiva em relação aos subsistemas constituintes. A entropia é uma função continua, diferenciável e monotonicamente crescente da energia.

Postulado IV. A entropia de qualquer sistema é zero no estado para o qual

$$
\left(\frac{\partial U}{\partial S}\right)_{V, N_{1}, \cdots, N_{r}}=0
$$

Como será visto mais adiante, $(\partial U / \partial S)_{V, N_{1}, \cdots, N_{r}}$ será definida como a temperatura absoluta. A partir do postulado I e II define-se a entropia como sendo a função 


$$
S=S\left(U, V, N_{1}, \cdots, N_{2}\right)
$$

É possível resolvê-la de maneira unívoca para a energia interna $U$ escrita na forma

$$
U=U\left(S, V, N_{1}, \cdots, N_{2}\right) .
$$

Ambas as funções dadas em A. 2 e A. 3 são relações fundamentais que contém toda a informação termodinâmica do sistema estudado, de maneira que pode-se optar ou pela representação entrópica (A. 2) ou pela representação energética (A. 3). Nos trechos a seguir será usada esta última.

\subsubsection{Definição de parâmetros intensivos}

Diferenciando A. 3, tem-se:

$$
\begin{gathered}
d U=\frac{\partial U}{\partial S} d S+\frac{\partial U}{\partial V} d V+\frac{\partial U}{\partial N_{1}} d N_{1}+\frac{\partial U}{\partial N_{2}} d N_{2}+\cdots+\frac{\partial U}{\partial N_{r}} d N_{r} \\
d U=\frac{\partial U}{\partial S} d S+\frac{\partial U}{\partial V} d V+\sum_{i=1}^{r} \frac{\partial U}{\partial N_{i}} d N_{i} .
\end{gathered}
$$

Dentro do formalismo termodinâmico, define-se os parâmetros intensivos temperatura absoluta, pressão e potencial eletroquímico do i-ésimo componente químico, respectivamente, como sendo 


$$
\begin{gathered}
\frac{\partial U}{\partial S} \equiv T, \\
\frac{\partial U}{\partial V} \equiv-P, \\
\frac{\partial U}{\partial N_{i}} \equiv \mu_{i} .
\end{gathered}
$$

O potencial eletroquímico também é chamado apenas de potencial químico. $T, P, \mu$ são ditos parâmetros intensivos porque não dependem do tamanho do sistema, diferentemente de $V, U$ e $S$, que são chamados de parâmetros extensivos. Reescrevendo A. 4 à luz desses parâmetros intensivos, vem:

$$
d U=T d S-P d V+\sum_{i=1}^{r} \mu_{i} d N_{i}
$$

O termo $-P d V$ em A. 8 se refere ao trabalho mecânico quase-estático $d W$. O sinal de menos (-) tem relação com a convenção de que se o trabalho é feito sobre o sistema, então ele será positivo pois $d V$, a variação infinitesimal de volume, será negativo. O termo $T d S$ se refere ao calor quase-estático $d Q$ trocado entre o sistema e sua vizinhança. Eventualmente, a descrição de um sistema mais complexo pode incluir outros termos além daqueles presentes na A. 8, como momento de dipolo elétrico e/ou magnético.

É interessante observar que se o sistema for fechado para matéria, isto é, matéria não entra nem sai do sistema e, portanto, $d N_{i}=0$, então A. 8 pode ser escrita como

$$
d U=d Q+d W
$$

que é a $1^{\underline{a}}$ Lei da Termodinâmica.

\subsubsection{Relação de Euler}

A característica da extensividade da função $S$, associada ao conteúdo do postulado III, implica em 


$$
S\left(\lambda U, \lambda V, \lambda N_{1}, \cdots, \lambda N_{2}\right)=\lambda S\left(U, V, N_{1}, \cdots, N_{2}\right),
$$

para qualquer $\lambda$. Da mesma forma, na representação energética, tem-se

$$
U\left(\lambda S, \lambda V, \lambda N_{1}, \cdots, \lambda N_{2}\right)=\lambda U\left(S, V, N_{1}, \cdots, N_{2}\right) .
$$

Diferenciando A. 11 em relação a $\lambda$, vem:

$$
\frac{\partial U}{\partial(\lambda S)} \frac{\partial(\lambda S)}{\partial \lambda}+\frac{\partial U}{\partial(\lambda V)} \frac{\partial(\lambda V)}{\partial \lambda}+\frac{\partial U}{\partial\left(\lambda N_{1}\right)} \frac{\partial\left(\lambda N_{1}\right)}{\partial \lambda}+\cdots+\frac{\partial U}{\partial\left(\lambda N_{r}\right)} \frac{\partial\left(\lambda N_{r}\right)}{\partial \lambda}=U
$$

Particularmente, para $\lambda=1$, obtém-se:

$$
\frac{\partial U}{\partial S} S+\frac{\partial U}{\partial V} V+\frac{\partial U}{\partial N_{1}} N_{1}+\cdots+\frac{\partial U}{\partial N_{r}} N_{r}=U
$$

Usando as definições dos parâmetros intensivos (Seção 5.3.2), pode-se reescrever a última expressão como:

$$
\begin{gathered}
T S-P V+\mu_{1} N_{1}+\cdots+\mu_{r} N_{r}=U \\
T S-P V+\sum_{i=1}^{r} \mu_{i} N_{i}=U
\end{gathered}
$$

que é a chamada relação de Euler.

\subsubsection{Relação de Gibbs-Duhem}

Diferenciando A. 14, tem-se:

$$
d U=T d S+S d T-P d V-V d P+\sum_{i=1}^{r} \mu_{i} d N_{i}+\sum_{i=1}^{r} N_{i} d \mu_{i}
$$

Substituindo A. 8 em A. 15, vem: 


$$
\begin{gathered}
T d S-P d V+\sum_{i=1}^{r} \mu_{i} d N_{i}=T d S+S d T-P d V-V d P+\sum_{i=1}^{r} \mu_{i} d N_{i}+\sum_{i=1}^{r} N_{i} d \mu_{i} \\
0=S d T-V d P+\sum_{i=1}^{r} N_{i} d \mu_{i},
\end{gathered}
$$

que é a chamada relação de Gibbs-Duhem.

\subsubsection{Potenciais Termodinâmicos}

Os potenciais termodinâmicos são obtidos pelo processo matemático conhecido como transformação de Legendre. Os potenciais termodinâmicos mais comuns são a energia interna $(U)$, já comentada anteriormente, a energia livre de Helmholtz $(F)$, a energia livre de Gibbs $(G)$ e a entalpia $(H)$. Será dado atenção para os dois últimos potenciais, porque são os usados neste trabalho.

\section{Entalpia (H)}

Entalpia corresponde à transformação de Legendre de $U$ que substitui o volume pela pressão como uma variável independente. Ela é definida por

$$
H=U+P V,
$$

com

$$
H=H\left(S, P, N_{1}, \cdots, N_{r}\right) .
$$

A entalpia é um potencial particularmente útil quando $P$ é constante, por exemplo, em um processo que acontece em reservatórios abertos e em contato com a pressão atmosférica. Diferenciando A. 17, tem-se:

$$
d H=d U+P d v+V d P .
$$

Substituindo A. 8 em A. 19, vem: 


$$
\begin{gathered}
d H=T d S-P d V+\sum_{i=1}^{r} \mu_{i} d N_{i}+P d V+V d P \\
d H=T d S+\sum_{i=1}^{r} \mu_{i} d N_{i}+V d P
\end{gathered}
$$

Se o processo é isobárico, $d P=0$. Além disso, se o sistema é fechado para entrada ou saída de matéria, então $d N_{i}=0$. Logo, lembrando que $T d S=d Q$, A. 20 pode ser reescrita como:

$$
d H_{P, N}=d Q
$$

onde os índices $P$ e $N$ enfatizam que o processo é isobárico e que não há trocas de matéria. Portanto, nessa situação, a variação de entalpia se relacionada com o calor trocado entre o sistema e a sua vizinhança.

\section{Energia livre de Gibbs (G)}

A energia livre de Gibbs corresponde à transformação de Legendre de $U$ que substitui entropia pela temperatura e volume pela pressão, tornando-as variáveis independentes. É definida como:

$$
G=U-T S+P V
$$

com

$$
G=G\left(T, P, N_{1}, \cdots, N_{r}\right)
$$

Esse potencial é bastante útil quando $P$ e $T$ são constantes. Substituindo A. 14 em A. 22, obtém-se: 


$$
\begin{gathered}
G=T S-P V+\sum_{i=1}^{r} \mu_{i} N_{i}-T S+P V, \\
G=\sum_{i=1}^{r} \mu_{i} N_{i} .
\end{gathered}
$$

Para o sistema formado por um único componente químico, tem-se:

$$
G=\mu N \Rightarrow \mu=\frac{G}{N} .
$$

Portanto, a energia livre de Gibbs fornece informação sobre o potencial químico e, no caso de A. 25, este último corresponde à energia livre de Gibbs molar.

Diferenciando-se A. 22, vem:

$$
d G=d U-T d S-S d T+P d V+V d P .
$$

Substituindo A. 8 em A. 27, tem-se:

$$
\begin{gathered}
d G=T d S-P d V+\sum_{i=1}^{r} \mu_{i} d N_{i}-T d S-S d T+P d V+V d P . \\
d G=\sum_{i=1}^{r} \mu_{i} d N_{i}-S d T+V d P .
\end{gathered}
$$

Se $P$ e $T$ são constantes, a expressão anterior fica

$$
d G_{T, P}=\sum_{i=1}^{r} \mu_{i} d N_{i}
$$

onde os índices $P$ e $T$ enfatizam que o processo é isobárico e isotérmico.

\section{$\underline{\text { Relação entre } \Delta \mathrm{H}, \Delta \mathrm{G} \text { e } \Delta S}$}

Substituindo A. 17 em A. 22, tem-se: 


$$
G=H-T S
$$

A. 31

Diferenciando-se A. 31:

$$
d G=d H-T d S-S d T .
$$

A. 32

Se $P$ e $T$ são constantes, então $d T=0$ e $d H$ traz informação sobre o calor trocado entre o sistema e a vizinhança à pressão constante (ver A. 21), de forma que A. 32 pode ser reescrita como

$$
d G=d H-T d S
$$

Para uma variação finita, pode-se então escrever que

$$
\Delta G=\Delta H-T \Delta S
$$

A. 34 


\subsection{Bibliografia}

AGUIAR, J. et al. Thermodynamics and micellar properties of tetradecyltrimethylammonium bromide in formamide-water mixtures. Journal of Colloid and Interface Science, v. 255, n. 2, p. 382-390, Nov 15 2002. ISSN 0021-9797. Disponível em: <<Go to ISI >://WOS:000179263700022 >.

ANDERSEN, K. K. et al. The Role of Decorated SDS Micelles in Sub-CMC Protein Denaturation and Association. Journal of Molecular Biology, v. 391, n. 1, Aug 72009. ISSN 0022-2836. Disponível em: <<Go to ISI >://WOS:000268651400015 >.

ANDERSON, J. L. et al. Surfactant solvation effects and micelle formation in ionic liquids. Chemical Communications, n. 19, p. 2444-2445, Oct 7 2003. ISSN 1359-7345. Disponível em: <<Go to ISI>://WOS:000186029500025 >.

ANGARTEN, R. G. Termodinâmica de micelização de alquilglicosídeos em $\mathbf{H}_{2} \mathrm{O}$ e em D2O. 2007. 92 (Mestrado). Universidade Estadual de Campinas, Campinas, SP.

ANTONIO, C. B. Estudo termodinâmico de associação de surfactantes zwitteriônicos e sua interação com polímeros através de titulação calorimétrica. 2011. 99 (Mestrado). Instituto de Química, Universidade Estadual de Campinas, Campinas, SP.

ATKINS, P. W.; DE PAULA, J. Físico-química. Livros Técnicos e Científicos, 2008. ISBN 9788521616016. Disponível em: < http://books.google.com.br/books?id=lKLfOgAACAAI $>$.

ATTWOOD, D.; FLORENCE, A. T. Surfactant systems: Their chemistry, pharmacy and biology. London: Chapman \& Hall, 1983.

BACKLUND, S. et al. AGGREGATION OF TETRADECYLTRIMETHYLAMMONIUM BROMIDE IN WATER, 1,2-ETHANEDIOL, AND THEIR MIXTURES. Journal of Colloid and Interface Science, v. 131, n. 2, p. 393-401, Sep 1989. ISSN 0021-9797. Disponível em: < <Go to ISI>://WOS:A1989AM84400008>. 
BARBOSA, L. R. S. Estudo de Sistemas de Relevância Biológica por Espalhamento de Raios-X à Baixo Ângulo. 2008. (Tese de Doutoramento). Instituto de Física, Universidade de São Paulo, São Paulo.

CALLEN, H. B. Thermodynamics and an Introduction to Themostatistics. New York: John Wiley \& Sons, 1985.

CANTU, L. et al. Consistency of microstructural modeling of micelles: Letter concerning "thermotropic behavior and stability of monosialoganglioside micelles in aqueous solution". Biophysical Journal, v. 74, n. 3, p. 1600-1603, Mar 1998. ISSN 0006-3495. Disponível em: <<Go to ISI >://WOS:000073398500045 >.

CAPALBI, A.; GENTE, G.; LA MESA, C. Solution properties of alkyl glucosides, alkyl thioglucosides and alkyl maltosides. Colloids and Surfaces a-Physicochemical and Engineering Aspects, v. 246, n. 1-3, p. 99-108, Oct 1 2004. ISSN 0927-7757. Disponível em: $<<$ Go to ISI $>$ ://WOS:000224904200011 >.

CARPENA, P. et al. Problems associated with the treatment of conductivityconcentration data in surfactant solutions: Simulations and experiments. Langmuir, v. 18, n. 16, Aug 6 2002. ISSN 0743-7463. Disponível em: $<<$ Go to ISI $>: / /$ WOS:000177224400017 >.

CASTELlETTO, V.; HAMLEY, I. W. Modelling small-angle scattering data from micelles. Current Opinion in Colloid \& Interface Science, v. 7, n. 3-4, p. 167-172, Aug 2002. ISSN 1359-0294. Disponível em: <<Go to ISI>://WOS:000177945800003 >.

CHATTERJEE, A. et al. Thermodynamics of micelle formation of ionic surfactants: A critical assessment for sodium dodecyl sulfate, cetyl pyridinium chloride and dioctyl sulfosuccinate ( $\mathrm{Na}$ salt) by microcalorimetric, conductometric, and tensiometric measurements. Journal of Physical Chemistry B, v. 105, n. 51, Dec 27 2001. ISSN 15206106. Disponível em: <<Go to ISI>://WOS:000173079500017>.

CHEN, S. H. SMALL-ANGLE NEUTRON-SCATTERING STUDIES OF THE STRUCTURE AND INTERACTION IN MICELLAR AND MICROEMULSION SYSTEMS. Annual Review of Physical Chemistry, v. 37, p. 351-399, 1986 1986. ISSN 0066-426X. Disponível em: <<Go to ISI>://WOS:A1986E909200013>. 
CHEVALIER, Y.; ZEMB, T. THE STRUCTURE OF MICELLES AND MICROEMULSIONS. Reports on Progress in Physics, v. 53, n. 3, Mar 1990. ISSN 00344885. Disponível em: <<Go to ISI>://WOS:A1990CY11400002 >.

CRAIEVICH, A. F. SAXS em materiais nanoestruturados - Aspectos Básicos e Aplicações Curso Nanostar: Instituto de Física da Universidade de São Paulo 2009.

D'ANDREA, M. G. et al. Thermodynamic and Structural Characterization of Zwitterionic Micelles of the Membrane Protein Solubilizing Amidosulfobetaine Surfactants ASB-14 and ASB-16. Langmuir, v. 27, n. 13, p. 8248-8256, Jul 5 2011. ISSN 0743-7463. Disponível em: <<Go to ISI $>$ ://WOS:000292124000036 >.

DAS, C.; DAS, B. Thermodynamic and Interfacial Adsorption Studies on the Micellar Solutions of Alkyltrimethylammonium Bromides in Ethylene Glycol (1) + Water (2) Mixed Solvent Media. Journal of Chemical and Engineering Data, v. 54, n. 2, p. 559-565, Feb 2009. ISSN 0021-9568. Disponível em: <<Go to ISI >://WOS:000263371000069>.

DUPUY, C.; AUVRAY, X.; PETIPAS, C. Anomeric effects on the structure of micelles of alkyl maltosides in water. Langmuir, v. 13, n. 15, p. 3965-3967, Jul 23 1997. ISSN 07437463. Disponível em: <<Go to ISI>://WOS:A1997XM64200013>.

ELWORTHY, P. H.; FLORENCE, A. T.; MACFARLANE, C. B. Solubilization by surfaceactive agents and its applications in chemistry and the biological sciences. London: Chapman \& Hall, 1968.

EVANS, D. F.; WENNERSTRÖM, H. The colloidal domain: Where physics, chemistry, biology, and technology meet. 2nd ed. New York: Wiley-VCH, 1999.

FELIPPE, A. C. Auto-associação do colato de sódio ( $\mathrm{NaC}$ em misturas com o surfactante aniônico dodecil sulfato de sódio (SDS) e o polímero neutro hidrossolúvel poli(óxido de etileno) (PEO). 2006. (Dissertação de mestrado). Universidade Federal de Santa Catarina, Florianópolis, SC.

FRAHM, J.; DIEKMANN, S.; HAASE, A. ELECTROSTATIC PROPERTIES OF IONIC MICELLES IN AQUEOUS-SOLUTIONS. Berichte Der Bunsen-Gesellschaft-Physical Chemistry Chemical Physics, v. 84, n. 6, p. 566-571, 1980. ISSN 0005-9021. Disponível em: <<Go to ISI >://WOS:A1980KA42400009 >. 
GALGANO, P. D.; EL SEOUD, O. A. Micellar properties of surface active ionic liquids: A comparison of 1-hexadecyl-3-methylimidazolium chloride with structurally related cationic surfactants. Journal of Colloid and Interface Science, v. 345, n. 1, p. 1-11, May 1 2010. ISSN 0021-9797. Disponível em: < <Go to ISI>://WOS:000275922100001 >.

Surface active ionic liquids: Study of the micellar properties of 1-(1-alkyl)-3methylimidazolium chlorides and comparison with structurally related surfactants. Journal of Colloid and Interface Science, v. 361, n. 1, p. 186-194, Sep 1 2011. ISSN 00219797. Disponível em: <<Go to ISI>://WOS:000292628500024>.

GARCIAMATEOS, I.; VELAZQUEZ, M. M.; RODRIGUEZ, L. J. CRITICAL MICELLE CONCENTRATION DETERMINATION IN BINARY-MIXTURES OF IONIC SURFACTANTS BY DECONVOLUTION OF CONDUCTIVITY CONCENTRATION CURVES. Langmuir, v. 6, n. 6, p. 1078-1083, Jun 1990. ISSN 0743-7463. Disponível em: < $<$ Go to ISI >://WOS:A1990DK31300009>.

GIEHM, L. et al. SDS-Induced Fibrillation of alpha-Synuclein: An Alternative Fibrillation Pathway. Journal of Molecular Biology, v. 401, n. 1, p. 115-133, Aug 6 2010. ISSN 00222836. Disponível em: <<Go to ISI >://WOS:000280658400010 >.

GODDARD, E. D.; BENSON, G. C. CONDUCTIVITY OF AQUEOUS SOLUTIONS OF SOME PARAFFIN CHAIN SALTS. Canadian Journal of Chemistry-Revue Canadienne De Chimie, v. 35, n. 9, p. 986-991, 1957 1957. ISSN 0008-4042. Disponível em: <<Go to ISI $>$ :/WOS:A1957WN48800006 >.

GRACIANI, M. D. et al. Water-N,N-dimethylformamide alkyltrimethylammonium bromide micellar solutions: Thermodynamic, structural, and kinetic studies. Langmuir, v. 21, n. 8, p. 3303-3310, Apr 12 2005. ISSN 0743-7463. Disponível em: < <Go to ISI $>$ ://WOS:000228218700018 >.

Handbook of detergents: Part D - Formulation. CRC Taylor \& Francis, 2006.

HE, L. Z. et al. Comparison of small-angle scattering methods for the structural analysis of octyl-beta-maltopyranoside micelles. Journal of Physical Chemistry B, v. 106, n. 31, p. 7596-7604, Aug 8 2002. ISSN 1520-6106. Disponível em: $<<$ Go to ISI>://WOS:000177322500006 >. 
HOFFMANN, B.; PLATZ, G. Phase and aggregation behaviour of alkylglycosides. Current Opinion in Colloid \& Interface Science, v. 6, n. 2, p. 171-177, Apr 2001. ISSN 1359-0294. Disponível em: <<Go to ISI>://WOS:000168920000013 >.

HOLMBERG, K.; JÖNSSON, B.; KRONBERG, B. Surfactants and polymers in aqueous solution. Segunda edição. John Wiley \& Sons, LTD, 2003.

HOLT, C. et al. Substructure of bovine casein micelles by small-angle X-ray and neutron scattering. Colloids and Surfaces a-Physicochemical and Engineering Aspects, v. 213, n. 2-3, p. 275-284, Feb 12 2003. ISSN 0927-7757. Disponível em: < <Go to ISI >://WOS:000181004400016 >.

ISRAELACHVILI, J. N. Intermolecular and surface forces. 2nd edition. London: Academic Press, 1991.

JOHNSON, I.; OLOFSSON, G.; JONSSON, B. MICELLE FORMATION OF IONIC AMPHIPHILES - THERMOCHEMICAL TEST OF A THERMODYNAMIC MODEL. Journal of the Chemical Society-Faraday Transactions I, v. 83, p. 3331-3344, 19871987. ISSN 0300-9599. Disponível em: <<Go to ISI>://WOS:A1987K901400010 >.

KOSHY, P. et al. Swelling and elongation of tetradecyltrimethylammonium bromide micelles induced by anionic sodium laurate. Soft Matter, v. 7, n. 10, p. 4778-4786, 2011 2011. ISSN 1744-683X. Disponível em:<<Go to ISI>://WOS:000290227400028 >.

KOTZ, J.; KOSMELLA, S.; BEITZ, T. Self-assembled polyelectrolyte systems. Progress in Polymer Science, v. 26, n. 8, p. 1199-1232, Oct 2001. ISSN 0079-6700. Disponível em: < $<$ Go to ISI >://WOS:000172076000002 >.

LI, F.; ROSEN, M. J.; SULTHANA, S. B. Surface properties of cationic gemini surfactants and their interaction with alkylglucoside or -maltoside surfactants. Langmuir, v. 17, n. 4, p. 1037-1042, Feb 20 2001. ISSN 0743-7463. Disponível em: < <Go to ISI >://WOS:000167064600012 >. 
LIPFERT, J. et al. Size and shape of detergent micelles determined by small-angle x-ray scattering. Journal of Physical Chemistry B, v. 111, n. 43, p. 12427-12438, Nov 12007. ISSN 1520-6106. Disponível em: <<Go to ISI >://WOS:000250556600013 >.

LUZZATI, V.; MUSTACCHI, H.; SKOULIOS, A. STRUCTURE OF THE LIQUIDCRYSTAL PHASES OF THE SOAP-WATER SYSTEM - MIDDLE SOAP AND NEAT SOAP. Nature, v. 180, n. 4586, p. 600-601, 1957 1957. ISSN 0028-0836. Disponível em: < $<$ Go to ISI >://WOS:A1957ZP93800022 >.

MOLLER, A. et al. Location of butanol in mixed micelles with alkyl glucosides studied by SANS. Journal of Physical Chemistry B, v. 102, n. 45, p. 8958-8964, Nov 5 1998. ISSN 1089-5647. Disponível em: <<Go to ISI >://WOS:000076937200004 >.

MOROI, Y. Micelles: Theoretical and applied aspects. New York: Plenum Press, 1992.

NELSON, D. L.; COX, M. M. Princípios de bioquímica de Lehninger. 5a ed. Porto Alegre: Artmed, 2011.

OH, S. G.; SHAH, D. O. THE EFFECT OF MICELLAR LIFETIME ON THE RATE OF SOLUBILIZATION AND DETERGENCY IN SODIUM DODECYL-SULFATE SOLUTIONS. Journal of the American Oil Chemists Society, v. 70, n. 7, p. 673-678, Jul 1993. ISSN 0003-021X. Disponível em: < <Go to ISI>://WOS:A1993LL50500004 >.

OLIVEIRA, C. L. P. Investigating Macromolecular Complexes in Solution by Small Angle X-Ray Scattering. In: CHANDRASEKARAN, A. (Ed.). Current Trends in X-Ray Crystallography: InTech, 2011. cap. 16, p.367-391. ISBN 978-953-307-754-3.

OLIVEIRA, C. L. P. et al. A SAXS Study of Glucagon Fibrillation. Journal of Molecular Biology, v. 387, n. 1, p. 147-161, Mar 20 2009. ISSN 0022-2836. Disponível em: < <Go to ISI $>$ ://WOS:000264610000012 >.

OLIVEIRA, C. L. P. D. Estudos de Espalhamento de Raios $X$ a Baixos Ângulos por Sistemas Biológicos: Teoria e Aplicações. 2005. (Tese de doutorado). Universidade de Campinas, Campinas, SP. 
OLIVEIRA, C. L. P. D.; PEDERSEN, J. S. Program package for data treatment, analysis and modeling 2009.

OLOFSSON, G.; LOH, W. On the use of Titration Calorimetry to Study the Association of Surfactants in Aqueous Solutions. Journal of the Brazilian Chemical Society, v. 20, n. 4, 2009 2009. ISSN 0103-5053. Disponível em: <<Go to ISI>://WOS:000266403400002 >.

ORTHABER, D.; BERGMANN, A.; GLATTER, O. SAXS experiments on absolute scale with Kratky systems using water as a secondary standard. Journal of Applied Crystallography, v. 33, p. 218-225, Apr 2000. ISSN 0021-8898. Disponível em: < <Go to ISI>://WOS:000086740300004 >.

OTZEN, D. Protein-surfactant interactions: A tale of many states. Biochimica Et Biophysica Acta-Proteins and Proteomics, v. 1814, n. 5, p. 562-591, May 2011. ISSN 15709639. Disponível em: <<Go to ISI >://WOS:000291237300005 >.

PEDERSEN, J. S. Analysis of small-angle scattering data from colloids and polymer solutions: modeling and least-squares fitting. Advances in Colloid and Interface Science, v. 70, Jul 18 1997. ISSN 0001-8686. Disponível em: < <Go to ISI $>$ ://WOS:A1997XZ31600003 >.

PEREZ-RODRIGUEZ, M. et al. A comparative study of the determination of the critical micelle concentration by conductivity and dielectric constant measurements. Langmuir, v. 14, n. 16, p. 4422-4426, Aug 4 1998. ISSN 0743-7463. Disponível em: < <Go to ISI $>$ ://WOS:000075292100012 >.

PERGER, T.-M.; BESTER-ROGAC, M. Thermodynamics of micelle formation of alkyltrimethylammonium chlorides from high performance electric conductivity measurements. Journal of Colloid and Interface Science, v. 313, n. 1, p. 288-295, Sep 1 2007. ISSN 0021-9797. Disponível em: < <Go to ISI >://WOS:000248351900037 >.

PIERCE, M. M.; RAMAN, C. S.; NALL, B. T. Isothermal titration calorimetry of proteinprotein interactions. Methods-a Companion to Methods in Enzymology, v. 19, n. 2, Oct 1999. ISSN 1046-2023. Disponível em: <<Go to ISI>://WOS:000083250600004 >.

RAYLEIGH, L. The incidence of light upon a transparent sphere of dimensions comparable with the wave-length. Proceedings of the Royal Society of London Series a- 
Containing Papers of a Mathematical and Physical Character, v. 84, n. 567, Jun 1910. ISSN 0950-1207. Disponível em: < <Go to ISI>://WOS:000202812900004 >.

REISSHUS.F; LUZZATI, V. SMALL-ANGLE X-RAY SCATTERING STUDY OF STRUCTURE OF SOAP AND DETERGENT MICELLES. Journal of Colloid and Interface Science, v. 21, n. 5, p. 534-\&, 1966 1966. ISSN 0021-9797. Disponível em: < <Go to ISI>://WOS:A19667810800007 >.

ROGERS, F. J.; YOUNG, D. A. NEW, THERMODYNAMICALLY CONSISTENT, INTEGRAL-EQUATION FOR SIMPLE FLUIDS. Physical Review A, v. 30, n. 2, 1984 1984. ISSN 1050-2947. Disponível em: < <Go to ISI>://WOS:A1984TC44100040 >.

SENG, W. P. et al. Calorimetric studies of model hydrophobically modified alkalisoluble emulsion polymers with varying spacer chain length in ionic surfactant solutions. Macromolecules, v. 33, n. 5, Mar 7 2000. ISSN 0024-9297. Disponível em: < <Go to ISI>://WOS:000085832700044 >.

SESTA, B. PHYSICOCHEMICAL PROPERTIES OF DECYLDIMETHYLAMMONIUM PROPANESULFONATE AND ITS HOMOLOGOUS COMPOUNDS IN AQUEOUSMEDIUM. Journal of Physical Chemistry, v. 93, n. 22, p. 7677-7680, Nov 2 1989. ISSN 0022-3654. Disponível em: <<Go to ISI>://WOS:A1989AY09900029>.

SHIMIZU, S.; PIRES, P. A. R.; EL SEOUD, O. A. Thermodynamics of micellization of benzyl(2-acylaminoethyl)dimethylammonium chloride surfactants in aqueous solutions: A conductivity and titration calorimetry study. Langmuir, v. 20, n. 22, Oct 26 2004. ISSN 0743-7463. Disponível em: <<Go to ISI>://WOS:000224679800017>.

SORENSEN, C. M.; WANG, G. M. Size distribution effect on the power law regime of the structure factor of fractal aggregates. Physical Review E, v. 60, n. 6, p. 7143-7148, Dec 1999. ISSN 1539-3755. Disponível em: <<Go to ISI>://WOS:000084600700030 >.

SUGIHARA, G. et al. An electroconductivity study on degree of counterion binding or dissociation of a-sulfonatomyristic acid methyl ester micelles in water as a function of temperature. Colloid and Polymer Science, v. 275, n. 8, p. 790-796, Aug 1997. ISSN 0303402X. Disponível em: <<Go to ISI>://WOS:A1997XX03200011 >. 
TANFORD, C. The hydrophobic effect: Formation of micelles and biological membranes. New York: Wiley-Interscience, 1980.

TRAN, C. D.; YU, S. F. Near-infrared spectroscopic method for the sensitive and direct determination of aggregations of surfactants in various media. Journal of Colloid and Interface Science, v. 283, n. 2, p. 613-618, Mar 15 2005. ISSN 0021-9797. Disponível em: < $<$ Go to ISI $>$ ://WOS:000227393300046 >.

TSAMALOUKAS, A. D.; BECK, A.; HEERKLOTZ, H. Modeling the Micellization Behavior of Mixed and Pure n-Alkyl-Maltosides. Langmuir, v. 25, n. 8, p. 4393-4401, Apr 21 2009. ISSN 0743-7463. Disponível em: <<Go to ISI>://WOS:000265281700033 >.

VASS, S. et al. Ambiguity in determining the shape of alkali alkyl sulfate micelles from small-angle scattering data. Langmuir, v. 24, n. 2, p. 408-417, Jan 15 2008. ISSN 0743-7463. Disponível em: <<Go to ISI >://WOS:000252208200014 >.

WANG, Y. L. et al. Microcalorimetry study of interaction between ionic surfactants and hydrophobically modified polymers in aqueous solutions. Langmuir, v. 13, n. 12, p. 31193123, Jun 11 1997. ISSN 0743-7463. Disponível em: <<Go to ISI>://WOS:A1997XE16700010 $>$.

WARD, A. F. H. The influence of the solvent on the formation of micelles in colloidal electrolytes I. Electrical conductivities of sodium dodecyl sulphate in ethyl alcohol-water mixtures. Proceedings of the Royal Society of London Series a-Mathematical and Physical Sciences, v. 176, n. A966, p. 0412-0427, Nov 1940. ISSN 0080-4630. Disponível em: $<<$ Go to ISI $>$ ://WOS:000200943500007 >.

WILLIAMS, R. J.; PHILLIPS, J. N.; MYSELS, K. J. THE CRITICAL MICELLE CONCENTRATION OF SODIUM LAURYL SULPHATE AT 25-DEGREES-C. Transactions of the Faraday Society, v. 51, n. 5, 1955 1955. Disponível em: < <Go to ISI>://WOS:A1955WH40400019>.

ZANA, R.; PICOT, C.; DUPLESSIX, R. EFFECT OF ALCOHOL ON THE PROPERTIES OF MICELLAR SYSTEMS .5. SMALL-ANGLE NEUTRON-SCATTERING STUDY. Journal of Colloid and Interface Science, v. 93, n. 1, p. 43-53, 1983 1983. ISSN 0021-9797. Disponível em: <<Go to ISI >://WOS:A1983QM29700006 >. 
ZANA, R. et al. EFFECT OF ALCOHOL ON THE PROPERTIES OF MICELLAR SYSTEMS .1. CRITICAL MICELLIZATION CONCENTRATION, MICELLE MOLECULAR-WEIGHT AND IONIZATION DEGREE, AND SOLUBILITY OF ALCOHOLS IN MICELLAR SOLUTIONS. Journal of Colloid and Interface Science, v. 80, n. 1, p. 208-223, 1981 1981. ISSN 0021-9797. Disponível em: < <Go to ISI>://WOS:A1981LD88800025 >.

ZHANG, L.; SOMASUNDARAN, P.; MALTESH, C. Electrolyte effects on the surface tension and micellization of n-dodecyl beta-D-maltoside solutions. Langmuir, v. 12, n. 10, p. 2371-2373, May 15 1996. ISSN 0743-7463. Disponível em: < <Go to ISI>://WOS:A1996UL43200009 >. 